\title{
Quantitative Untersuchung der Anhangsorgane der Haut bei einem erwachsenen Ainu. ${ }^{1)}$
}

Von

\section{Matsuo Kawai.}

Aus dem Anatomischen Institut der Keio Universität, Tokyo.

Inhalt.

I. Einleitung. . . . . . . . . . . . . . . . . . . . . . 444

II. Material und Methode. . . . . . . . . . . . . . . . . 444

III. Eigene Befunde . . . . . . . . . . . . . . . . . . . 447

1. Menge der Schweissclrüse . . . . . . . . . . . . . . 447

2. Menge der Talgdrüse . . . . . . . . . . . . . . . . 457

3. Menge des Haarbalgmuskels . . . . . . . . . . . . . 468

IV. Tabellarische Zusammenstellung . . . . . . . . . . . . . 482

1. Schweissdrüse. . . . . . . . . . . . . . . . . . . 482

a. Menge und Ausmündungszahl der Drüse in den einzelnen Körperteilen. . . . . . . . . . . . . . . . . . 482

b. Reihenfolge der Mengengrösse und Ausmündungszahl der Drüse in einzelnen Körperteilen . . . . . . . . . . 483

c. Menge und Ausmündlungszahl der Drïse in den Hauptkörperabschnitten. . . . . . . . . . . . . . . . 484

2. Talgdrüse . . . . . . . . . . . . . . . . . . . . 485

a. Menge der Drüse in den einzelnen Körperteilen. . . . 485

b. Menge der Drüse in den Hauptkörperabschnitten . . . 487

c. Reihenfolge der Mengengrösse der Drüse in einzelnen Körperteilen . . . . . . . . . . . . . . . . . . 488

3. Haarbalgmuskel . . . . . . . . . . . . . . . . . . 489

a. Menge des Muskels in den einzelnen Körperteilen . . . 489

b. Menge des Muskels in den Hauptkörperabschnitten . . 491

c. Reihenfolge der Mengengrösse des Muskels in einzelnen Körperteilen . . . . . . . . . . . . . . . . . . 492

V. Zusammenfassung. . . . . . . . . . . . . . . . . . . 493

1) Diese Abhandlung ist die 7. Mitteilung von „Quantitative Untersuchung der Anhangsorgane der Haut von K. Okajima." 


\section{Einleitung.}

Über die Bestimmung der Menge der Hautanhangsorgane von den verschiedenen Körperregionen in verschiedenen Rassen, Altersstufen und in beiden Geschlechtern haben schon Okajima ${ }^{1)}$, Taniguchi' ${ }^{2}$, Koibuchi ${ }^{3)}$., Yamada, ${ }^{4}$ Kosaka ${ }^{5}$ und Taniguchi, Kosaka und Nakano ${ }^{6)}$ ausführlich erforscht. Ich werde hier die Befunde bei einem 28 jährigen Ainu berichten.

\section{Material und Methode.}

Das mir zur Verfügung gestellte Material, das von Herrn Professor S. Kodama des Anatomischen Institutes zu Sapporo Herrn Professor K. Okajima überreicht wurde, stammt aus einem 28 jährigen männlichen Ainu, der an Pleuroperitonitis gestorben war. Die Leiche wurde nach dem Tode sogleich mit 10\% Formalinlösung injiziert und fixiert. Die Hautstücke von ca. $1.2 \mathrm{qcm}$ Grösse mit genügendem Unterhautgewebe wurden sorgfältig von diesem Material herausgeschnitten, in Zelloidin eingebettet und in Flächenschnittserien von $40 \mu$ Dicke zerlegt. Folgende 15 Körperteile wurden verfolgt.

I. Kopf :

1. Scheitel

2. Stirn (Behaarungsgrenze)

II. Hals :

3. Hals (vorderer mittlerer Teil)

III. Rumpf :

4. Brust (rechte Seite)

5. Bauch (rechte Seite)

1) Quantitative Untersuchung des Haarbalgmuskels bei den Säugetieren. Folia Anat. Japon. Bd. VII. 1929.

2) Quantitative Untersuchung der Anhangsorgane der Haut bei den japanischen Neugeborenen. Folia Anat. Japon. Bd. IX. 1931.

3) Quantitative Untersuchung der Anhangsorgane der Haut bei dem japanischen Kind. Folia Anat. Japon. Bd. X. 1932.

4) Quantitative Untersuchung der Anhangsorgane der Haut bei dem Deutschen. Folia Anat. Japon. Bd. X. 1932.

5) Quantitative Untersuchung der Anhangsorgane der Haut bei einem japanischen Fetus. Folia Anat. Japon. Bd. X. 1932.

6) Quantitative Untersuchung der Anhangsorgane der Haut bei einem koreanischen Kind. Folia Anat. Japon. Bd. XI. 1933. 
Quantitative Untersuchung der Anhangsorgane der Haut bei einem erwachsenen Ainu. 445

6. Rücken (rechte Seite)

7. Gesäss (rechte Seite)

IV. Obere Extremität :

S. Oberarın (Beugeseite der mittleren Höhe, rechts)

9. Oberarm (Streckseite der mittleren Höhe, rechts)

10. Vorderarm (Beugeseite der mittleren Höhe, rechts)

11. Vorderarm (Streckseite der mittleren Höhe, rechts)

V. Untere Extremität :

12. Oberschenkel (Medialseite der oberen Höhe, rechts)

13. Oberschenkel (Lateralseite der oberen Höhe, rechts)

14. Unterschenkel (Streckseite der mittleren Höhe, rechts)

15. Unterschenkel (Beugeseite der mittleren Höhe, rechts)

Die Färbung geschah mit Hämatoxylin(Hansen)-Eosin.

Das Haar, der Haarbalgmuskel, die Talgdrüse und Schweissdrüse in jedem Schnitt wurden immer 30 mal vergrössert auf ein Papierstück mit dem bestimmten Gewicht projiziert gezeichnet; dam wurden die gezeichneten Gegenstände aus allen Papierstücken sorgfältig mit Schere herausgeschnitten und mittelst der Torsionswage genau gewogen.

Zur Berechnung des Volumens brauchte ich folgende Gleichung nach. Okajima:

$$
\mathrm{V}=\frac{\mathrm{FD} \Sigma \mathrm{W}}{\mathrm{W}_{1} \mathrm{~m}^{2}}
$$

$\mathrm{V}=$ Volumen der Gegenstände,

$\mathrm{F}=$ Flächeninhalt des einzelnen Papierstückes,

$\mathrm{W}_{1}=$ Gewicht des einzelnen Papierstückes,

$W=$ Gewicht des Gegenstandes in einem Schnitt,

$\mathrm{D}=$ Dicke des Schnittes,

$m=$ Vergrösserung.

Nun werde ich in folgenden meine Daten tabellarisch angeben. 


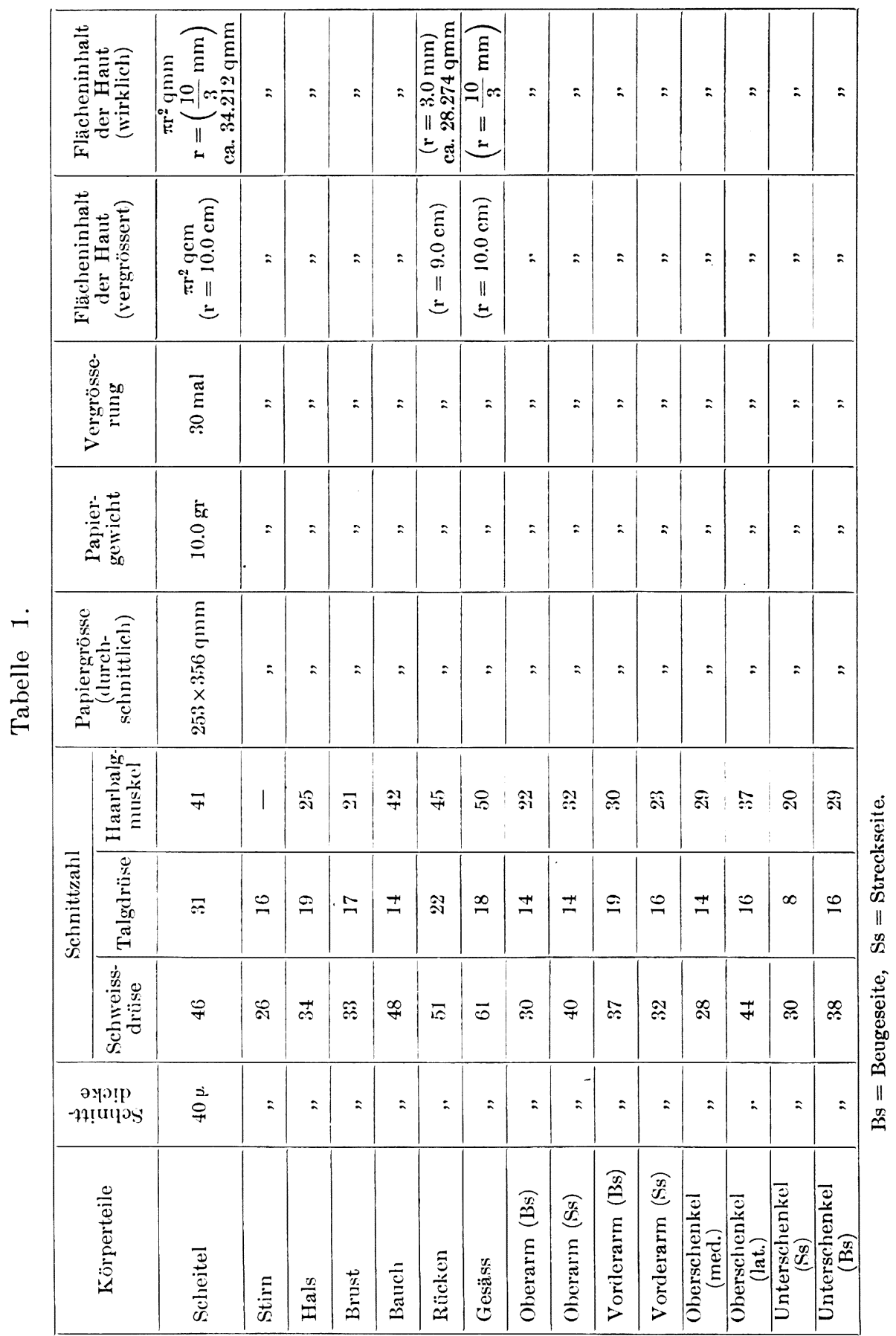


Quantitative Untersuchung der Anhangsorgane der Haut bei einem erwachsenen Ainu. 447

\section{Eigene Befunde.}

\section{Menge der Schweissdrüse.}

Tabelle 2.

Schweissdrüse. Scheitelhaut.

\begin{tabular}{|c|c|c|}
\hline $\begin{array}{l}\text { Schnitt- } \\
\text { nummer }\end{array}$ & $\begin{array}{l}\text { Zahl der } \\
\text { Drüsen- } \\
\text { stücke }\end{array}$ & $\begin{array}{l}\text { Gewicht der } \\
\text { ausgeschnit- } \\
\text { tenen Papier- } \\
\text { stücke }\end{array}$ \\
\hline 1 & 5 & $0.8 \mathrm{mg}$ \\
\hline 2 & 7 & 0.9 \\
\hline 3 & 10 & 1.2 \\
\hline 4 & 25 & 3.2 \\
\hline 5 & 41 & 5.1 \\
\hline 6 & 62 & 7.1 \\
\hline 7 & 70 & 8 \\
\hline 8 & 84 & 9 \\
\hline 9 & 74 & 9 \\
\hline 10 & 81 & 9 \\
\hline 11 & 81 & 9.1 \\
\hline 12 & 81 & 11 \\
\hline 13 & 90 & 13.8 \\
\hline 14 & 90 & 11 \\
\hline 15 & 89 & 11.5 \\
\hline 16 & 83 & 11 \\
\hline 17 & 89 & 12.5 \\
\hline 18 & 88 & 12 \\
\hline 19 & 8.5 & 13 \\
\hline 20 & 80 & 11.4 \\
\hline 21 & 79 & 12.2 \\
\hline 22 & 86 & 16.2 \\
\hline 23 & 104 & 24.4 \\
\hline 24 & 100 & 18 \\
\hline 25 & 95 & 22 \\
\hline 26 & 98 & 31.3 \\
\hline 27 & 79 & 38.8 \\
\hline 28 & 101 & 51.6 \\
\hline 29 & 104 & 73.1 \\
\hline 30 & 101 & 88 \\
\hline 31 & 110 & 129 \\
\hline 32 & 132 & 142.4 \\
\hline 33 & 118 & 137 \\
\hline 34 & 121 & 130 \\
\hline 35 & 99 & 111 \\
\hline 36 & 106 & 95 \\
\hline 37 & 98 & 80 \\
\hline 38 & 81 & 59 \\
\hline 39 & 56 & 41.8 \\
\hline 40 & 49 & 28.8 \\
\hline 41 & 33 & 20 \\
\hline 42 & 18 & 17 \\
\hline 43 & 9 & 14.4 \\
\hline 44 & 11 & 6.4 \\
\hline 45 & 6 & 2.5 \\
\hline 46 & 3 & 1 \\
\hline & & 1560.5 \\
\hline
\end{tabular}

Volumen in $\pi \mathrm{r}^{2} \mathrm{qmm}\left(\mathrm{r}=\frac{10}{3} \mathrm{~mm}\right)$

$=\mathrm{V}\left(\right.$ in $\left.\pi \times\left(\frac{10}{3}\right)^{2} \mathrm{gmm}\right)=\frac{\mathrm{FD} \Sigma \mathrm{IV}}{\mathrm{W}_{1} \mathrm{~m}^{2}}$

$=\frac{(25.3 \times 356) \times 0.04 \times 1560.5}{10000 \times 30^{2}}$

$=\frac{5622044.560}{9000000}=0.62467 \mathrm{cmm}$,

also in $1 \mathrm{qcm}$ umgerechnet

$V($ in $1 \mathrm{qcm})=0.624672 \times \frac{1}{\pi} \times \frac{100}{\left(\frac{100}{30}\right)^{2}}$

$=0.624672 \times \frac{1}{\pi} \times \frac{100}{\frac{100^{2}}{30^{2}}}$

$=0.624672 \times \frac{1}{\pi} \times \frac{100 \times 30^{2}}{100^{2}}$

$=0.624672 \times \frac{1}{\pi} \times \frac{900}{100}$

$=0.62+672 \times 0.318309 \times 9$

$=1.7895 \fallingdotseq 1.790 \mathrm{cmm}$.

Ferner in $1 \mathrm{gcm}$ gleichmässig verteilt angenommen, bildet die Drüse eine kontinuierliche Schicht in Ausgleichs-(Durchschnitts-)dicke von

$$
\left.\frac{1.7895}{100}=0.017895 \mathrm{~mm} \text { (rund } 17.9 \mu\right) .
$$


Tabelle 3 .

Schweissdrüse. Stirnhaut.

\begin{tabular}{|c|c|c|}
\hline $\begin{array}{l}\text { Schnitt- } \\
\text { nummer }\end{array}$ & $\begin{array}{l}\text { Zahl der } \\
\text { Drüsen- } \\
\text { stï̈cke }\end{array}$ & $\begin{array}{l}\text { Gewicht der } \\
\text { ausgeschnit- } \\
\text { tenen Papier- } \\
\text { stücke }\end{array}$ \\
\hline 1 & 6 & $1 \mathrm{mg}$ \\
\hline 2 & 13 & 2 \\
\hline 3 & 19 & 4 \\
\hline 4 & 40 & 7 \\
\hline 5 & 68 & 12 \\
\hline 6 & 100 & 20 \\
\hline 7 & 89 & 16 \\
\hline 8 & 87 & 22.5 \\
\hline 9 & 96 & 40.6 \\
\hline 10 & 92 & 61 \\
\hline 11 & 85 & 102 \\
\hline 12 & 94 & 206 \\
\hline 13 & 103 & 359.5 \\
\hline 14 & 109 & 507 \\
\hline 15 & 123 & 573.5 \\
\hline 16 & 115 & 575 \\
\hline 17 & 125 & 469.7 \\
\hline 18 & 121 & 286 \\
\hline 19 & 106 & $15 \% .3$ \\
\hline 20 & 77 & 97 \\
\hline 21 & 52 & 56 \\
\hline 22 & 35 & 42.8 \\
\hline 23 & 16 & 13.5 \\
\hline 24 & 7 & 9.5 \\
\hline 25 & 4 & 3.6 \\
\hline 26 & 1 & 0.2 \\
\hline & & 3639.7 \\
\hline
\end{tabular}

$\mathrm{V}\left(\right.$ in $\left.\pi \mathrm{r}^{2} \mathrm{qmm}\right)=1.456980 \mathrm{cmm}$.

$\mathrm{V}$ (in $1 \mathrm{gcm})=4.174 \mathrm{cmm}$.

Ausgleichsdicke $=0.04174 \mathrm{~mm}$

(rund 41.7 u.).
Tabelle 4.

Schweissdrüse. Halshaut.

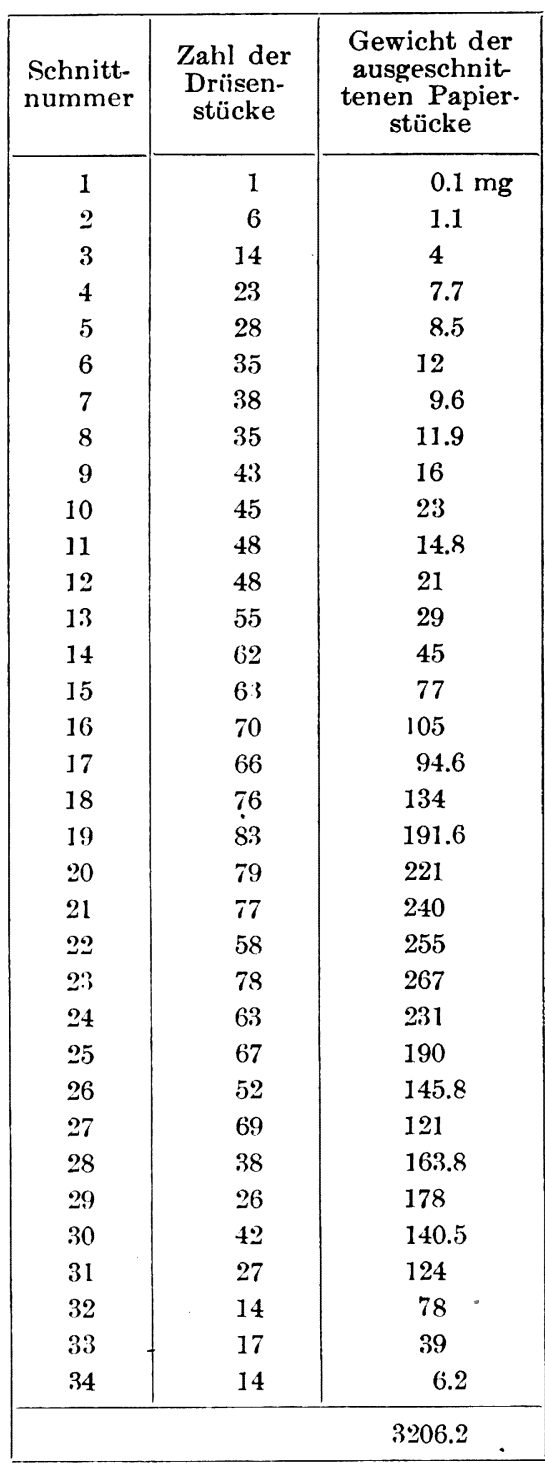

$\mathrm{V}\left(\right.$ in $\left.\pi \mathrm{r}^{2} \mathrm{qmm}\right)=1.283449 \mathrm{cmm}$.

$\mathrm{V}($ in $1 \mathrm{gcm})=3.677 \mathrm{cmm}$.

Ausgleichsdicke $=0.03677 \mathrm{~mm}$

(rund $36.8 \mu$ ). 
Quantitative Untersuchung der Anhangsorgane der Haut bei einem erwachsenen Ainu. 449

Tabelle 5 .

Schweissdrüse. Brusthaut.

\begin{tabular}{|c|c|c|}
\hline $\begin{array}{l}\text { Schnitt- } \\
\text { nummer }\end{array}$ & $\begin{array}{l}\text { Zahl der } \\
\text { Drüsen- } \\
\text { stücke }\end{array}$ & $\begin{array}{l}\text { Gewicht der } \\
\text { ausgeschnit- } \\
\text { tenen Papier- } \\
\text { stücke }\end{array}$ \\
\hline 1 & 1 & $0.1 \mathrm{mg}$ \\
\hline 2 & 7 & 1.5 \\
\hline 3 & 11 & 2.3 \\
\hline 4 & 15 & 4 \\
\hline 5 & 24 & 7 \\
\hline 6 & 28 & 8.2 \\
\hline 7 & 34 & 10.6 \\
\hline 8 & 41 & 14 \\
\hline 9 & 42 & 14.5 \\
\hline 10 & 47 & 17.7 \\
\hline 11 & 55 & 22.9 \\
\hline 12 & 54 & 31.8 \\
\hline 13 & 57 & 64.5 \\
\hline 14 & 55 & 98.1 \\
\hline 15 & 58 & 114 \\
\hline 16 & 71 & 185.4 \\
\hline 17 & 73 & 256.8 \\
\hline 18 & 70 & 329.6 \\
\hline 19 & 70 & 321 \\
\hline 20 & 76 & 274 \\
\hline 21 & 52 & 309 \\
\hline 22 & 49 & 369 \\
\hline 23 & 70 & 326 \\
\hline 24 & 36 & 381.2 \\
\hline 25 & 38 & 380 \\
\hline 26 & 46 & 346.7 \\
\hline 27 & 35 & 278 \\
\hline 28 & 38 & 218.5 \\
\hline 29 & 30 & 198 \\
\hline 30 & 19 & 154 \\
\hline 31 & 20 & 75.4 \\
\hline 32 & 9 & 26 \\
\hline 33 & 7 & 2 \\
\hline & & 4841.8 \\
\hline
\end{tabular}

$\mathrm{V}\left(\right.$ in $\left.\pi \mathrm{r}^{2} \mathrm{qmm}\right)=1.938183 \mathrm{cmm}$.

$\mathrm{V}($ in $1 \mathrm{gcm})=5.55: 2 \mathrm{cmm}$.

Ausgleichsdicke $=0.05552 \mathrm{~mm}$

(rund $55.5 \mu$.).
Tabelle $5^{\prime}$.

Apokrine Schweissdrüse ${ }^{11}$. Brusthaut.

\begin{tabular}{|c|c|c|}
\hline $\begin{array}{c}\text { Schnitt- } \\
\text { numımer }\end{array}$ & $\begin{array}{c}\text { Zahl der } \\
\text { Drüsen- } \\
\text { stücke }\end{array}$ & $\begin{array}{c}\text { Gewicht der } \\
\text { ausgeschnit- } \\
\text { tenen Papier- } \\
\text { stücke }\end{array}$ \\
\hline 1 & 2 & $4 \mathrm{mg}$ \\
2 & 6 & 7.3 \\
3 & 3 & 18.6 \\
4 & 5 & 6 \\
\hline
\end{tabular}

$\mathrm{V}\left(\right.$ in $\left.\pi \mathrm{r}^{2} \mathrm{gmm}\right)=0.014371 \mathrm{cmm}$.

$\mathrm{V}($ in $1 \mathrm{qcm})=0.041 \mathrm{cmm}$.

Ausgleichsdicke $=0.00041 \mathrm{~mm}$

(rund $0.41 \mu$ ).

1) An der Brust bemerkte ich apokrine Schweissdrïsen, wie die Tabelle $5^{\prime}$ zeigt. Die Menge der apokrinen Schweissdrüsen ist nicht so gross, nur $0.041 \mathrm{cmm}$ in $1 \mathrm{qcm}$. Sie münden in die Haarbalghöhle aus. Bei der Volumenbestimmung der Schweissdrüsen habe ich die Menge dieser apokrinen Schweissdrüsen auch hinzugefügt. 
Tabelle 6.

Schweissdrüse. Bauchhaut.

\begin{tabular}{|c|c|c|}
\hline $\begin{array}{l}\text { Schnitt- } \\
\text { nummer }\end{array}$ & $\begin{array}{l}\text { Zahl der } \\
\text { Drüsen- } \\
\text { stücke }\end{array}$ & $\begin{array}{l}\text { Gewicht der } \\
\text { ausgeschnit- } \\
\text { tenen Papier- } \\
\text { stïcke }\end{array}$ \\
\hline 1 & 4 & $0.8 \mathrm{mg}$ \\
\hline 2 & 10 & 2 \\
\hline 3 & 16 & 3.5 \\
\hline 4 & 20 & 4 \\
\hline 5 & 28 & 6 \\
\hline 6 & 42 & 7.8 \\
\hline 7 & 49 & 15.2 \\
\hline 8 & 56 & 12.2 \\
\hline 9 & 56 & 12 \\
\hline 10 & 62 & 16.1 \\
\hline 11 & 71 & 17.8 \\
\hline 12 & 73 & 18 \\
\hline 13 & 71 & 21.2 \\
\hline 14 & 73 & 18.6 \\
\hline 15 & 78 & 20 \\
\hline 16 & 69 & 21.6 \\
\hline 17 & 73 & 25 \\
\hline 18 & 79 & 24 \\
\hline 19 & 75 & 25 \\
\hline 20 & 88 & 29.2 \\
\hline 21 & 89 & 36 \\
\hline 22 & 92 & 48.8 \\
\hline 23 & 92 & 82 \\
\hline 24 & 101 & 104 \\
\hline 25 & 93 & 140 \\
\hline 26 & 96 & 134 \\
\hline 27 & 95 & 185.2 \\
\hline 28 & 106 & 211.5 \\
\hline 29 & 115 & 220.3 \\
\hline 30 & 76 & 261.1 \\
\hline 31 & 75 & 246.7 \\
\hline 32 & 72 & 224.8 \\
\hline 33 & 62 & 175 \\
\hline 34 & 49 & 155.2 \\
\hline 35 & 50 & 132 \\
\hline 36 & 34 & 133.2 \\
\hline
\end{tabular}

\begin{tabular}{|c|c|c|}
37 & 31 & $114 \mathrm{mg}$ \\
38 & 21 & 140 \\
39 & 24 & 132 \\
40 & 18 & 76.8 \\
41 & 18 & 41.6 \\
42 & 23 & 20 \\
43 & 4 & 30 \\
44 & 8 & 26.1 \\
45 & 3 & 21.6 \\
46 & 4 & 12.9 \\
47 & 3 & 6 \\
48 & 4 & 1 \\
\hline
\end{tabular}

$\mathrm{V}$ (in $\left.\pi \mathrm{r}^{2} \mathrm{qmm}\right)=1.365751 \mathrm{cmm}$.

$\mathrm{V}($ in $1 \mathrm{gcm})=3.913 \mathrm{cmm}$.

Ausgleichsdicke $=0.03913 \mathrm{~mm}$

(rund $39.1 \mu$ ). 
Quantitative Untersuchung der Anhangsorgane der Haut bei einem erwachsenen Ainu. 451

\section{Tabelle 7.}

Schweissdrüse. Rückenhaut.

\begin{tabular}{|c|c|c|}
\hline $\begin{array}{l}\text { Schnitt- } \\
\text { nummer }\end{array}$ & $\begin{array}{c}\text { Zahl der } \\
\text { Drüsen- } \\
\text { stücke }\end{array}$ & $\begin{array}{l}\text { Gewicht der } \\
\text { ausgeschnit- } \\
\text { tenen Papier- } \\
\text { stücke }\end{array}$ \\
\hline 1 & 3 & $0.4 \mathrm{mg}$ \\
\hline 2 & 10 & 2 \\
\hline 3 & 17 & 3 \\
\hline 4 & 19 & 4 \\
\hline 5 & 25 & 5 \\
\hline 6 & 34 & 6.3 \\
\hline 7 & 40 & 10.5 \\
\hline 8 & 39 & 10 \\
\hline 9 & 53 & 12.8 \\
\hline 10 & 49 & 9.8 \\
\hline 11 & 56 & 12 \\
\hline 12 & 63 & 12.4 \\
\hline 13 & 65 & 13.5 \\
\hline 14 & 64 & 17.1 \\
\hline 15 & 66 & 14 \\
\hline 16 & 65 & 15.2 \\
\hline 17 & 64 & 14.6 \\
\hline 18 & 64 & 19 \\
\hline 19 & 62 & 25 \\
\hline 20 & 62 & 44.3 \\
\hline 21 & 63 & 50.4 \\
\hline 22 & 70 & 65 \\
\hline 23 & 72 & 73 \\
\hline 24 & 68 & 77.3 \\
\hline 25 & 71 & 93.3 \\
\hline 26 & 62 & 115 \\
\hline 27 & 57 & 93.8 \\
\hline 28 & 52 & 170.2 \\
\hline 29 & 62 & 191.6 \\
\hline 30 & 51 & 191.3 \\
\hline 31 & 53 & 199 \\
\hline 32 & 52 & 191 \\
\hline 33 & 56 & 236 \\
\hline 34 & 40 & 242.5 \\
\hline 35 & 42 & 213.5 \\
\hline 36 & 38 & 222.5 \\
\hline 37 & 41 & 216 \\
\hline 38 & 38 & 172.9 \\
\hline 39 & 29 & 139.5 \\
\hline 40 & 29 & 110.1 \\
\hline 41 & 24 & 102.3 \\
\hline 42 & 19 & 91.3 \\
\hline 43 & 19 & 62 \\
\hline 44 & 12 & 52 \\
\hline 45 & 8 & 45 \\
\hline 46 & 8 & 39.2 \\
\hline 47 & 8 & 36.8 \\
\hline 48 & 8 & 31.5 \\
\hline 49 & 7 & 15.8 \\
\hline 50 & 3 & 4.8 \\
\hline 51 & 1 & 1.2 \\
\hline & & 3796.7 \\
\hline
\end{tabular}

Volumen in $\pi \mathrm{r}^{2} \mathrm{qmm}(\mathrm{r}=3.0 \mathrm{~mm})$

$=\mathrm{V}\left(\right.$ in $\left.\pi \times(3.0)^{2} \mathrm{qmm}\right)=\frac{\mathrm{FDNW}}{\mathrm{W}_{1} \mathrm{~m}^{2}}$

$=\frac{(253 \times 356) \times 0.04 \times 3796.7}{10000 \times 30^{2}}$

$=\frac{13678447.024}{9000000}=1.519827 \mathrm{cmm}$,

also in $1 \mathrm{qcm}$ umgerechnet

$\mathrm{V}($ in $1 \mathrm{qcm})=1.519827 \times \frac{1}{\pi} \times \frac{100}{\left(\frac{90}{30}\right)^{2}}$

$=1.519827 \times \frac{1}{\pi} \times \frac{100}{9}$

$=1.519827 \times 0.318309 \times 11.1111$

$=5.3753 \fallingdotseq 5.375 \mathrm{cmm}$.

Ferner in $1 \mathrm{gcm}$ gleichmässig verteilt angenommen, bildet die Drüse eine kontinuierliche Schicht in Ausgleichs-(Durchschnitts-)dicke von

$$
\frac{5.3753}{100}=0.053753 \mathrm{~mm} \text { (rund } 53.8 \mathrm{r} \text { ). }
$$


Tabelle 8 .

Schweissdrüse. Gesässhaut.

\begin{tabular}{|c|c|c|}
\hline $\begin{array}{l}\text { Schnitt- } \\
\text { nummer }\end{array}$ & $\begin{array}{l}\text { Zahl der } \\
\text { Drüsen- } \\
\text { stücke }\end{array}$ & $\begin{array}{l}\text { Gewicht der } \\
\text { ausgeschnit- } \\
\text { tenen Papier- } \\
\text { stücke }\end{array}$ \\
\hline 1 & 1 & $0.1 \mathrm{mg}$ \\
\hline 2 & 2 & 0.1 \\
\hline 3 & 12 & 2 \\
\hline 4 & 20 & 2.2 \\
\hline 5 & 35 & 4 \\
\hline 6 & 38 & 4.5 \\
\hline 7 & 49 & 6 \\
\hline 8 & 51 & 6.1 \\
\hline 9 & 56 & $6.1 \cdot$ \\
\hline 10 & 58 & 6.3 \\
\hline 11 & 59 & 8 \\
\hline 12 & 57 & 8 \\
\hline 13 & 65 & 11 \\
\hline 14 & 64 & 13 \\
\hline 15 & 66 & 11 \\
\hline 16 & 72 & 14.2 \\
\hline 17 & 66 & 12 \\
\hline 18 & 69 & 15 \\
\hline 19 & 68 & 17 \\
\hline 20 & 67 & 16.8 \\
\hline 21 & 71 & 23 \\
\hline 22 & 77 & 31.8 \\
\hline 23 & 75 & 36 \\
\hline 24 & 90 & 42 \\
\hline 25 & 82 & 41.4 \\
\hline 26 & 91 & 51.5 \\
\hline 27 & 83 & 52 \\
\hline 28 & 101 & 67 \\
\hline 29 & 93 & 108 \\
\hline 30 & 112 & 138.1 \\
\hline 31 & 90 & 202.2 \\
\hline 32 & 87 & 275.6 \\
\hline 33 & 94 & 315.4 \\
\hline 34 & 97 & 309 \\
\hline 35 & 84 & 311 \\
\hline 36 & 76 & 263.4 \\
\hline
\end{tabular}

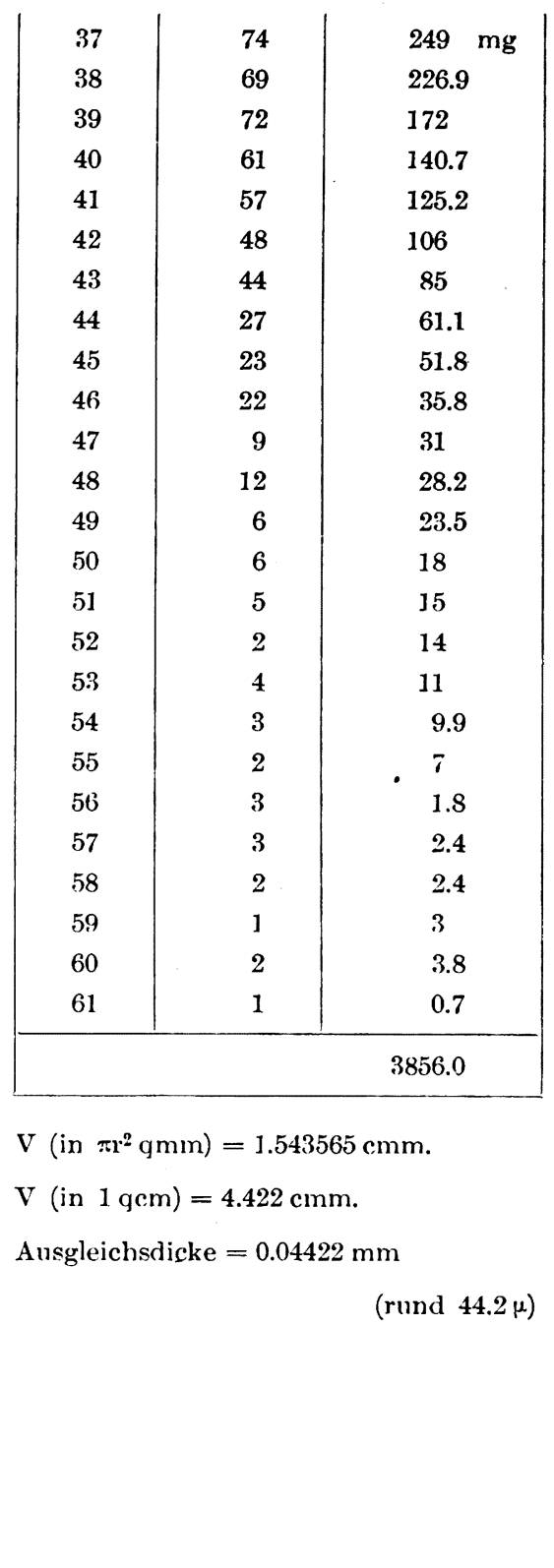


Quantitative Untersuchung der Anhangsorgane der Haut bei einem erwachsenen Ainu. 453

Tabelle 9.

Schweissdrüse. Oberarm

(Beugeseite).

\begin{tabular}{|c|c|c|}
\hline $\begin{array}{l}\text { Schnitt- } \\
\text { nummer }\end{array}$ & $\begin{array}{l}\text { Zahl der } \\
\text { Drüsen- } \\
\text { stücke }\end{array}$ & $\begin{array}{l}\text { Gewicht der } \\
\text { ausgeschnit- } \\
\text { tenen Papier- } \\
\text { stücke }\end{array}$ \\
\hline 1 & 1 & $0.1 \mathrm{mg}$ \\
\hline 2 & 7 & 0.9 \\
\hline 3 & 15 & 2 \\
\hline 4 & 27 & 4.8 \\
\hline 5 & 44 & 8.6 \\
\hline 6 & 54 & 10.1 \\
\hline 7 & 57 & 11 \\
\hline 8 & 57 & 13 \\
\hline 9 & 71 & 15.2 \\
\hline 10 & 74 & 17.5 \\
\hline 11 & 77 & 18.2 \\
\hline 12 & 91 & 29 \\
\hline 13 & 117 & 59 \\
\hline 14 & 109 & 105 \\
\hline 15 & 127 & 201.6 \\
\hline 16 & 141 & 306 \\
\hline 17 & 134 & 366 \\
\hline 18 & 148 & 295 \\
\hline 19 & 124 & 184 \\
\hline 20 & 64 & 141.8 \\
\hline 21 & 56 & 137 \\
\hline 22 & 50 & 129 \\
\hline 23 & 52 & 119 \\
\hline 24 & 33 & 138.3 \\
\hline 25 & 33 & 93 \\
\hline 26 & 22 & 45 \\
\hline 27 & 17 & 18.6 \\
\hline 28 & 10 & 19.1 \\
\hline 29 & 2 & 20 \\
\hline 30 & 7 & 4.4 \\
\hline & & 2512.2 \\
\hline
\end{tabular}

$\mathrm{V}$ (in $\left.\pi \mathrm{r}^{2} \mathrm{qrnm}\right)=1.005639 \mathrm{cmm}$.

$\mathrm{V}($ in $1 \mathrm{gcm})=2.881 \mathrm{cmm}$.

Ausgleichsdicke $=0.02881 \mathrm{~mm}$
Tabelle 10.

Schweissdrüse. Oberarm (Streckseite).

\begin{tabular}{|c|c|c|}
\hline $\begin{array}{l}\text { Schnitt- } \\
\text { nummer }\end{array}$ & $\begin{array}{l}\text { Zahl der } \\
\text { Drüsen- } \\
\text { stücke }\end{array}$ & $\begin{array}{l}\text { Gewicht der } \\
\text { ausgeschnit- } \\
\text { tenen Papier- } \\
\text { stücke }\end{array}$ \\
\hline $\begin{array}{r}1 \\
2 \\
3 \\
4 \\
5 \\
6 \\
7 \\
8 \\
9 \\
10 \\
11 \\
12 \\
13 \\
14 \\
15 \\
16 \\
17 \\
18 \\
19 \\
20 \\
21 \\
22 \\
23 \\
24 \\
25 \\
26 \\
27 \\
28 \\
29 \\
30 \\
31 \\
32 \\
33 \\
34 \\
35 \\
36 \\
37 \\
38 \\
39 \\
40\end{array}$ & $\begin{array}{r}3 \\
9 \\
21 \\
40 \\
51 \\
60 \\
72 \\
69 \\
76 \\
79 \\
83 \\
82 \\
85 \\
74 \\
76 \\
82 \\
86 \\
95 \\
104 \\
96 \\
98 \\
84 \\
82 \\
82 \\
71 \\
67 \\
61 \\
54 \\
54 \\
50 \\
38 \\
32 \\
24 \\
10 \\
7 \\
7 \\
4 \\
1 \\
6 \\
1\end{array}$ & $\begin{array}{c}0.4 \mathrm{mg} \\
1.8 \\
3.6 \\
6 \\
8.9 \\
11.7 \\
14 \\
13.7 \\
14.6 \\
18 \\
18.3 \\
19.1 \\
23.1 \\
21.3 \\
31 \\
36 \\
49.3 \\
95.3 \\
134 \\
154 \\
184.4 \\
183 \\
190 \\
187 \\
190 \\
168 \\
199.2 \\
196.1 \\
145 \\
122.5 \\
83.7 \\
81 \\
56 \\
50 \\
28 \\
17 \\
12 \\
14 \\
6.8 \\
0.3 \\
\end{array}$ \\
\hline & & 2788.1 \\
\hline
\end{tabular}

Ausgleichsdicke $=0.03197 \mathrm{~mm}$

(rund 32.0 u.).

(rund $28.8 \mu$ ). 
Tabelle 11.

Schweissdrüse. Vorderarm (Beugeseite).

\begin{tabular}{|c|c|c|}
\hline $\begin{array}{l}\text { Schnitt- } \\
\text { nummer }\end{array}$ & $\begin{array}{l}\text { Zahl der } \\
\text { Drüsen- } \\
\text { stücke }\end{array}$ & $\begin{array}{l}\text { Gewicht der } \\
\text { ausgeschnit- } \\
\text { tenen Papier- } \\
\text { stücke }\end{array}$ \\
\hline 1 & 1 & $0.2 \mathrm{mg}$ \\
\hline 2 & 3 & 0.6 \\
\hline 3 & 6 & 1 \\
\hline 4 & 11 & 2 \\
\hline 5 & 26 & 5.4 \\
\hline 6 & 44 & 9 \\
\hline 7 & 58 & 13.3 \\
\hline 8 & 65 & 16.5 \\
\hline 9 & 67 & 15.8 \\
\hline 10 & 74 & 15.2 \\
\hline 11 & 78 & 20 \\
\hline 12 & 87 & 31 \\
\hline 13 & 93 & 27.6 \\
\hline 14 & 87 & 26 \\
\hline 15 & 99 & 61 \\
\hline 16 & 91 & 88 \\
\hline 17 & 111 & 86 \\
\hline 18 & 113 & 192.3 \\
\hline 19 & 120 & 190 \\
\hline 20 & 121 & 294 \\
\hline 21 & 98 & 345.8 \\
\hline 22 & 110 & 450 \\
\hline 23 & 92 & 408 \\
\hline 24 & 95 & 370.2 \\
\hline 25 & 91 & 375 \\
\hline 26 & 79 & 396 \\
\hline 27 & 64 & 312 \\
\hline 28 & 59 & 260.2 \\
\hline 29 & 36 & 166.5 \\
\hline 30 & 23 & 112 \\
\hline 31 & 16 & 54 \\
\hline 32 & 14 & 33.6 \\
\hline 33 & 3 & 16 \\
\hline 34 & 1 & 5 \\
\hline 35 & 1 & 7 \\
\hline 36 & 2 & 2 \\
\hline 37 & 2 & 1 \\
\hline & & 4409.2 \\
\hline
\end{tabular}

$\mathrm{V}\left(\right.$ in $\left.\pi \mathrm{r}^{2} \mathrm{qmm}\right)=1.765013 \mathrm{cmm}$.

$\mathrm{V}($ in $1 \mathrm{gcm})=5.056 \mathrm{cmm}$.

Ausgleichśdicke $=0.05056 \mathrm{~mm}$

(rund $50.6 \mu$ ).
Tabelle 12.

Schweissdrüse. Vorderarm (Streckseite).

\begin{tabular}{|c|c|c|}
\hline $\begin{array}{l}\text { Schnitt- } \\
\text { nummer }\end{array}$ & $\begin{array}{l}\text { Zahl der } \\
\text { Drüsen- } \\
\text { stücke }\end{array}$ & $\begin{array}{l}\text { Gewicht der } \\
\text { ausgeschnit- } \\
\text { tenen Papier- } \\
\text { stücke }\end{array}$ \\
\hline 1 & 1 & $0.1 \mathrm{mg}$ \\
\hline 2 & 1 & 0.1 \\
\hline 3 & 5 & 1.4 \\
\hline 4 & 6 & 1.2 \\
\hline 5 & 11 & 1.8 \\
\hline 6 & 19 & 3.2 \\
\hline 7 & 19 & 3.6 \\
\hline 8 & 28 & 6 \\
\hline 9 & 35 & 7 \\
\hline 10 & 40 & 9.2 \\
\hline 11 & 50 & 10.4 \\
\hline 12 & 56 & 12.2 \\
\hline 13 & 73 & 32 \\
\hline 14 & 87 & 53 \\
\hline 15 & 84 & 71.4 \\
\hline 16 & 86 & 85 \\
\hline 17 & 106 & 66 \\
\hline 18 & 92 & 104 \\
\hline 19 & 88 & 186.4 \\
\hline 20 & 88 & 196.6 \\
\hline 21 & 91 & 144 \\
\hline 22 & 78 & 143.1 \\
\hline 23 & 68 & 188 \\
\hline 24 & 70 & 168 \\
\hline 25 & 65 & 264 \\
\hline 26 & 59 & 327.3 \\
\hline 27 & 50 & 160 \\
\hline 28 & 32 & 141 \\
\hline 29 & 19 & 48 \\
\hline 30 & 6 & 17.2 \\
\hline 31 & 1 & 4.5 \\
\hline 32 & 2 & 7.5 \\
\hline & & 2463.2 \\
\hline
\end{tabular}

$\mathrm{V}$ (in $\left.\pi \mathrm{r}^{2} \mathrm{qmm}\right)=0.986024 \mathrm{cmm}$.

$\mathrm{V}($ in $1 \mathrm{gcm})=2.825 \mathrm{cmm}$.

Ausgleichsdicke $=0.02825 \mathrm{~mm}$

(rund $28.3 \mu$ ). 
Quantitative Untersuchung der Anhangsorgane der Haut bei einem erwachsenen Ainu. 455

Tabelle 13.

Schweissdrüse. Oberschenke] (medial).

\begin{tabular}{|c|c|c|}
\hline $\begin{array}{l}\text { Schnitt- } \\
\text { nummer }\end{array}$ & $\begin{array}{l}\text { Zahl der } \\
\text { Drüsen- } \\
\text { stücke }\end{array}$ & $\begin{array}{l}\text { Gewicht der } \\
\text { ausgeschnit- } \\
\text { tenen Papier- } \\
\text { stücke }\end{array}$ \\
\hline 1 & 3 & $0.5 \mathrm{mg}$ \\
\hline 2 & 6 & 1 \\
\hline 3 & 20 & 4 \\
\hline 4 & 23 & 5 \\
\hline 5 & 31 & 8 \\
\hline 6 & 32 & 9 \\
\hline 7 & 40 & 12.3 \\
\hline 8 & 45 & 12.7 \\
\hline 9 & 51 & 13.5 \\
\hline 10 & 47 & 18.2 \\
\hline 11 & 60 & 26.9 \\
\hline 12 & 58 & 63 \\
\hline 13 & 72 & 121.8 \\
\hline 14 & 78 & 150.2 \\
\hline 15 & 75 & 165 \\
\hline 16 & 68 & 169 \\
\hline 17 & 70 & 201 \\
\hline 18 & 63 & 215.6 \\
\hline 19 & 51 & 244.5 \\
\hline 20 & 53 & 204 \\
\hline 21 & 45 & 162.8 \\
\hline 22 & 29 & 139 \\
\hline 23 & . 20 & 133 \\
\hline 24 & 22 & 108 \\
\hline 25 & 22 & 84.5 \\
\hline 26 & 16 & 70.2 \\
\hline 27 & 13 & 36 \\
\hline 28 & 4 & 8 \\
\hline & & 2386.7 \\
\hline
\end{tabular}

$\mathrm{V}\left(\right.$ in $\left.\pi \mathrm{r}^{2} \mathrm{qmm}\right)=0.955401 \mathrm{cmm}$.

$\mathrm{V}($ in $1 \mathrm{gcm})=2.737 \mathrm{cmm}$.

Ausgleichsdicke $=0.02737 \mathrm{~mm}$

(rund $27.4 \varphi$ ).
Tabelle 14

Schweissdrüse. Oberschenkel (lateral).

\begin{tabular}{|c|c|c|}
\hline $\begin{array}{l}\text { Schnitt- } \\
\text { nummer }\end{array}$ & $\begin{array}{l}\text { Zahl der } \\
\text { Drüsen- } \\
\text { stïcke }\end{array}$ & $\begin{array}{l}\text { Gewicht der } \\
\text { ausgeschnit- } \\
\text { tenen Papier- } \\
\text { stïcke }\end{array}$ \\
\hline 1 & 6 & $2 \quad \mathrm{mg}$ \\
\hline 2 & 11 & 2.4 \\
\hline 3 & 14 & 3.2 \\
\hline 4 & 32 & 8 \\
\hline 5 & 40 & 10.2 \\
\hline 6 & 48 & 11 \\
\hline 7 & 54 & 16.4 \\
\hline 8 & 51 & 17 \\
\hline 9 & 51 & 16.3 \\
\hline 10 & 56 & 21.1 \\
\hline 11 & 57 & 19 \\
\hline 12 & 58 & 24 \\
\hline 13 & 61 & 36.2 \\
\hline 14 & 62 & 44 \\
\hline 15 & 70 & 70 \\
\hline 16 & 71 & 65.5 \\
\hline 17 & 68 & 67 \\
\hline 18 & 73 & $1: 32$ \\
\hline 19 & 77 & 172.5 \\
\hline 20 & 68 & 178.8 \\
\hline 21 & 72 & 196 \\
\hline 22 & 90 & 216 \\
\hline 23 & 54 & 237.5 \\
\hline 24 & 56 & 204 \\
\hline 25 & 69 & 200 \\
\hline 26 & 54 & 191 \\
\hline 27 & 52 & 152 \\
\hline 28 & 43 & 127 \\
\hline 29 & 30 & 99 \\
\hline 30 & $4:$ & 94.3 \\
\hline 31 & 35 & 116.8 \\
\hline 32 & 36 & 118 \\
\hline 33 & 36 & 96 \\
\hline 34 & 29 & 57 \\
\hline 35 & 13 & 33.4 \\
\hline 36 & 8 & 29.2 \\
\hline 37 & 8 & 20.6 \\
\hline 38 & 5 & 15.6 \\
\hline 39 & 8 & $19.5)$ \\
\hline 40 & 3 & 15 \\
\hline 41 & 2 & 8 \\
\hline 42 & 3 & 5 \\
\hline 43 & 5 & 4 \\
\hline 44 & 6 & 1 \\
\hline & & 3172.5 \\
\hline
\end{tabular}

$\mathrm{V}\left(\right.$ in $\left.\pi \mathrm{r}^{2} \mathrm{qmm}\right)=1.269959 \mathrm{cmm}$.

$\mathrm{V}($ in $1 \mathrm{qcm})=3.638 \mathrm{cmm}$.

Ausgleichsdicke $=0.03638 \mathrm{~mm}$

(rund $36.4 \mu$.). 
Tabelle 15.

Schweissdrüse. Unterschenkel (Streckseite).

\begin{tabular}{|c|c|c|}
\hline $\begin{array}{l}\text { Schnitt- } \\
\text { nummer }\end{array}$ & $\begin{array}{c}\text { Zahl der } \\
\text { Drüsen- } \\
\text { stücke }\end{array}$ & $\begin{array}{l}\text { Gewicht der } \\
\text { ausgeschnit- } \\
\text { tenen Papier- } \\
\text { stücke }\end{array}$ \\
\hline 1 & 1 & $0.1 \mathrm{mg}$ \\
\hline$\dot{2}$ & 3 & 0.2 \\
\hline 3 & 8 & 1.2 \\
\hline 4 & 16 & 3 \\
\hline 5 & 29 & 7 \\
\hline 6 & 29 & 7 \\
\hline 7 & 52 & 11.2 \\
\hline 8 & 66 & 16.6 \\
\hline 9 & 62 & 14.3 \\
\hline 10 & 65 & 22 \\
\hline 11 & 64 & 23 \\
\hline 12 & 55 & 33 \\
\hline 13 & 77 & 45 \\
\hline 14 & 79 & 77 \\
\hline 15 & 73 & 132 \\
\hline 16 & 107 & 236.3 \\
\hline 17 & 86 & 363 \\
\hline 18 & 87 & 337.8 \\
\hline 19 & 91 & 362 \\
\hline 20 & 72 & 345 \\
\hline 21 & 65 & 267 \\
\hline 22 & 54 & 154.8 \\
\hline 23 & 27 & 86 \\
\hline 24 & 14 & 91.3 \\
\hline 25 & 16 & 55 \\
\hline 26 & 5 & 18.5 \\
\hline 27 & 8 & 12.2 \\
\hline 28 & 2 & 10.9 \\
\hline 29 & 2 & 6 \\
\hline 30 & 1 & 0.2 \\
\hline & & 2738.6 \\
\hline
\end{tabular}

$\mathrm{V}$ (in $\left.\pi \mathrm{r}^{2} \mathrm{qmm}\right)=1.096268 \mathrm{cmm}$.

$\mathrm{V}($ in $1 \mathrm{gcm})=3.141 \mathrm{cmm}$.

Ausgleichsdicke $=0.03141 \mathrm{~mm}$
Tabelle 16.

Schweissdrüse. Unterschenkel (Beugeseite).

\begin{tabular}{|c|c|c|}
\hline $\begin{array}{l}\text { Schnitt- } \\
\text { nummer }\end{array}$ & $\begin{array}{l}\text { Zahl der } \\
\text { Drüsen- } \\
\text { stücke }\end{array}$ & $\begin{array}{l}\text { Gewicht der } \\
\text { ausgeschnit- } \\
\text { tenen Papier- } \\
\text { stücke }\end{array}$ \\
\hline $\begin{array}{r}1 \\
2 \\
3 \\
4 \\
5 \\
6 \\
7 \\
8 \\
9 \\
10 \\
11 \\
12 \\
13 \\
14 \\
15 \\
16 \\
17 \\
18 \\
19 \\
20 \\
21 \\
22 \\
23 \\
24 \\
25 \\
26 \\
27 \\
28 \\
29 \\
30 \\
31 \\
32 \\
33 \\
34 \\
35 \\
36 \\
37 \\
38\end{array}$ & $\begin{array}{r}1 \\
2 \\
3 \\
5 \\
9 \\
11 \\
17 \\
18 \\
35 \\
51 \\
57 \\
58 \\
60 \\
64 \\
65 \\
74 \\
78 \\
75 \\
85 \\
85 \\
91 \\
78 \\
73 \\
76 \\
67 \\
76 \\
58 \\
68 \\
58 \\
60 \\
43 \\
46 \\
30 \\
18 \\
16 \\
7 \\
3 \\
2\end{array}$ & $\begin{array}{c}0.2 \mathrm{mg} \\
0.5 \\
1 \\
1.5 \\
1.5 \\
2.5 \\
4.5 \\
5 \\
10 \\
13 \\
15 \\
13 \\
16 \\
16 \\
15 \\
34 \\
65 \\
114 \\
136 \\
134.5 \\
135 \\
144 \\
124.3 \\
144 \\
149.5 \\
157 \\
129 \\
140 \\
182.5 \\
209 \\
197 \\
154 \\
106 \\
82.5 \\
38 \\
20 \\
7.5 \\
1 \\
\end{array}$ \\
\hline & - & 2718.5 \\
\hline
\end{tabular}

$\mathrm{V}\left(\right.$ in $\left.\pi \mathrm{r}^{2} \mathrm{gmm}\right)=1.088222 \mathrm{cmm}$.

$\mathrm{V}($ in $1 \mathrm{gcm})=3.118 \mathrm{cmm}$.

Ausgleichsdicke $=0.03118 \mathrm{~mm}$

(rund $31.2 \mu$ ).

(rund $31.4 \mu$ ). 
Quantitative Untersuchung der Anhangsorgane der Haut bei einem erwachsenen Ainu. 457

\section{Menge der Talgdrüse.}

Tabelle 17.

Talgdrüse. Scheitelhaut.

\begin{tabular}{|c|c|c|}
\hline $\begin{array}{l}\text { Schnitt- } \\
\text { nummer }\end{array}$ & $\begin{array}{l}\text { Zahl der } \\
\text { Drüsen- } \\
\text { stücke }\end{array}$ & $\begin{array}{c}\text { Gewicht der } \\
\text { ausgeschnit- } \\
\text { tenen Papier- } \\
\text { stücke }\end{array}$ \\
\hline 1 & 3 & $1.1 \mathrm{mg}$ \\
\hline 2 & 3 & 2.5 \\
\hline 3 & 8 & 5 \\
\hline 4 & 18 & 12.4 \\
\hline 5 & 38 & 29.5 \\
\hline 6 & 46 & 68 \\
\hline 7 & 62 & 70.5 \\
\hline 8 & 79 & 91 \\
\hline 9 & 112 & 134.5 \\
\hline 10 & 127 & 157 \\
\hline 11 & 171 & 221.5 \\
\hline 12 & 173 & 251 \\
\hline 13 & 187 & 276 \\
\hline 14 & 207 & 283.6 \\
\hline 15 & 187 & .244 \\
\hline 16 & 201 & 256 \\
\hline 17 & 141 & 200 \\
\hline 18 & 117 & 149.2 \\
\hline 19 & 94 & 119 \\
\hline 20 & 72 & 71 \\
\hline 21 & 46 & 55 \\
\hline 22 & 35 & 36 \\
\hline 23 & 27 & 25 \\
\hline 24 & 16 & 14.5 \\
\hline 25 & 12 & 10.8 \\
\hline 26 & 11 & 9 \\
\hline 27 & 8 & 5.6 \\
\hline 28 & 3 & 3 \\
\hline 29 & 3 & 4.2 \\
\hline 30 & 2 & 3 \\
\hline 31 & 2 & 0.8 \\
\hline
\end{tabular}

$$
\begin{aligned}
& \text { Volumen in } \pi \mathrm{r}^{2} \mathrm{qmm}\left(\mathrm{r}=\frac{10}{3} \mathrm{~mm}\right) \\
& =\mathrm{V}\left(\text { in } \pi \times\left(\frac{10}{3}\right)^{2} \mathrm{gmm}\right)=\frac{\mathrm{FD} \Sigma \mathrm{W}}{\mathrm{W}_{1} \mathrm{~m}^{2}} \\
& =\frac{(253 \times 356) \times 0.04 \times 2809.7}{10000 \times 30^{2}} \\
& =\frac{10122562.384}{9000000}=1.124729 \mathrm{cmm}
\end{aligned}
$$

also in $1 \mathrm{gcm}$ umgerechnet

$\mathrm{V}($ in $1 \mathrm{gcm})=1.124729 \times \frac{1}{\pi} \times \frac{100}{\left(\frac{100}{30}\right)^{2}}$

$=1.124729 \times \frac{1}{\pi} \times \frac{100}{\frac{100^{2}}{30^{2}}}$

$=1.124729 \times \frac{1}{\pi} \times \frac{100 \times 30^{2}}{100^{2}}$

$=1.124729 \times \frac{1}{\pi} \times \frac{900}{100}$

$=1.124729 \times 0.318309 \times 9$

$=3.2221 \fallingdotseq 3.222 \mathrm{cmm}$.

Ferner in $1 \mathrm{qcm}$ gleichmässig verteilt angenommen, bildet die Drüse eine kontinuierliche Schicht in Ausgleichs-(Durchschnitts-)dicke von

$$
\frac{3.2221}{100}=0.032221 \mathrm{~mm}(\text { rund } 32.22 \mu) \text {. }
$$


Tabelle 18.

Talgdrüse. Stirnhaut.

\begin{tabular}{|c|c|c|}
\hline $\begin{array}{c}\text { Schnitt- } \\
\text { nummer }\end{array}$ & $\begin{array}{c}\text { Zahl der } \\
\text { Drüsen- } \\
\text { stücke }\end{array}$ & $\begin{array}{c}\text { Gewicht der } \\
\text { ausgeschnit- } \\
\text { tenen Papier- } \\
\text { stücke }\end{array}$ \\
\hline 1 & 2 & $1.1 \mathrm{mg}$ \\
2 & 8 & 4 \\
3 & 12 & 6 \\
4 & 35 & 17 \\
5 & 44 & 28 \\
6 & 45 & 38 \\
7 & 70 & 71 \\
8 & 100 & 113 \\
9 & 134 & 155 \\
10 & 152 & 176.3 \\
11 & 127 & 204.8 \\
12 & 123 & 152 \\
13 & 87 & 112 \\
14 & 52 & 65.4 \\
15 & 12 & 26.1 \\
16 & 2 & 4.5 \\
\hline & & 1174.2 \\
\hline
\end{tabular}

$\mathrm{V}\left(\right.$ in $\left.\pi \mathrm{r}^{2} \mathrm{qmm}\right)=0.470035 \mathrm{cmm}$.

$\mathrm{V}($ in $1 \mathrm{qcm})=1.347 \mathrm{cmm}$.

Ausgleichsdicke $=0.01347 \mathrm{~mm}$

(rund $13.47 u$ ).

Tabelle 19.

Talgdrüse. Halshaut.

\begin{tabular}{|c|c|c|}
\hline $\begin{array}{c}\text { Schnitt- } \\
\text { nummer }\end{array}$ & $\begin{array}{c}\text { Zahl der } \\
\text { Drüsen- } \\
\text { stücke }\end{array}$ & $\begin{array}{c}\text { Gewicht der } \\
\text { ausgeschnit- } \\
\text { tenen Papier- } \\
\text { stücke }\end{array}$ \\
\hline 1 & 1 & $0.1 \mathrm{mg}$ \\
2 & 3 & 1.5 \\
3 & 7 & 4.1 \\
4 & 6 & 10 \\
5 & 12 & 21 \\
6 & 7 & 13.5 \\
7 & 7 & 7 \\
8 & 10 & 15.5 \\
9 & 10 & 17 \\
10 & 9 & 25.6 \\
11 & 10 & 28.1 \\
12 & 7 & 13 \\
13 & 4 & 3 \\
14 & 6 & 7 \\
15 & 5 & 9 \\
16 & 6 & 15 \\
17 & 3 & 17 \\
18 & 6 & 8.9 \\
19 & 1 & 2 \\
\hline & & 218.3 \\
\hline
\end{tabular}

$\mathrm{V}$ (in $\left.\pi \mathrm{r}^{2} \mathrm{gmm}\right)=0.087386 \mathrm{cmm}$.

$\mathrm{V}$ (in $1 \mathrm{gcm})=0.250 \mathrm{cmm}$.

Ausgleichsdicke $=0.00250 \mathrm{~mm}$

(rund $2.50 \mu$ ).
Tabelle 20.

Talgdrüse. Brusthaut.

\begin{tabular}{|c|c|c|}
\hline $\begin{array}{l}\text { Schnitt- } \\
\text { nummer }\end{array}$ & $\begin{array}{c}\text { Zahl der } \\
\text { Drüsen- } \\
\text { stücke }\end{array}$ & $\begin{array}{l}\text { Gewieht der } \\
\text { ausgeschnit- } \\
\text { tenen Papier- } \\
\text { stäcke }\end{array}$ \\
\hline 1 & 3 & $2.1 \mathrm{mg}$ \\
\hline 2 & 6 & 0.5 \\
\hline 3 & 7 & 18.1 \\
\hline 4 & 11 & 15 \\
\hline 5 & 7 & 13.2 \\
\hline 6 & 19 . & 19.1 \\
\hline 7 & 24 & 25 \\
\hline 8 & 25 & 38 \\
\hline 9 & 33 & 50.2 \\
\hline 10 & 29 & 43 \\
\hline 11 & 20 & 29 \\
\hline 12 & 12 & 17 \\
\hline 13 & 12 & 20.2 \\
\hline 14 & 11 & 10.8 \\
\hline 15 & 6 & 9.6 \\
\hline 16 & 2 & 3 \\
\hline 17 & 1 & 2 \\
\hline \multicolumn{3}{|r|}{321.8} \\
\hline
\end{tabular}

$\mathrm{V}$ (in $\left.\pi \mathrm{r}^{2} \mathrm{gmm}\right)=0.128817 \mathrm{cmm}$.

$\mathrm{V}$ (in $1 \mathrm{gcm})=0.369 \mathrm{cmm}$.

Ausgleichsdicke $=0.00369 \mathrm{~mm}$

rund $3.69 \mu$ ).

Tabelle 21.

Talgdrüse. Bauchhaut.

\begin{tabular}{|c|c|c|}
\hline $\begin{array}{c}\text { Schnitt- } \\
\text { nummer }\end{array}$ & $\begin{array}{c}\text { Zahl der } \\
\text { Drüsen- } \\
\text { stücke }\end{array}$ & $\begin{array}{c}\text { Gewicht der } \\
\text { ausgeschnit- } \\
\text { tenen Papier- } \\
\text { stïcke }\end{array}$ \\
\hline 1 & 1 & $0.5 \mathrm{mg}$ \\
2 & 1 & 0.2 \\
3 & 2 & 1.8 \\
4 & 6 & 7.1 \\
5 & 9 & 16.5 \\
6 & 7 & 13.5 \\
7 & 2 & 5.5 \\
8 & 2 & 3.5 \\
9 & 4 & 5.5 \\
10 & 8 & 8.6 \\
11 & 7 & 12 \\
12 & 7 & 10.5 \\
13 & 6 & 8.7 \\
14 & 1 & 2.4 \\
\hline
\end{tabular}

$\mathrm{V}$ (in $\left.\pi \mathrm{r}^{2} \mathrm{qmm}\right)=0.038549 \mathrm{cmm}$.

$\mathrm{V}$ (in $1 \mathrm{gcm})=0.110 \mathrm{cmm}$.

Ausgleichsdicke $=0.00110 \mathrm{~mm}$

(rund $1.10 \mu$ ). 
Quantitative Untersuchung der Anhangsorgane der Haut bei einem erwachsenen Ainu. 459

Tabelle 22.

Talgdrüse. Rückenhaut.

\begin{tabular}{|c|c|c|}
\hline $\begin{array}{l}\text { Schnitt- } \\
\text { nummer }\end{array}$ & $\begin{array}{l}\text { Zahl der } \\
\text { Drüsen- } \\
\text { stücke }\end{array}$ & $\begin{array}{c}\text { Gewicht der } \\
\text { ausgeschnit- } \\
\text { tenen Papier- } \\
\text { stiicke }\end{array}$ \\
\hline 1 & 1 & $0.2 \mathrm{mg}$ \\
\hline 2 & 2 & 1.9 \\
\hline 3 & 2 & 1.6 \\
\hline 4 & 1 & 2 \\
\hline 5 & 4 & 3.8 \\
\hline 6 & 6 & 10.9 \\
\hline 7 & 10 & 15 \\
\hline 8 & 12 & 13.9 \\
\hline 9 & 12 & 14.9 \\
\hline 10 & 17 & 17.5 \\
\hline 11 & 19 & 27.1 \\
\hline 12 & 19 & 29.7 \\
\hline 13 & 25 & 38 \\
\hline 14 & 22 & 31 \\
\hline 15 & 21 & 24 \\
\hline 16 & 14 & 20 \\
\hline 17 & 10 & 17.1 \\
\hline 18 & 11 & 11.8 \\
\hline 19 & 5 & 7 \\
\hline 20 & 4 & 4 \\
\hline 21 & 2 & 3.5 \\
\hline 22 & 2 & 1 \\
\hline & & 295.9 \\
\hline
\end{tabular}

Volumen in $\pi \mathrm{r}^{2} \mathrm{gmm}(\mathrm{r}=3.0 \mathrm{~mm})$

$=\mathrm{V}\left(\right.$ in $\left.\pi \times(3.0)^{2} \mathrm{gmm}\right)=\frac{\mathrm{FD} \Sigma \mathrm{WV}}{\mathrm{W}_{1} \mathrm{~m}^{2}}$

$=\frac{(25.3 \times 356) \times 0.04 \times 295.9}{10000 \times 30^{2}}$

$=\frac{1066044.848}{9000000}=0.118449 \mathrm{cmm}$,

also in $1 \mathrm{gcm}$ umgerechnet

$\mathrm{V}($ in $1 \mathrm{gcm})=0.118449 \times \frac{1}{\pi} \times \frac{100}{\left(\frac{90}{30}\right)^{2}}$

$=0.118449 \times \frac{1}{\pi} \times \frac{100}{9}$

$=0.118449 \times 0.318309 \times 11.1111$

$=0.4189 \fallingdotseq 0.419 \mathrm{cmm}$.

Ferner in $1 \mathrm{qcm}$ gleichmässig verteilt angenommen, bildet die Drüse eine kontinuierliche Schicht in Ausgleichs-(Durchschnitts-)dicke von

$$
\frac{0.4189}{100}=0.004189 \mathrm{~mm}(\text { rund } 4.19 \mu) .
$$


Tabelle 23.

Talgdrüse. Gesässhaut.

\begin{tabular}{|c|c|c|}
\hline $\begin{array}{c}\text { Schnitt- } \\
\text { nummer }\end{array}$ & $\begin{array}{c}\text { Zahl der } \\
\text { Drüsen- } \\
\text { stücke }\end{array}$ & $\begin{array}{c}\text { Gewicht der } \\
\text { ausgeschnit- } \\
\text { tenen Papier- } \\
\text { stücke }\end{array}$ \\
\hline 1 & 2 & $0.8 \mathrm{mg}$ \\
2 & 1 & 1.2 \\
3 & 5 & 2.8 \\
4 & 7 & 4.1 \\
5 & 9 & 8.1 \\
6 & 11 & 9.1 \\
7 & 10 & 6.3 \\
8 & 10 & 11 \\
9 & 11 & 16 \\
10 & 13 & 20.2 \\
11 & 18 & 17.1 \\
12 & 13 & 16 \\
13 & 14 & 14.1 \\
14 & 14 & 12.1 \\
15 & 11 & 12 \\
16 & 10 & 10.6 \\
17 & 6 & 5 \\
18 & 1 & 1 \\
\hline
\end{tabular}

$\mathrm{V}\left(\right.$ in $\left.\pi \mathrm{r}^{2} \mathrm{qmm}\right)=0.067051 \mathrm{cmm}$. $\mathrm{V}$ (in $1 \mathrm{qcm})=0.192 \mathrm{cmm}$.

Ausgleichsdicke $=0.00192 \mathrm{~mm}$

(rund $1.92 \mu$ ).

Tabelle 24.

Talgdrüse. Oberarm

(Beugeseite).

\begin{tabular}{|c|c|c|}
\hline $\begin{array}{c}\text { Schnitt- } \\
\text { nummer }\end{array}$ & $\begin{array}{c}\text { Zahl der } \\
\text { Drüsen- } \\
\text { stïcke }\end{array}$ & $\begin{array}{c}\text { Gewicht der } \\
\text { ausgeschnit- } \\
\text { tenen Papier- } \\
\text { stücke }\end{array}$ \\
\hline 1 & 2 & J.5 mg \\
2 & 7 & 4.1 \\
3 & 10 & 16.2 \\
4 & 10 & 9.5 \\
5 & 5 & 4 \\
6 & 3 & 3.3 \\
7 & 1 & 0.8 \\
8 & 1 & 0.5 \\
9 & 3 & 2.3 \\
10 & 2 & 1.8 \\
11 & 3 & 1.8 \\
12 & 1 & 0.6 \\
13 & 1 & 0.5 \\
14 & 1 & 0.6 \\
\hline
\end{tabular}

$\mathrm{V}\left(\right.$ in $\left.\pi \mathrm{r}^{2} \mathrm{gmm}\right)=0.019014 \mathrm{cmm}$.

$\mathrm{V}($ in $1 \mathrm{gcm})=0.0 .54 \mathrm{cmm}$.

Ausgleichsdicke $=0.00054 \mathrm{~mm}$

(rund $0.54 \mu$ ).
Tabelle 25.

Talgdrüse. Oberarm

(Streckseite).

\begin{tabular}{|c|c|c|}
\hline $\begin{array}{c}\text { Schnitt- } \\
\text { nummer }\end{array}$ & $\begin{array}{c}\text { Zahl der } \\
\text { Drüsen- } \\
\text { stücke }\end{array}$ & $\begin{array}{c}\text { Gewicht der } \\
\text { ausgeschnit- } \\
\text { tenen Papier- } \\
\text { stücke }\end{array}$ \\
\hline 1 & 1 & $0.4 \mathrm{mg}$ \\
2 & 3 & 2.2 \\
3 & 7 & 6 \\
4 & 13 & 13 \\
5 & 15 & 30.1 \\
6 & 20 & 39.5 \\
7 & 25 & 45.3 \\
8 & 21 & 39.5 \\
9 & 18 & 41.1 \\
10 & 12 & 26 \\
11 & 11 & 20.9 \\
12 & 6 & 11.4 \\
13 & 4 & 9.3 \\
14 & 1 & 1.5 \\
\hline \multicolumn{2}{|c}{} \\
\hline
\end{tabular}

$\mathrm{V}\left(\right.$ in $\left.\pi \mathrm{r}^{2} \mathrm{qmm}\right)=0.114566 \mathrm{cmm}$.

$\mathrm{V}$ (in $1 \mathrm{gcm})=0.328 \mathrm{cmm}$.

Ausgleichsdicke $=0.00328 \mathrm{~mm}$

(rund $3.28 \mu$ ).

Tabelle 26.

Talgdrüse. Vorderarm

(Beugeseite).

\begin{tabular}{|c|c|c|}
\hline $\begin{array}{l}\text { Schnitt- } \\
\text { nummer }\end{array}$ & $\begin{array}{c}\text { Zahl der } \\
\text { Drüsen- } \\
\text { stücke }\end{array}$ & $\begin{array}{l}\text { Gewicht der } \\
\text { ausgeschnit- } \\
\text { tenen Papier- } \\
\text { stücke. }\end{array}$ \\
\hline 1 & 1 & $0.1 \mathrm{mg}$ \\
\hline 2 & $\hat{1}$ & 0.5 \\
\hline 3 & 3 & 1.9 \\
\hline 4 & 4 & 1.7 \\
\hline 5 & 4 & 2.5 \\
\hline 6 & 3 & 3 \\
\hline 7 & 7 & 5 \\
\hline 8 & 10 & 10.5 \\
\hline 9 & 10 & 12 \\
\hline 10 & 4 & 7 \\
\hline 11 & 7 & 4.5 \\
\hline 12 & 4 & 7 \\
\hline 13 & 3 & 2 \\
\hline 14 & 1 & 1 \\
\hline 15 & 1 & 0.7 \\
\hline 16 & 1 & 0.9 \\
\hline 17 & 1 & 0.1 \\
\hline 18 & 2 & 0.8 \\
\hline 19 & 1 & 0.8 \\
\hline \multicolumn{3}{|r|}{62.0} \\
\hline
\end{tabular}

(rund $0.71 \mu$ ). 
Quantitative Untersuchung der Anhangsorgane der Haut bei einem erwachsenen Ainu. 461

Tabelle 27.

Talgdrüse. Vorderarm

(Streckseite).

\begin{tabular}{|c|c|c|}
\hline $\begin{array}{c}\text { Schnitt- } \\
\text { nummer }\end{array}$ & $\begin{array}{c}\text { Zahl der } \\
\text { Drüsen- } \\
\text { stïcke }\end{array}$ & $\begin{array}{c}\text { Gewicht der } \\
\text { ausgeschnit- } \\
\text { tenen Papier- } \\
\text { stücke }\end{array}$ \\
\hline 1 & 2 & $0.3 \mathrm{mg}$ \\
2 & 4 & 2 \\
3 & 8 & 11 \\
4 & 9 & 8 \\
5 & 5 & 8 \\
6 & 4 & 1 \\
7 & 6 & 4.5 \\
8 & 7 & 8 \\
9 & 17 & 17.6 \\
10 & 11 & 16 \\
11 & 13 & 12.5 \\
12 & 7 & 13 \\
13 & 7 & 8 \\
14 & 7 & 9 \\
15 & 5 & 10.4 \\
16 & 1 & 0.1 \\
\hline
\end{tabular}

$\mathrm{V}\left(\right.$ in $\left.\pi \mathrm{r}^{2} \mathrm{qmm}\right)=0.051799 \mathrm{cmm}$.

$\mathrm{V}($ in $1 \mathrm{gcm})=0.148 \mathrm{cmm}$.

Ausgleichsdicke $=0.00148 \mathrm{~mm}$

(rund $1.48 \mu$ ).

Tabelle 28.

Talgdrüse. Oberschenkel (medial).

\begin{tabular}{|c|c|c|}
\hline $\begin{array}{c}\text { Schnitt- } \\
\text { nummer }\end{array}$ & $\begin{array}{c}\text { Zahl der } \\
\text { Drüsen- } \\
\text { stïcke }\end{array}$ & $\begin{array}{c}\text { Gewicht der } \\
\text { ausgeschnit- } \\
\text { tenen Papier- } \\
\text { stücke }\end{array}$ \\
\cline { 1 - 3 } 1 & 1 & $0.1 \mathrm{mg}$ \\
2 & 1 & 0.6 \\
3 & 2 & 1 \\
4 & 9 & 7.1 \\
5 & 7 & 7 \\
6 & 7 & 5.8 \\
7 & 7 & 4.4 \\
8 & 4 & 3.8 \\
9 & 4 & 3.1 \\
10 & 2 & 1.4 \\
11 & 3 & 1.5 \\
12 & 2 & 1.4 \\
13 & 1 & 0.6 \\
14 & 1 & 0.1 \\
\hline
\end{tabular}

$\mathrm{V}$ (in $\left.\pi \mathrm{r}^{2} \mathrm{~g} \mathrm{~mm}\right)=0.015171 \mathrm{cmm}$.

$\mathrm{V}$ (in $1 \mathrm{qcm})=0.043 \mathrm{cmm}$.

Ausgleichsdicke $=0.00043 \mathrm{~mm}$

(rund $0.43 \mu$ ).
Tabelle 29.

Talgdrüse. Oberschenkel

(lateral).

\begin{tabular}{|c|c|c|}
\hline $\begin{array}{c}\text { Schnitt- } \\
\text { nummer }\end{array}$ & $\begin{array}{c}\text { Zahl der } \\
\text { Drüsen- } \\
\text { stücke }\end{array}$ & $\begin{array}{c}\text { Gewicht der } \\
\text { ausgeschnit- } \\
\text { tenen Papier- } \\
\text { stücke }\end{array}$ \\
\hline 1 & 1 & $0.1 \mathrm{mg}$ \\
2 & 4 & 3.5 \\
3 & 5 & 4.5 \\
4 & 2 & 1.1 \\
5 & 3 & 2.8 \\
6 & 5 & 2.6 \\
7 & 4 & 1.4 \\
8 & 3 & 2 \\
9 & 2 & 1.5 \\
10 & 1 & 1.5 \\
11 & 2 & 1 \\
12 & 1 & 0.8 \\
13 & 3 & 0.8 \\
14 & 2 & 0.8 \\
15 & 3 & 2.5 \\
16 & 1 & 0.1 \\
\hline \multicolumn{2}{|c}{} & \\
\hline
\end{tabular}

$\mathrm{V}\left(\right.$ in $\left.\pi \mathrm{r}^{2} \mathrm{qmm}\right)=0.010488 \mathrm{cmm}$.

$V($ in $1 \mathrm{gcm})=0.030 \mathrm{cmm}$.

Ausgleichsdicke $=0.00030 \mathrm{~mm}$

(rund $0.30 \mu$ ).

Tabelle 30 .

Talgdrüse. Unterschenkel

(Streckseite).

\begin{tabular}{|c|c|c|}
\hline $\begin{array}{c}\text { Schnitt- } \\
\text { nummer }\end{array}$ & $\begin{array}{c}\text { Zahl der } \\
\text { Drüsen- } \\
\text { stïcke }\end{array}$ & $\begin{array}{c}\text { Gewicht der } \\
\text { ausgeschnit- } \\
\text { tenen Papier- } \\
\text { stïcke }\end{array}$ \\
\hline 1 & 3 & $1 \mathrm{mg}$ \\
2 & 5 & 2.3 \\
3 & 2 & 2 \\
4 & 9 & 8.9 \\
5 & 11 & 10 \\
6 & 8 & 6.6 \\
7 & 3 & 1.9 \\
8 & 1 & 0.2 \\
\hline
\end{tabular}

$\mathrm{V}$ (in $\left.\pi \mathrm{r}^{2} \mathrm{qmm}\right)=0.013170 \mathrm{cmm}$.

$\mathrm{V}($ in $1 \mathrm{qcm})=0.038 \mathrm{cmm}$.

Ausgleichsdicke $=0.00038 \mathrm{~mm}$

(rund $0.38 \mu$. ). 
Tabelle 31.

Talgdrüse. Unterschenkel

(Beugeseite).

\begin{tabular}{|c|c|c|}
\hline $\begin{array}{l}\text { Schnitt- } \\
\text { nummer }\end{array}$ & $\begin{array}{l}\text { Zahl der } \\
\text { Drüsen- } \\
\text { stücke }\end{array}$ & $\begin{array}{l}\text { Gewicht der } \\
\text { ausgeschnit- } \\
\text { tenen Papier- } \\
\text { stücke }\end{array}$ \\
\hline 1 & 1 & $0.6 \mathrm{mg}$ \\
\hline 2 & 1 & 0.9 \\
\hline 3 & 1 & 0.5 \\
\hline 4 & 4 & 2.4 \\
\hline 5 & 8 & 12 \\
\hline 6 & 12 & 14.8 \\
\hline 7 & 8 & 13 \\
\hline 8 & 1 & 2 \\
\hline 9 & 2 & 1.2 \\
\hline 10 & 2 & 2 \\
\hline 11 & 2 & 2.1 \\
\hline 12 & 3 & 4 \\
\hline 13 & 1 & 3 \\
\hline 14 & 1 & 1 \\
\hline 15 & 1 & 0.1 \\
\hline 16 & 1 & 0.1 \\
\hline & & 59.7 \\
\hline
\end{tabular}

$\mathrm{V}\left(\right.$ in $\left.\pi \mathrm{r}^{2} \mathrm{qmm}\right)=0.023898 \mathrm{cmm}$.

$\mathrm{V}($ in $1 \mathrm{gcm})=0.068 \mathrm{cmm}$.

Ausgleichsdicke $=0.00068 \mathrm{~mm}$

(rund 0.68 u.). 
Quantitative Untersuchung der Anhangsorgane der Haut bei einem erwachsenen Ainu. 463

Tabelle 32 .

Volumen der Talgdrüsenindividuen in Scheitelhaut.

\begin{tabular}{|c|c|c|c|c|c|}
\hline $\begin{array}{c}\text { Drüsen- } \\
\text { nummer }\end{array}$ & $\begin{array}{c}\text { Haarzahl } \\
\text { in einer } \\
\text { Gruppe }\end{array}$ & Schnittzahl & $\begin{array}{c}\text { Zahl der } \\
\text { Drüsen- } \\
\text { stücke }\end{array}$ & $\begin{array}{c}\text { Gewicht der } \\
\text { ausgeschn. } \\
\text { Papierstücke }\end{array}$ & $\begin{array}{c}\text { Volumen des } \\
\text { Drüsenindiv. }\end{array}$ \\
\cline { 2 - 5 } $\mathrm{a}$ & 6 & 15 & 97 & $128.4 \mathrm{mg}$ & $0.051399 \mathrm{cmm}$ \\
$\mathrm{b}$ & 6 & 19 & 80 & 109 & 0.043633 \\
$\mathrm{c}$ & 5 & 18 & 93 & 141.5 & 0.056643 \\
$\mathrm{~d}$ & 5 & 17 & 66 & 107 & 0.042832 \\
$\mathrm{e}$ & 5 & 17 & 81 & 144.1 & 0.057684 \\
$\mathrm{f}$ & 5 & 14 & 67 & 77 & 0.030823 \\
$\mathrm{~g}$ & 5 & 16 & 51 & 52.1 & 0.020856 \\
$\mathrm{~h}$ & 4 & 15 & 38 & 59 & 0.023618 \\
$\mathrm{i}$ & 4 & 15 & 47 & 77 & 0.030823 \\
$\mathrm{j}$ & 4 & 12 & 42 & 86.5 & 0.034626 \\
\hline
\end{tabular}

1)

Tabelle 33.

Volumen der Talgdrüsenindividuen in Halshaut.

\begin{tabular}{|c|c|c|c|c|c|}
\hline $\begin{array}{l}\text { Drüsen- } \\
\text { nummer }\end{array}$ & $\begin{array}{l}\text { Haarzahl } \\
\text { in einer } \\
\text { Gruppe }\end{array}$ & Schnittzahl & $\begin{array}{l}\text { Zahl der } \\
\text { Drïsen- } \\
\text { stïcke }\end{array}$ & $\begin{array}{l}\text { Gewicht der } \\
\text { ausgeschn. } \\
\text { Papierstücke }\end{array}$ & $\begin{array}{l}\text { Volumen des } \\
\text { Drüsenindiv. }\end{array}$ \\
\hline $\begin{array}{l}a \\
b \\
c \\
d \\
e \\
f \\
g \\
h \\
i \\
j\end{array}$ & $\begin{array}{l}4 \\
4 \\
4 \\
3 \\
3 \\
3 \\
3 \\
3 \\
3 \\
2\end{array}$ & $\begin{array}{r}6 \\
8 \\
10 \\
7 \\
7 \\
6 \\
6 \\
8 \\
9 \\
8\end{array}$ & $\begin{array}{l}23 \\
29 \\
24 \\
23 \\
22 \\
17 \\
13 \\
25 \\
21 \\
17\end{array}$ & $\begin{array}{l}43.1 \mathrm{mg} \\
47 \\
39.5 \\
38 \\
41 \\
33 \\
17 \\
39.5 \\
28.5 \\
20\end{array}$ & $\begin{array}{l}0.017253 \mathrm{cmm} \\
0.018814 \\
0.015812 \\
0.015211 \\
0.016412 \\
0.013210 \\
0.006805 \\
0.015812 \\
0.011409 \\
0.008006\end{array}$ \\
\hline
\end{tabular}

Tabelle 34.

Volumen der Talgdrüsenindividuen in Brusthaut.

\begin{tabular}{|c|c|c|c|c|c|}
\hline $\begin{array}{l}\text { Drüsen- } \\
\text { nummer }\end{array}$ & $\begin{array}{l}\text { Haarzahl } \\
\text { in einer } \\
\text { Gruppe }\end{array}$ & Schnittzahl & $\begin{array}{l}\text { Zahl der } \\
\text { Drüisen- } \\
\text { stücke }\end{array}$ & $\begin{array}{l}\text { Gewicht dex } \\
\text { ausgeschn. } \\
\text { Papierstïcke }\end{array}$ & $\begin{array}{l}\text { Volumen des } \\
\text { Drüsenindiv. }\end{array}$ \\
\hline $\begin{array}{l}a \\
b \\
c \\
d \\
e \\
f \\
g \\
h \\
i \\
j\end{array}$ & $\begin{array}{l}3 \\
3 \\
3 \\
3 \\
3 \\
3 \\
3 \\
3 \\
2 \\
2\end{array}$ & $\begin{array}{r}8 \\
8 \\
9 \\
8 \\
10 \\
8 \\
8 \\
8 \\
7 \\
9\end{array}$ & $\begin{array}{l}23 \\
35 \\
28 \\
41 \\
22 \\
29 \\
27 \\
37 \\
18 \\
25\end{array}$ & $\begin{array}{l}30 \quad \mathrm{mg} \\
59.8 \\
70.7 \\
59 \\
37 \\
45 \\
52 \\
107 \\
21.9 \\
52\end{array}$ & $\begin{array}{l}0.012009 \mathrm{~cm} \\
0.023938 \\
0.028301 \\
0.023618 \\
0.014811 \\
0.018014 \\
0.020816 \\
0.042832 \\
0.008767 \\
0.020816\end{array}$ \\
\hline
\end{tabular}

1) Da an der Stirn die Haargruppen schwer voneinander zu unterscheiden waren, indem die Haare gleichmässig zerstreut sich finden, so habe ich das Volumen des Talgdrüsen- und Muskelindividuums nicht nach den Haargruppen berechnet. 
Tabelle 35 .

Volumen der Talgdrüsenindividuen in Bauchhaut.

\begin{tabular}{|c|c|c|c|c|c|}
\hline $\begin{array}{c}\text { Drüsen- } \\
\text { nummer }\end{array}$ & $\begin{array}{c}\text { Haarzahl } \\
\text { in einer } \\
\text { Gruppe }\end{array}$ & Schnittzahl & $\begin{array}{c}\text { Zahl der } \\
\text { Drüsen- } \\
\text { stücke }\end{array}$ & $\begin{array}{c}\text { Gewicht der } \\
\text { ausgeschn. } \\
\text { Papierstïcke }\end{array}$ & $\begin{array}{c}\text { Volumen des } \\
\text { Drüsenindiv. }\end{array}$ \\
\cline { 2 - 6 } & 3 & 6 & 10 & $19 \mathrm{mg}$ & $0.007606 \mathrm{cmm}$ \\
$\mathrm{b}$ & 3 & 4 & 12 & 23 & 0.009207 \\
$\mathrm{c}$ & 3 & 5 & 9 & 12.9 & 0.005164 \\
$\mathrm{~d}$ & 2 & 3 & 6 & 6.3 & 0.002522 \\
$\mathrm{e}$ & 2 & 5 & 5 & 7.6 & 0.003042 \\
$\mathrm{f}$ & 2 & 6 & 15 & 36.8 & 0.014731 \\
$\mathrm{~g}$ & 2 & 8 & 22 & 36.1 & 0.014451 \\
$\mathrm{~h}$ & 2 & 4 & 8 & 18 & 0.007205 \\
$\mathrm{i}$ & 2 & 5 & 11 & 18 & 0.007205 \\
$\mathrm{j}$ & 1 & 4 & 5 & 4.3 & 0.001721 \\
\hline
\end{tabular}

Tabelle 36.

Volumen der Talgdrüsenindividuen in Rückenhaut.

\begin{tabular}{|c|c|c|c|c|c|}
\hline $\begin{array}{c}\text { Drüsen- } \\
\text { nummer }\end{array}$ & $\begin{array}{c}\text { Haarzahl } \\
\text { in einer } \\
\text { Gruppe }\end{array}$ & Schnittzahl & $\begin{array}{c}\text { Zahl der } \\
\text { Drüsen- } \\
\text { stücke }\end{array}$ & $\begin{array}{c}\text { Gewicht der } \\
\text { ausgeschn. } \\
\text { Papierstïcke }\end{array}$ & $\begin{array}{c}\text { Volumen des } \\
\text { Drüsenindiv. }\end{array}$ \\
\cline { 1 - 4 } $\mathrm{a}$ & 4 & 11 & 37 & $62.4 \mathrm{mg}$ & $0.024979 \mathrm{cmm}$ \\
$\mathrm{b}$ & 3 & 8 & 25 & 25 & 0.010008 \\
$\mathrm{c}$ & 3 & 10 & 29 & 28.5 & 0.011409 \\
$\mathrm{~d}$ & 3 & 9 & 39 & 43.8 & 0.017533 \\
$\mathrm{e}$ & 2 & 8 & 17 & 14.8 & 0.005924 \\
$\mathrm{f}$ & 2 & 7 & 21 & 24 & 0.009607 \\
$\mathrm{~g}$ & 2 & 8 & 15 & 18.5 & 0.007406 \\
$\mathrm{~h}$ & 2 & 10 & 11 & 14.6 & 0.005844 \\
$\mathrm{i}$ & 2 & 10 & 12 & 6.6 & 0.006245 \\
$\mathrm{j}$ & 2 & 6 & 6 & 6.8 & 0.002722 \\
\hline
\end{tabular}

Tabelle 37 .

Volumen der Talgdrüsenindividuen in Gesässhaut.

\begin{tabular}{|c|c|c|c|c|c|}
\hline $\begin{array}{c}\text { Drüsen- } \\
\text { nummer }\end{array}$ & $\begin{array}{c}\text { Haarzahl } \\
\text { in einer } \\
\text { Gruppe }\end{array}$ & Schnittzahl & $\begin{array}{c}\text { Zahl der } \\
\text { Drüsen- } \\
\text { stïcke }\end{array}$ & $\begin{array}{c}\text { Gewicht der } \\
\text { ausgeschn. } \\
\text { Papierstücke }\end{array}$ & $\begin{array}{c}\text { Volumen des } \\
\text { Drüsenindiv. }\end{array}$ \\
\cline { 1 - 5 } a & 5 & 11 & 20 & $19.3 \mathrm{mg}$ & $0.007726 \mathrm{cmm}$ \\
$\mathrm{b}$ & 5 & 16 & 21 & 23 & 0.009207 \\
$\mathrm{c}$ & 5 & 14 & 29 & 31.1 & 0.012449 \\
$\mathrm{~d}$ & 5 & 3 & 5 & 4 & 0.001601 \\
$\mathrm{e}$ & 4 & 8 & 21 & 17.2 & 0.006885 \\
$\mathrm{f}$ & 3 & 5 & 15 & 10.5 & 0.004203 \\
$\mathrm{~g}$ & 3 & 6 & 10 & 10.8 & 0.004323 \\
$\mathrm{~h}$ & 3 & 7 & 9 & 7 & 0.002802 \\
$\mathrm{i}$ & 2 & 8 & 8 & 6 & 0.002402 \\
$\mathrm{j}$ & 2 & 9 & 9 & 8 & 0.003202 \\
\hline
\end{tabular}


Tabelle 38.

Volumen der Talgdrüsenindividuen im Oberarm (Beugeseite).

\begin{tabular}{|c|c|c|c|c|c|}
\hline $\begin{array}{c}\text { Drüsen- } \\
\text { nummer }\end{array}$ & $\begin{array}{c}\text { Haarzahl } \\
\text { in einer } \\
\text { Gruppe }\end{array}$ & Schnittzahl & $\begin{array}{c}\text { Zahl der } \\
\text { Drüsen- } \\
\text { stïcke }\end{array}$ & $\begin{array}{c}\text { Gewicht der } \\
\text { ausgeschn. } \\
\text { Papierstücke }\end{array}$ & $\begin{array}{c}\text { Volumen des } \\
\text { Drüsenindiv. }\end{array}$ \\
\hline a & 3 & 7 & 16 & $13.6 \mathrm{mg}$ & $0.005444 \mathrm{cmm}$ \\
$\mathrm{b}$ & 3 & 5 & 10 & 12.5 & 0.005004 \\
$\mathrm{c}$ & 3 & 6 & 6 & 4.5 & 0.001801 \\
$\mathrm{~d}$ & 3 & 4 & 6 & 7.1 & 0.002842 \\
$\mathrm{e}$ & $\mathbf{3}$ & 3 & 5 & 3 & 0.001201 \\
$\mathrm{f}$ & 2 & 3 & 9 & 10 & 0.004003 \\
$\mathrm{~g}$ & 2 & 5 & 6 & 3.6 & 0.001441 \\
$\mathrm{~h}$ & $\mathbf{2}$ & 5 & 11 & 7.3 & 0.002922 \\
$\mathrm{i}$ & $\mathbf{2}$ & 5 & 8 & 5 & 0.002002 \\
$\mathrm{j}$ & $\mathbf{1}$ & 4 & 4 & 2.8 & 0.001121 \\
\hline
\end{tabular}

Tabelle 39 .

Voluınen der Talgdrüsenindividuen im Oberarm (Streckseite).

\begin{tabular}{|c|c|c|c|c|c|}
\hline $\begin{array}{c}\text { Drüsen- } \\
\text { nummer }\end{array}$ & $\begin{array}{c}\text { Haarzahl } \\
\text { in einer } \\
\text { Gruppe }\end{array}$ & Schnittzahl & $\begin{array}{c}\text { Zahl der } \\
\text { Drüsen- } \\
\text { stïcke }\end{array}$ & $\begin{array}{c}\text { Gewicht der } \\
\text { ausgeschn. } \\
\text { Papierstücke }\end{array}$ & $\begin{array}{c}\text { Volumen des } \\
\text { Drüsenindiv. }\end{array}$ \\
\cline { 1 - 5 } a & 3 & 8 & 15 & $38 \mathrm{mg}$ & $0.015211 \mathrm{cmm}$ \\
$\mathrm{b}$ & 3 & 10 & 20 & 31.7 & 0.012690 \\
$\mathrm{c}$ & 3 & 10 & 19 & 21 & 0.008406 \\
$\mathrm{~d}$ & 3 & 10 & 25 & 43 & 0.017213 \\
$\mathrm{e}$ & 3 & 8 & 14 & 32.8 & 0.013130 \\
$\mathrm{f}$ & 3 & 9 & 14 & 23 & 0.009207 \\
$\mathrm{~g}$ & 3 & 4 & 17 & 28.5 & 0.011409 \\
$\mathrm{~h}$ & 2 & 7 & 14 & 14 & 0.005604 \\
$\mathrm{i}$ & 2 & 5 & 8 & 13 & 0.005204 \\
$\mathrm{j}$ & 2 & 7 & 12 & 12.8 & 0.005124 \\
\hline
\end{tabular}

Tabelle 40.

Volumen der Talgdrüsenindividuen im Vorderarm (Beugeseite).

\begin{tabular}{|c|c|c|c|c|c|}
\hline $\begin{array}{c}\text { Drüsen- } \\
\text { nummer }\end{array}$ & $\begin{array}{c}\text { Haarzahl } \\
\text { in einer } \\
\text { (iruppe }\end{array}$ & Schnittzahl & $\begin{array}{c}\text { Zahl der } \\
\text { Drüsen- } \\
\text { stücke }\end{array}$ & $\begin{array}{c}\text { Gewicht der } \\
\text { ausgeschn. } \\
\text { Papierstïcke }\end{array}$ & $\begin{array}{c}\text { Volumen des } \\
\text { Drüsenindiv. }\end{array}$ \\
\hline a & 3 & 9 & 17 & $14.8 \mathrm{mg}$ & $0.005924 \mathrm{cmm}$ \\
$\mathrm{b}$ & 3 & 15 & 24 & 21.4 & 0.008566 \\
$\mathrm{c}$ & 3 & 8 & 11 & 12 & 0.004804 \\
$\mathrm{~d}$ & 2 & 7 & 8 & 3 & 0.001201 \\
$\mathrm{e}$ & 2 & 8 & 11 & 8.2 & 0.003282 \\
$\mathrm{f}$ & 2 & 7 & 13 & 8.6 & 0.003443 \\
$\mathrm{~g}$ & 2 & 6 & 7 & 3.2 & 0.001281 \\
$\mathrm{~h}$ & 2 & 5 & 5 & 2.2 & 0.000881 \\
$\mathrm{i}$ & 2 & 6 & 8 & 4.5 & 0.001801 \\
$\mathrm{j}$ & 1 & 3 & 4 & 1.5 & 0.000600 \\
\hline
\end{tabular}


Tabelle 41.

Volumen der Talgdrüsenindividuen im Vorderarm (Streckseite).

\begin{tabular}{|cc|c|c|c|c|}
\hline $\begin{array}{c}\text { Drüsen- } \\
\text { nummer }\end{array}$ & $\begin{array}{c}\text { Haarzahl } \\
\text { in einer } \\
\text { Gruppe }\end{array}$ & Schnittzahl & $\begin{array}{c}\text { Zahl der } \\
\text { Drüsen- } \\
\text { stïcke }\end{array}$ & $\begin{array}{c}\text { Gewicht der } \\
\text { ausgeschn. } \\
\text { Papierstücke }\end{array}$ & $\begin{array}{c}\text { Volumen des } \\
\text { Drüsenindiv. }\end{array}$ \\
\cline { 1 - 5 } a & 3 & 7 & 22 & $31 \mathrm{mg}$ & $0.012409 \mathrm{cmm}$ \\
$\mathrm{b}$ & 3 & 5 & 18 & 29 & 0.011609 \\
$\mathrm{c}$ & 3 & 7 & 9 & 9.8 & 0.003923 \\
$\mathrm{~d}$ & 3 & 5 & 13 & 21.8 & 0.008727 \\
$\mathrm{e}$ & 3 & 6 & 15 & 28.8 & 0.011529 \\
$\mathrm{f}$ & 3 & 6 & 14 & 19.1 & 0.007646 \\
$\mathrm{~g}$ & 3 & 4 & 12 & 16.2 & 0.006485 \\
$\mathrm{~h}$ & 2 & 4 & 8 & 9 & 0.003603 \\
$\mathrm{i}$ & 2 & 5 & 9 & 8.9 & 0.003563 \\
$\mathrm{j}$ & 1 & 3 & 6 & 7.9 & 0.003162 \\
\hline
\end{tabular}

Tabelle 42.

Volumen der Talgdrüsenindividuen im Oberschenkel (medial).

\begin{tabular}{|c|c|c|c|c|c|}
\hline $\begin{array}{c}\text { Drüsen- } \\
\text { nummer }\end{array}$ & $\begin{array}{c}\text { Haarzahl } \\
\text { in einer } \\
\text { Gruppe }\end{array}$ & schnittzahl & $\begin{array}{c}\text { Zahl der } \\
\text { Drüsen- } \\
\text { stücke }\end{array}$ & $\begin{array}{c}\text { Gewicht der } \\
\text { ausgeschn. } \\
\text { Papierstücke }\end{array}$ & $\begin{array}{c}\text { Volumen des } \\
\text { Drüsenindiv. }\end{array}$ \\
\cline { 1 - 5 } a & 3 & 8 & 6 & $6 \mathrm{mg}$ & $0.002402 \mathrm{cmm}$ \\
$\mathrm{b}$ & 3 & 7 & 8 & 6.1 & 0.002442 \\
$\mathrm{c}$ & 3 & 5 & 4 & 3 & 0.001201 \\
$\mathrm{~d}$ & 3 & 5 & 8 & 7.2 & 0.002882 \\
$\mathrm{e}$ & 3 & 6 & 12 & 11 & 0.004403 \\
$\mathrm{f}$ & 3 & 4 & 7 & 8.5 & 0.003403 \\
$\mathrm{~g}$ & 3 & 7 & 10 & 8.5 & 0.003403 \\
$\mathrm{~h}$ & 2 & 4 & 5 & 1.1 & 0.000440 \\
$\mathrm{i}$ & 2 & 3 & 3 & 3.5 & 0.001401 \\
$\mathrm{j}$ & 2 & 4 & 4 & 2 & 0.000801 \\
\hline
\end{tabular}

Tabelle 43.

Volumen der Talgdrüsenindividuen im Oberschenkel (lateral).

\begin{tabular}{|c|c|c|c|c|c|}
\hline $\begin{array}{c}\text { Drüsen- } \\
\text { nummer }\end{array}$ & $\begin{array}{c}\text { Haarzahl } \\
\text { in einer } \\
\text { (iruppe }\end{array}$ & Schnittzahl & $\begin{array}{c}\text { Zahl der } \\
\text { Drïsen- } \\
\text { stïcke }\end{array}$ & $\begin{array}{c}\text { (iewicht der } \\
\text { ausgeschn. } \\
\text { Papierstïcke }\end{array}$ & $\begin{array}{c}\text { Volumen des } \\
\text { Drüsenindiv. }\end{array}$ \\
\cline { 1 - 5 } $\mathrm{y}$ & 3 & 7 & 10 & $5.7 \mathrm{mg}$ & $0.002282 \mathrm{cmm}$ \\
$\mathrm{y}$ & 3 & 8 & 8 & 4 & 0.001601 \\
$\mathrm{c}$ & 3 & 8 & 9 & 4 & 0.001601 \\
$\mathrm{~d}$ & 3 & 9 & 13 & 10.9 & 0.004363 \\
$\mathrm{e}$ & 3 & 6 & 8 & 5 & 0.002002 \\
$\mathrm{f}$ & 3 & 6 & 8 & 4.8 & 0.001921 \\
$\mathrm{~g}$ & 3 & 13 & 13.8 & 0.005524 \\
$\mathrm{~h}$ & 3 & 6 & 8 & 7 & 0.002802 \\
$\mathrm{i}$ & 2 & 8 & 8 & 4.8 & 0.001921 \\
$\mathrm{j}$ & 2 & 4 & 4 & -.6 & 0.001041 \\
\hline
\end{tabular}


Quantitative Untersuchung der Anhangsorgane der Haut bei einem erwachsenen Ainu. 467

Tabelle 44 .

Volumen der Talgdrüsenindividuen im Unterschenkel (Streckseite).

\begin{tabular}{|c|c|c|c|c|c|}
\hline $\begin{array}{c}\text { Drüsen- } \\
\text { nummer }\end{array}$ & $\begin{array}{c}\text { Haarzahl } \\
\text { in einer } \\
\text { Gruppe }\end{array}$ & Schnittzahl & $\begin{array}{c}\text { Zahl der } \\
\text { Drüsen- } \\
\text { stücke }\end{array}$ & $\begin{array}{c}\text { Gewicht der } \\
\text { ausgeschn. } \\
\text { Papierstücke }\end{array}$ & $\begin{array}{c}\text { Volumen des } \\
\text { Drüsenindiv. }\end{array}$ \\
\cline { 1 - 3 } $\mathrm{y}$ & 3 & 5 & 10 & $6 \mathrm{mg}$ & $0.002402 \mathrm{cmm}$ \\
$\mathrm{y}$ & 3 & 3 & 6 & 4.5 & 0.001801 \\
$\mathrm{c}$ & 3 & 5 & 12 & 9 & 0.003603 \\
$\mathrm{~d}$ & 3 & 3 & 15 & 14 & 0.005604 \\
$\mathrm{e}$ & 3 & 3 & 7 & 7.3 & 0.002922 \\
$\mathrm{f}$ & 3 & 4 & 8 & 9.6 & 0.003843 \\
$\mathrm{~g}$ & 3 & 5 & 13 & 16 & 0.006405 \\
$\mathrm{~h}$ & 3 & 6 & 11 & 12.8 & 0.004003 \\
$\mathrm{i}$ & 3 & 7 & 13 & 10.5 & 0.005124 \\
$\mathrm{j}$ & 3 & 5 & 12 & & 0.004203 \\
\hline
\end{tabular}

Tabelle 45 .

Volumen der Talgdrüsenindividuen im Unterschenkel (Beugeseite).

\begin{tabular}{|c|c|c|c|c|c|}
\hline $\begin{array}{c}\text { Drüsen- } \\
\text { nummer }\end{array}$ & $\begin{array}{c}\text { Haarzahl } \\
\text { in einer } \\
\text { Gruppe }\end{array}$ & Schnittzahl & $\begin{array}{c}\text { Zahl der } \\
\text { Drüsen- } \\
\text { stücke }\end{array}$ & $\begin{array}{c}\text { Gewicht der } \\
\text { ausgeschn. } \\
\text { Papierstïcke }\end{array}$ & $\begin{array}{c}\text { Volumen des } \\
\text { Drüisenindiv. }\end{array}$ \\
\cline { 1 - 3 } & 3 & 4 & 7 & $7 \mathrm{mg}$ & $0.002802 \mathrm{cmm}$ \\
$\mathrm{a}$ & 3 & 4 & 6 & 7 & 0.002802 \\
$\mathrm{c}$ & 3 & 4 & 7 & 9.2 & 0.003683 \\
$\mathrm{~d}$ & 3 & 5 & 8 & 17 & 0.006805 \\
$\mathrm{e}$ & 3 & 5 & 9 & 11 & 0.004403 \\
$\mathrm{f}$ & 3 & 5 & 13 & 20.5 & 0.008206 \\
$\mathrm{~g}$ & 1 & 4 & 4 & 4 & 0.001601 \\
$\mathrm{~h}$ & 1 & 4 & - & - & - \\
$\mathrm{i}$ & - & - & - & - & - \\
$\mathrm{j}$ & - & - & - & -8 & \\
\hline
\end{tabular}




\section{Menge des Haarbalgmuskels. ${ }^{\text {) }}$}

Tabelle 46.

Muskel. Scheitelhaut.

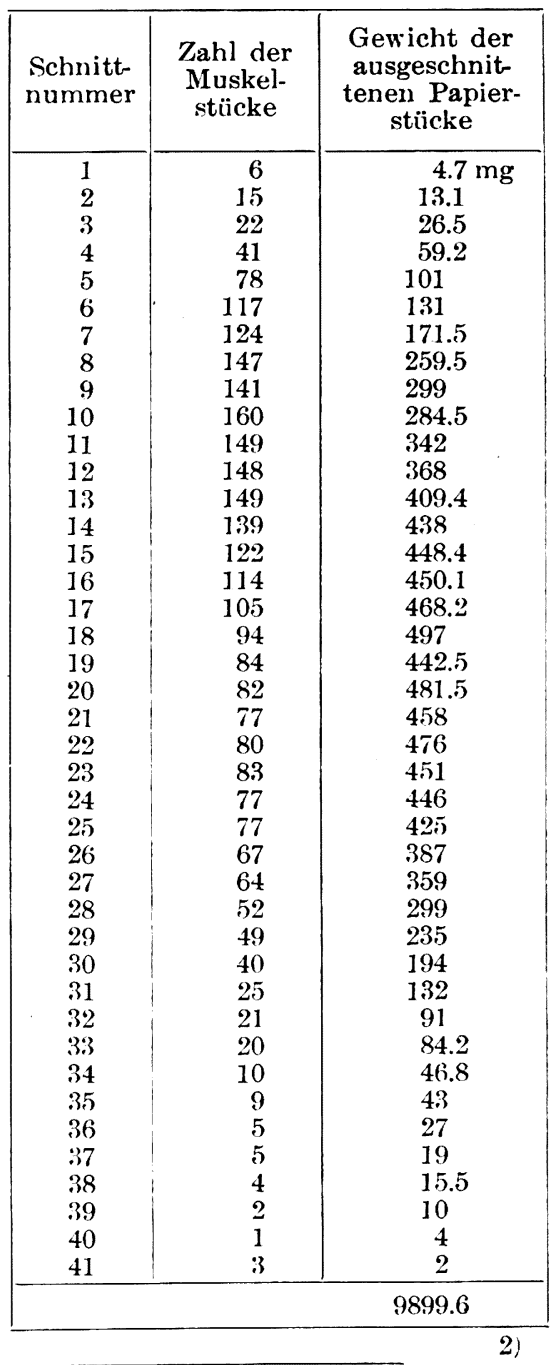

Volumen in $\pi \mathrm{r}^{2} \mathrm{qmm}\left(\mathrm{r}=\frac{10}{3} \mathrm{~mm}\right)$

$=\mathrm{V}\left(\right.$ in $\left.\pi \times\left(\frac{10}{3}\right)^{2} \mathrm{gmm}\right)=\frac{F D \Sigma W}{\mathrm{~W}_{1} \mathrm{~m}^{2}}$

$=\frac{(253 \times 356) \times 0.04 \times 9899.6}{10000 \times 30^{2}}$

$=\frac{35665486.912}{9000000}=3.962832 \mathrm{cmm}$,

also in $1 \mathrm{gem}$ uıngerechnet

$\mathrm{V}($ in $1 \mathrm{gcm})=3.962832 \times \frac{1}{\pi} \times \frac{100}{\left(\frac{100}{30}\right)^{2}}$

$=3.962832 \times \frac{1}{\pi} \times \frac{100}{\frac{100^{2}}{30^{2}}}$

$=3.962832 \times \frac{1}{\pi} \times \frac{100 \times 30^{2}}{100^{2}}$

$=3.962832 \times \frac{1}{\pi} \times \frac{900}{100}$

$=3.962832 \times 0.318309 \times 9$

$=11.3526 \fallingdotseq 11.353 \mathrm{cmm}$.

Ferner in $1 \mathrm{gcm}$ gleichmässig verteilt angenommen, bildet der Muskel eine kontinuierliche Schicht in Ausgleichs(Durchschnitts-)dicke von

$$
\left.\frac{11.3526}{100}=0.113526 \mathrm{~mm}(\text { rund }] 13.5 \mu\right)
$$

1) Bei der Volumenbestimmung in einem bestimmten Hautflächeninhalt habe ich die langen, feinen, schwach gefärbten glatten Muskeln mitgerechnet, welche mit Haarbalg, Haarbalgmuskeln und Drüsen keinen direkten Zusammenhang zu haben schienen und nur in 1 oder höchstens in 2 Serienschnitten $(40 \mu$ dick $)$ auftraten. Solche Muskeln befinden sich fast an allen untersuchten Körperteilen, aber ihre Ṁenge ist ausserordentlich gering. 
Quantitative Untersuchung der Anhangsorgane der Haut bei einem erwachsenen Ainu. 469

Tabelle 47.

Muskel. Halshaut.

\begin{tabular}{|c|c|c|}
\hline $\begin{array}{l}\text { Schnitt- } \\
\text { nummer }\end{array}$ & $\begin{array}{l}\text { Zahl der } \\
\text { Muskel- } \\
\text { stücke }\end{array}$ & $\begin{array}{l}\text { Gewicht der } \\
\text { ausgeschnit- } \\
\text { tenen Papier- } \\
\text { stücke }\end{array}$ \\
\hline 1 & 2 & $1 \mathrm{mg}$ \\
\hline 2 & 5 & 6.6 \\
\hline 3 & 7 & 29.5 \\
\hline 4 & 12 & 49.9 \\
\hline 5 & 15 & 40 \\
\hline 6 & 19 & 41.9 \\
\hline 7 & 16 & 46 \\
\hline 8 & 19 & 47 \\
\hline 9 & 27 & 53 \\
\hline 10 & 23 & 46 \\
\hline 11 & 13 & 42 \\
\hline 12 & 18 & 41.1 \\
\hline 13 & 14 & 48 \\
\hline 14 & 16 & 39 \\
\hline 15 & 11 & 56.9 \\
\hline 16 & 12 & 41.7 \\
\hline 17 & 8 & 20.4 \\
\hline 18 & 5 & 14.7 \\
\hline 19 & 5 & 20 \\
\hline 20 & 5 & 10 \\
\hline 21 & 2 & 10 \\
\hline 22 & 5 & 17.1 \\
\hline 23 & 4 & 16.6 \\
\hline 24 & 2 & 6.8 \\
\hline 25 & 2 & 2 \\
\hline & & 747.2 \\
\hline
\end{tabular}

$\mathrm{V}\left(\right.$ in $\left.\pi \mathrm{r}^{2} \mathrm{qmm}\right)=0.299106 \mathrm{cmm}$.

$\mathrm{V}($ in $1 \mathrm{gcm})=0.857 \mathrm{cmm}$.

Ausgleichsdicke $=0.00857 \mathrm{~mm}$

(rund 8.6 u.).
Tabelle 48.

Muskel. Brusthaut.

\begin{tabular}{|c|c|c|}
\hline $\begin{array}{l}\text { Schnitt- } \\
\text { nummer }\end{array}$ & $\begin{array}{l}\text { Zahl der } \\
\text { Muskel- } \\
\text { stücke }\end{array}$ & $\begin{array}{l}\text { Gewicht der } \\
\text { ausgeschnit- } \\
\text { tenen Papier- } \\
\text { stücke }\end{array}$ \\
\hline 1 & 5 & $6.5 \mathrm{mg}$ \\
\hline 2 & 8 & 20.4 \\
\hline 3 & 11 & 21.5 \\
\hline 4 & 15 & 36 \\
\hline 5 & 18 & 56.2 \\
\hline 6 & 21 & 85 \\
\hline 7 & 34 & 118.9 \\
\hline 8 & 35 & 117.4 \\
\hline 9 & 30 & 127.5 \\
\hline 10 & 35 & 126.3 \\
\hline 11 & 35 & 128.3 \\
\hline 12 & 32 & 136 \\
\hline 13 & 30 & 121 \\
\hline 14 & 26 & 109 \\
\hline 15 & 15 & 92.5 \\
\hline 16 & 10 & 39.9 \\
\hline 17 & 11 & 35.6 \\
\hline 18 & 9 & 26 \\
\hline 19 & 5 & 13 \\
\hline 20 & 5 & 7.1 \\
\hline 21 & 3 & 2 \\
\hline & & 1426.1 \\
\hline
\end{tabular}

$\mathrm{V}\left(\right.$ in $\left.\pi \mathrm{r}^{2} \mathrm{qmm}\right)=0.570871 \mathrm{cmm}$.

$\mathrm{V}$ (in $1 \mathrm{gcm})=1.635 \mathrm{cmm}$.

Ausgleichsdicke $=0.01635 \mathrm{~mm}$

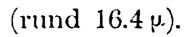

2) Ich konnte nicht die Stirn untersuchen, da hier der Haarhalgmuskel selır klein und fein ist. Bei der Stirn sind in der Nähe der Hautoberfläche die Muskeln netzartig durchkreuzt und schwer voneinander zu unterscheiden, da die Muskeln gleichmässig zerstreut sich finden. Aber auf der flüchtigen mikroskopischen Betrachtung scheint ihre Menge dem Scheitel nächst zu folgen. 
Tabelle 49.

Muskel. Bauchhaut.

\begin{tabular}{|c|c|c|}
\hline $\begin{array}{l}\text { Schnitt- } \\
\text { nummer }\end{array}$ & $\begin{array}{l}\text { Zahl der } \\
\text { Muskel- } \\
\text { stücke }\end{array}$ & $\begin{array}{l}\text { Gewicht der } \\
\text { ausgeschnit- } \\
\text { tenen Papier- } \\
\text { stücke }\end{array}$ \\
\hline 1 & 1 & $0.1 \mathrm{mg}$ \\
\hline 2 & 1 & 0.1 \\
\hline 3 & 2 & 0.3 \\
\hline 4 & 1 & 1 \\
\hline 5 & 1 & 1 \\
\hline 6 & 1 & 0.5 \\
\hline 7 & 5 & 4 \\
\hline 8 & 10 & 7 \\
\hline 9 & 17 & 14.6 \\
\hline 10 & 23 & 25.4 \\
\hline 11 & 36 & 39.4 \\
\hline 12 & 34 & 37.8 \\
\hline 13 & 38 & 46.7 \\
\hline 14 & 32 & 43.5 \\
\hline 15 & 41 & 69 \\
\hline 16 & 33 & 52 \\
\hline 17 & 37 & 68.2 \\
\hline 18 & 25 & 72.1 \\
\hline 19 & 25 & 80 \\
\hline 20 & 28 & 82.2 \\
\hline 21 & 32 & 70.4 \\
\hline 22 & 22 & 57.3 \\
\hline 23 & 16 & 59.1 \\
\hline 24 & 18 & 59 \\
\hline 25 & 12 & 48 \\
\hline 26 & 16 & 38.8 \\
\hline 27 & 20 & 41 \\
\hline 28 & 16 & 37.5 \\
\hline 29 & 16 & 28.5 \\
\hline 30 & 14 & 26.5 \\
\hline 31 & 14 & 8 \\
\hline 32 & 11 & 14.5 \\
\hline 33 & 12 & 15.8 \\
\hline 34 & 11 & 12.2 \\
\hline 35 & 8 & 5.4 \\
\hline 36 & 8 & 6 \\
\hline 37 & 4 & 7.6 \\
\hline 38 & 6 & 9.4 \\
\hline 39 & 4 & 3.6 \\
\hline 40 & 1 & 0.1 \\
\hline 41 & 2 & 2 \\
\hline 42 & 2 & 1.3 \\
\hline & & 1196.9 \\
\hline
\end{tabular}

$V\left(\right.$ in $\left.\pi \mathrm{r}^{2} \mathrm{qmm}\right)=0.479122 \mathrm{cmm}$.

$V($ in $1 \mathrm{qcm})=1.373 \mathrm{cmm}$.

Ausgleichsdicke $=0.01373 \mathrm{~mm}$ 
Quantitative Untersuchung der Anhangsorgane der Haut bei einem erwachsenen Ainu. 471

Tabelle 50.

Muskel. Rückenhaut.

\begin{tabular}{|c|c|c|}
\hline $\begin{array}{l}\text { Schnitt- } \\
\text { nummer }\end{array}$ & $\begin{array}{l}\text { Zahl der } \\
\text { Muskel- } \\
\text { stücke }\end{array}$ & $\begin{array}{l}\text { Gewicht der } \\
\text { ausgeschnit- } \\
\text { tenen Papier- } \\
\text { stïcke }\end{array}$ \\
\hline 1 & 2 & $2.2 \mathrm{mg}$ \\
\hline 2 & 3 & 3 \\
\hline 3 & 6 & 7 \\
\hline 4 & 9 & 9 \\
\hline 5 & 12 & 21 \\
\hline 6 & 15 & 32 \\
\hline 7 & 14 & 23.5 \\
\hline 8 & 18 & 30 \\
\hline 9 & 30 & 46 \\
\hline 10 & 25 & 30 \\
\hline 11 & 23 & 30.5 \\
\hline 12 & 30 & 45 \\
\hline 13 & 37 & 63 \\
\hline 14 & 30 & 61.2 \\
\hline 15 & 26 & 53.1 \\
\hline 16 & 29 & 50 \\
\hline 17 & 27 & 58 \\
\hline 18 & 27 & 60 \\
\hline 19 & 28 & 75.8 \\
\hline 20 & 31 & 87 \\
\hline 21 & 25 & 81.2 \\
\hline 22 & 18 & 72 \\
\hline 23 & 22 & 91 \\
\hline 24 & 24 & 66 \\
\hline 25 & 29 & 66 \\
\hline 26 & 32 & 63.1 \\
\hline 27 & 25 & 56 \\
\hline 28 & 24 & 49.5 \\
\hline 29 & 19 & 30.7 \\
\hline 30 & 18 & 26 \\
\hline 31 & 13 & 19.2 \\
\hline 32 & 11 & 19.2 \\
\hline 33 & 8 & 12.2 \\
\hline 34 & 5 & 6.9 \\
\hline 35 & 6 & 2.5 \\
\hline 36 & 2 & ].1 \\
\hline 37 & 3 & 0.6 \\
\hline 38 & 6 & 3 \\
\hline 39 & 2 & 2 \\
\hline 40 & 3 & 2 \\
\hline 41 & 2 & 0.9 \\
\hline 42 & 1 & 0.1 \\
\hline $4 ?$ & 1 & 0.1 \\
\hline 44 & 2 & 1 \\
\hline 45 & 3 & 2 \\
\hline
\end{tabular}

Volumen in $\pi \mathrm{r}^{2} \mathrm{gmm}(\mathrm{r}=3.0 \mathrm{~mm})$

$=V\left(\right.$ in $\left.\pi \times(3.0)^{2} \mathrm{gmm}\right)=\frac{\mathrm{FD} \Sigma \mathrm{WV}}{\mathrm{W}_{1} \mathrm{~m}^{2}}$

$=\frac{(25.3 \times 356) \times 0.04 \times 1462.1}{10000 \times 30^{2}}$

$=\frac{5267536.912}{9000000}=0.585282 \mathrm{cmm}$,

also in 1 qcm umgerechnet

$\mathrm{V}($ in $1 \mathrm{qcm})=0.585282 \times \frac{1}{\pi} \times \frac{100}{\left(\frac{90}{30}\right)^{2}}$

$=0.585282 \times \frac{1}{\pi} \times \frac{100}{9}$

$=0.585282 \times 0.318309 \times 11.1111$

$=2.0699 \fallingdotseq 2.070 \mathrm{cmm}$.

Ferner in $1 \mathrm{gcm}$ gleichmässig verteilt angenommen, bildet der Muskel eine kontinuierliche Schicht in Ausgleichs(Durchschnitts-)dicke von

$\frac{2.0699}{100}=0.020699 \mathrm{~mm}$ (rund $\left.20.7 \mu\right)$. 
Tabelle 51.

Muskel. Gesässhaut.

\begin{tabular}{|c|c|c|}
\hline $\begin{array}{l}\text { Schnitt- } \\
\text { nummer }\end{array}$ & $\begin{array}{c}\text { Zahl der } \\
\text { Muske.- } \\
\text { stïcke }\end{array}$ & $\begin{array}{l}\text { Gewicht der } \\
\text { ausgeschnit- } \\
\text { tenen Papier- } \\
\text { stïcke }\end{array}$ \\
\hline 1 & 1 & $0.1 \mathrm{mg}$ \\
\hline 2 & 2 & 1 \\
\hline 3 & 3 & 2 \\
\hline 4 & 8 & 6.2 \\
\hline 5 & 27 & 19 \\
\hline 6 & 37 & 33.6 \\
\hline 7 & 66 & 63.1 \\
\hline 8 & 62 & 84.4 \\
\hline 9 & 71 & 133.8 \\
\hline 10 & 74 & 139.3 \\
\hline 11 & 80 & 185.5 \\
\hline 12 & 69 & 208.2 \\
\hline ]3 & 70 & 239.2 \\
\hline 14 & 61 & 236.7 \\
\hline 15 & 61 & 25.5 .5 \\
\hline 16 & 59 & 249 \\
\hline 17 & 51 & 271.2 \\
\hline 18 & 55 & 294 \\
\hline 19 & 51 & 271.6 \\
\hline 20 & 41 & 268 \\
\hline 21 & 39 & 266 \\
\hline 22 & 29 & 271.4 \\
\hline 23 & 28 & 232.8 \\
\hline 24 & 28 & 187 \\
\hline 25 & 20 & 135.3 \\
\hline 26 & 16 & 102.4 \\
\hline 27 & 18 & 57.3 \\
\hline 28 & 13 & 46 \\
\hline 29 & 10 & 12 \\
\hline 30 & 4 & 6 \\
\hline 31 & 6 & 6.8 \\
\hline 32 & 5 & 4.2 \\
\hline 33 & 3 & 3.1 \\
\hline 34 & 5 & 1.8 \\
\hline 35 & 3 & 4.2 \\
\hline 36 & 1 & 0.5 \\
\hline
\end{tabular}

\begin{tabular}{|l|l|l|}
37 & 2 & $1.5 \mathrm{mg}$ \\
38 & 3 & 6.6 \\
39 & 3 & 5.1 \\
40 & 2 & 1.5 \\
41 & 2 & 1 \\
42 & 1 & 0.1 \\
43 & 2 & 5.2 \\
44 & 4 & 3.1 \\
45 & 5 & 6.1 \\
46 & 6 & 7.8 \\
47 & 3 & 3.8 \\
48 & 1 & 1.2 \\
49 & 1 & 1.5 \\
50 & 1 & 1.1 \\
\hline
\end{tabular}

$\mathrm{V}\left(\right.$ in $\left.\pi \mathrm{r}^{2} \mathrm{qmm}\right)=1.738833 \mathrm{cmm}$.

$V($ in $1 \mathrm{gcm})=4.981 \mathrm{cmm}$.

Ausgleichsdicke $=0.04981 \mathrm{~mm}$

(rund $49.8 \mu$ ). 
Quantitative Untersuchung der Anhangsorgane der Haut bei einem erwachsenen Ainu. 473

Tabelle 52.

Muskel. Oberarm

(Beugeseite).

\begin{tabular}{|c|c|c|}
\hline $\begin{array}{l}\text { Schnitt- } \\
\text { nummer }\end{array}$ & $\begin{array}{l}\text { Zahl der } \\
\text { Muskel- } \\
\text { stïcke }\end{array}$ & $\begin{array}{l}\text { Gewicht der } \\
\text { ausgeschnit- } \\
\text { tenen Papier- } \\
\text { stücke }\end{array}$ \\
\hline 1 & 1 & $2.8 \mathrm{mg}$ \\
\hline 2 & 9 & 11 \\
\hline 3 & 24 & 40 \\
\hline 4 & 34 & 75 \\
\hline 5 & 44 & 129.8 \\
\hline 6 & 36 & 144 \\
\hline 7 & 37 & 135.8 \\
\hline 8 & 45 & 120 \\
\hline 9 & 38 & 96 \\
\hline 10 & 32 & 104.5 \\
\hline 11 & 40 & 78 \\
\hline 12 & 28 & 54 \\
\hline 13 & 20 & 59 \\
\hline 14 & 20 & 50.2 \\
\hline 15 & 14 & 40 \\
\hline 16 & 10 & 40 \\
\hline 17 & 8 & 42.8 \\
\hline 18 & 4 & 38.6 \\
\hline 19 & 6 & 22 \\
\hline 20 & 3 & 12.5 \\
\hline 21 & 3 & 4 \\
\hline \multirow[t]{2}{*}{22} & 1 & 1.2 \\
\hline & & 1301.2 \\
\hline
\end{tabular}

$\mathrm{V}\left(\right.$ in $\left.\pi \mathrm{r}^{2} \mathrm{qmm}\right)=0.520873 \mathrm{cmm}$.

$V($ in $1 \mathrm{gcm})=1.492 \mathrm{cmm}$.

Ausgleichsdicke $=0.01492 \mathrm{~mm}$

(rund $14.9 \mu$ ).
Tabelle 53.

Muskel. Oberarm

(Streckseite).

\begin{tabular}{|c|c|c|}
\hline $\begin{array}{l}\text { Schnitt- } \\
\text { nummer }\end{array}$ & $\begin{array}{l}\text { Zahl der } \\
\text { Muskel- } \\
\text { stücke }\end{array}$ & $\begin{array}{l}\text { Gewicht der } \\
\text { ausgeschnit- } \\
\text { tenen Papier- } \\
\text { stücke }\end{array}$ \\
\hline 1 & 2 & $3 \mathrm{mg}$ \\
\hline 2 & 24 & 27.5 \\
\hline 3 & 52 & 47.5 \\
\hline 4 & 66 & 78 \\
\hline 5 & 78 & 106.6 \\
\hline 6 & 86 & 134.6 \\
\hline 7 & 86 & 143 \\
\hline 8 & 85 & 183 \\
\hline 9 & 78 & 175.8 \\
\hline 10 & 60 & 174 \\
\hline 11 & 54 & 202.5 \\
\hline 12 & 55 & 192 \\
\hline 13 & 46 & 233.4 \\
\hline 14 & 37 & 185.2 \\
\hline 15 & 42 & 187.1 \\
\hline 16 & 31 & 160 \\
\hline 17 & 31 & 126.4 \\
\hline 18 & 26 & 86 \\
\hline 19 & 25 & 58 \\
\hline 20 & 20 & 33 \\
\hline 21 & 14 & 18.4 \\
\hline 22 & 17 & 13.1 \\
\hline 23 & 20 & 14.5 \\
\hline 24 & 9 & 7.5 \\
\hline 25 & 7 & 9 \\
\hline 26 & 9 & 12.7 \\
\hline 27 & 4 & 4 \\
\hline 28 & 5 & 3 \\
\hline 29 & 3 & 5.4 \\
\hline 30 & 4 & 3 \\
\hline 31 & 1 & 1 \\
\hline 32 & 1 & 1.2 \\
\hline & & 2629.4 \\
\hline
\end{tabular}

$\mathrm{V}\left(\right.$ in $\left.\pi \mathrm{r}^{2} \mathrm{qmm}\right)=1.052555 \mathrm{cmm}$.

$\mathrm{V}($ in $1 \mathrm{qcm})=3.015 \mathrm{cmm}$.

Ausgleichsdicke $=0.03015 \mathrm{~mm}$

(rund $30.2 \mu$ ). 
Tabelle 54 .

Muskel. Vorderarm

(Beugeseite).

\begin{tabular}{|c|c|c|}
\hline $\begin{array}{l}\text { Schnitt- } \\
\text { numiner }\end{array}$ & $\begin{array}{l}\text { Zahl der } \\
\text { Muskel- } \\
\text { stücke }\end{array}$ & $\begin{array}{l}\text { Gewicht der } \\
\text { ausgeschnit- } \\
\text { tenen Papier- } \\
\text { stücke }\end{array}$ \\
\hline 1 & 3 & $3.2 \mathrm{mg}$ \\
\hline 2 & 9 & 9.5 \\
\hline 3 & 17 & 14.8 \\
\hline 4 & 23 & 30.9 \\
\hline 5 & 36 & 37.5 \\
\hline 6 & 41 & 56 \\
\hline 7 & 47 & 87 \\
\hline 8 & 56 & 101.6 \\
\hline 9 & 53 & 87.8 \\
\hline 10 & 58 & 105 \\
\hline 11 & 55 & 104 \\
\hline 12 & 41 & 129 \\
\hline 13 & 39 & 125.3 \\
\hline 14 & 45 & 121 \\
\hline 15 & 43 & 85 \\
\hline 16 & 29 & 72.2 \\
\hline 17 & 29 & 62.8 \\
\hline 18 & 20 & 41 \\
\hline 19 & 15 & 33.3 \\
\hline 20 & 23 & 35 \\
\hline 21 & 16 & 22.4 \\
\hline 22 & 12 & 25 \\
\hline 23 & 12 & 17 \\
\hline 24 & 10 & 16 \\
\hline 25 & 5 & 6.5 \\
\hline 26 & 4 & 4.4 \\
\hline 27 & 2 & 1.2 \\
\hline 28 & $\because$ & 3 \\
\hline 29 & 3 & 5.8 \\
\hline 30 & 2 & 2.5 \\
\hline & & 1445.7 \\
\hline
\end{tabular}

$V\left(\right.$ in $\left.\pi r^{2} q \mathrm{~mm}\right)=0.578717 \mathrm{cmm}$.

$\mathrm{V}($ in $1 \mathrm{gcm})=1.658 \mathrm{cmm}$.

Ausgleichsdicke $=0.01658 \mathrm{~mm}$

(rund $16.6 \mu$ ).
Tabelle 55 .

Muskel. Vorderarm

(Streckseite).

\begin{tabular}{|c|c|c|}
\hline $\begin{array}{l}\text { Schnitt- } \\
\text { nummer }\end{array}$ & $\begin{array}{l}\text { Zahl der } \\
\text { Muskel- } \\
\text { stücke }\end{array}$ & $\begin{array}{l}\text { Gewicht der } \\
\text { ausgeschnit- } \\
\text { tenen Papier- } \\
\text { stücke }\end{array}$ \\
\hline 1 & 5 & $5 \mathrm{mg}$. \\
\hline 2 & 11 & 18.5 \\
\hline 3 & 12 & 32.7 \\
\hline 4 & 15 & 45 \\
\hline 5 & 25 & 52 \\
\hline 6 & 35 & 73 \\
\hline 7 & 39 & 163 \\
\hline 8 & 29 & 170 \\
\hline 9 & 41 & 175.3 \\
\hline 10 & 41 & 154.3 \\
\hline 11 & 51 & 161 \\
\hline 12 & 45 & 203 \\
\hline 13 & 37 & 208 \\
\hline 14 & 35 & 224 \\
\hline 15 & 30 & 223 \\
\hline 16 & 24 & 210 \\
\hline 17 & 23 & 161.2 \\
\hline 18 & 16 & 124.8 \\
\hline 19 & 8 & 84.1 \\
\hline 20 & 10 & 57.4 \\
\hline 21 & 9 & 32.8 \\
\hline 22 & 4 & 19.9 \\
\hline 23 & 2 & 2.1 \\
\hline & & 2600.1 \\
\hline
\end{tabular}

$\mathrm{V}$ (in $\left.\pi \mathrm{r}^{2} \mathrm{qmm}\right)=1.040826 \mathrm{cmm}$.

$\mathrm{V}($ in $1 \mathrm{gcm})=2.982 \mathrm{cnım}$.

Ausgleichsdicke $=0.02982 \mathrm{~mm}$

(rund $29.8 \mu$ ). 
Quantitative Untersuchung der Anhangsorgane der Haut bei einem erwachsenen Ainu. 475

Tabelle 56 .

Muskel. Oberschenkel (medial).

\begin{tabular}{|c|c|c|}
\hline $\begin{array}{l}\text { Schnitt- } \\
\text { nummer }\end{array}$ & $\begin{array}{l}\text { Zahl der } \\
\text { Muskel- } \\
\text { stücke }\end{array}$ & $\begin{array}{l}\text { Gewicht der } \\
\text { ausgeschnit- } \\
\text { tenen Papier- } \\
\text { stücke }\end{array}$ \\
\hline 1 & 4 & $2 \mathrm{mg}$ \\
\hline 2 & 4 & 3 \\
\hline 3 & 9 & 8.1 \\
\hline 4 & 14 & 19 \\
\hline 5 & 17 & 32.8 \\
\hline 6 & 21 & 41.3 \\
\hline 7 & 23 & 64 \\
\hline 8 & 29 & 75.1 \\
\hline 9 & 31 & 82 \\
\hline 10 & 26 & 98.1 \\
\hline 11 & 28 & 99 \\
\hline 12 & 11 & 90.6 \\
\hline 13 & 23 & 64 \\
\hline 14 & 15 & 32 \\
\hline 15 & 13 & 30.5 \\
\hline 16 & 20 & 31.5 \\
\hline 17 & 21 & 23 \\
\hline 18 & 13 & 18.4 \\
\hline 19 & 8 & 8 \\
\hline 20 & 12 & 11.1 \\
\hline 21 & 9 & 16 \\
\hline 22 & 9 & 19.3 \\
\hline 23 & 7 & 33.5 \\
\hline 24 & 8 & 42 \\
\hline 25 & 5 & 37.3 \\
\hline 26 & 4 & 40 \\
\hline 27 & 4 & $\simeq 5.8$ \\
\hline 28 & 1 & 1.9 \\
\hline 29 & 1 & 1.5 \\
\hline
\end{tabular}

$\mathrm{V}\left(\right.$ in $\left.\pi \mathrm{r}^{2} \mathrm{qmm}\right)=0.420638 \mathrm{cmm}$.

$\mathrm{V}($ in $1 \mathrm{gcm})=1.205 \mathrm{cmm}$.

Ausgleichsdicke $=0.01205 \mathrm{~mm}$

(rund $12.1 \mu$ ).
Tabelle 57.

Muskel. Oberschenkel (lateral).

\begin{tabular}{|c|c|c|}
\hline $\begin{array}{l}\text { Schnitt- } \\
\text { nummer }\end{array}$ & $\begin{array}{l}\text { Zahl der } \\
\text { Muskel- } \\
\text { stücke }\end{array}$ & $\begin{array}{l}\text { Gewicht der } \\
\text { ausgeschnit- } \\
\text { tenen Papier- } \\
\text { stücke }\end{array}$ \\
\hline $\begin{array}{r}1 \\
2 \\
3 \\
4 \\
5 \\
6 \\
7 \\
8 \\
9 \\
10 \\
11 \\
12 \\
13 \\
14 \\
15 \\
16 \\
17 \\
18 \\
19 \\
20 \\
21 \\
22 \\
23 \\
24 \\
25 \\
26 \\
27 \\
28 \\
29 \\
30 \\
31 \\
32 \\
33 \\
34 \\
35 \\
36 \\
37\end{array}$ & $\begin{array}{r}6 \\
17 \\
29 \\
38 \\
25 \\
31 \\
36 \\
49 \\
38 \\
34 \\
45 \\
51 \\
52 \\
46 \\
40 \\
35 \\
26 \\
26 \\
23 \\
15 \\
18 \\
15 \\
6 \\
6 \\
7 \\
8 \\
7 \\
10 \\
5 \\
10 \\
7 \\
2 \\
1 \\
1 \\
2 \\
3 \\
2\end{array}$ & 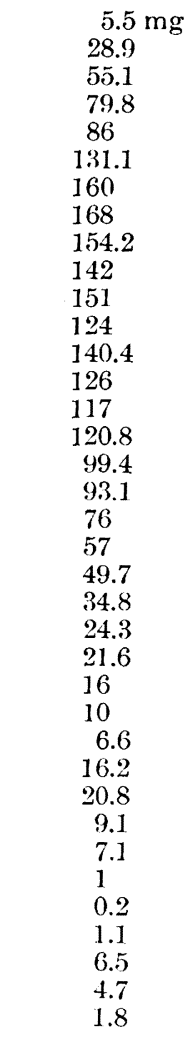 \\
\hline & & 2346.8 \\
\hline
\end{tabular}

$V\left(\right.$ in $\left.\pi r^{2} \mathrm{qmm}\right)=0.939429 \mathrm{cmm}$.

$\mathrm{V}\left(\right.$ in $1\left(\mathrm{~cm}_{\mathrm{cm}}\right)=2.691 \mathrm{cmm}$.

Ausgleichsdicke $=0.02691 \mathrm{~mm}$

(rund 26.9 !.). 
Tabelle 58.

Muskel. Unterschenkel (Streckseite).

\begin{tabular}{|c|c|c|}
\hline $\begin{array}{l}\text { Schnitt- } \\
\text { nummer }\end{array}$ & $\begin{array}{l}\text { Zahl der } \\
\text { Muskel- } \\
\text { stücke }\end{array}$ & $\begin{array}{l}\text { Gewicht der } \\
\text { ausgeschnit- } \\
\text { tenen Papier- } \\
\text { stücke }\end{array}$ \\
\hline 1 & 4 & $4 \mathrm{mg}$ \\
\hline 2 & 13 & 37 \\
\hline 3 & 27 & 129 \\
\hline 4 & 28 & 145.5 \\
\hline 5 & 36 & 219 \\
\hline 6 & 40 & 205.2 \\
\hline 7 & 30 & 270.5 \\
\hline 8 & 18 & 358 \\
\hline 9 & 24 & 320 \\
\hline 10 & 23 & 254.2 \\
\hline 11 & 20 & 190.8 \\
\hline 12 & 19 & 105.8 \\
\hline 13 & 16 & 36 \\
\hline 14 & 5 & 11.2 \\
\hline 15 & 4 & 7 \\
\hline 16 & 2 & 7.1 \\
\hline 17 & 1 & 1 \\
\hline 18 & 1 & 11 \\
\hline 19 & 1 & 0.9 \\
\hline 20 & 2 & 5 \\
\hline
\end{tabular}

$\mathrm{V}\left(\right.$ in $\left.\pi \mathrm{r}^{2} \mathrm{gmm}\right)=0.927981 \mathrm{cmm}$.

$\mathrm{V}($ in $1 \mathrm{qcm})=2.658 \mathrm{cmm}$.

Ausgleichsdicke $=0.02658 \mathrm{~mm}$
Tabelle 59.

Muskel. Unterschenkel (Beugeseite).

\begin{tabular}{|c|c|c|}
\hline $\begin{array}{l}\text { Schnitt- } \\
\text { nummer }\end{array}$ & $\begin{array}{l}\text { Zahl der } \\
\text { Muskel- } \\
\text { stücke }\end{array}$ & $\begin{array}{l}\text { Gewicht der } \\
\text { ausgeschnit- } \\
\text { tenen Papier- } \\
\text { stücke }\end{array}$ \\
\hline 1 & 1 & $0.8 \mathrm{mg}$ \\
\hline 2 & 1 & 0.8 \\
\hline 3 & 1 & 1.6 \\
\hline 4 & 1 & 1.1 \\
\hline 5 & 1 & 1.1 \\
\hline 6 & 3 & 4 \\
\hline 7 & 15 & 23.4 \\
\hline 8 & 18 & $72 A 1$ \\
\hline 9 & 17 & 72.1 \\
\hline 10 & 17 & 94.5 \\
\hline 11 & 17 & 126 \\
\hline 12 & 13 & 148 \\
\hline $13^{\circ}$ & 15 & 162 \\
\hline 14 & 16 & 185 \\
\hline 15 & 16 & 160 \\
\hline 16 & 14 & 95 \\
\hline 17 & 11 & 50.9 \\
\hline 18 & 10 & 24.1 \\
\hline 19 & 12 & 38.8 \\
\hline 20 & 7 & 52.3 \\
\hline 21 & 7 & 60.5 \\
\hline 22 & 6 & 30.6 \\
\hline 23 & 6 & 15.3 \\
\hline 24 & 4 & 5.8 \\
\hline 25 & 1 & 4 \\
\hline 26 & 1 & 10 \\
\hline 27 & 3 & 8.1 \\
\hline 28 & 2 & 3.2 \\
\hline 29 & 1 & 0.5 \\
\hline & 1451.6 \\
\hline
\end{tabular}

$\mathrm{V}\left(\right.$ in $\left.\pi \mathrm{r}^{2} \mathrm{gmm}\right)=0.581079 \mathrm{cmm}$. $\mathrm{V}$ (in $1 \mathrm{gcm})=1.665 \mathrm{cmm}$.

Ausgleichsdicke $=0.01665 \mathrm{~mm}$

(rund 16.7 $\mu$ ). 
Quantitative Untersuchung der Anhangsorgane der Haut bei einem erwachsenen Ainu. 477

Tabelle 60.

Volumen der Muskelindividuen in Scheitelhaut. ${ }^{1)}$

\begin{tabular}{|c|c|c|c|c|c|}
\hline $\begin{array}{c}\text { Muskel- } \\
\text { nummer }\end{array}$ & $\begin{array}{c}\text { Haarzahl } \\
\text { in einer } \\
\text { Gruppe }\end{array}$ & Schnittzahl & $\begin{array}{c}\text { Zahl der } \\
\text { Muskel- } \\
\text { stücke }\end{array}$ & $\begin{array}{c}\text { Gewicht der } \\
\text { ausgeschn. } \\
\text { Papietstücke }\end{array}$ & $\begin{array}{c}\text { Volumen des } \\
\text { Muskelindiv. }\end{array}$ \\
\cline { 1 - 3 } $\mathrm{a}$ & 6 & 29 & 132 & $472 \mathrm{mg}$ & $0.188943 \mathrm{cmm}$ \\
$\mathrm{b}$ & 6 & 28 & 86 & 345 & 0.138104 \\
$\mathrm{c}$ & 5 & 29 & 146 & 517 & 0.206956 \\
$\mathrm{~d}$ & 5 & 30 & 94 & 380.4 & 0.152275 \\
$\mathrm{e}$ & 5 & 25 & 98 & 392.5 & 0.157119 \\
$\mathrm{f}$ & 5 & 27 & 107 & 452 & 0.180937 \\
$\mathrm{~g}$ & 5 & 26 & 45 & 164.1 & 0.065690 \\
$\mathrm{~h}$ & 4 & 27 & 44 & 149 & 0.059645 \\
$\mathrm{i}$ & 4 & 29 & 55 & 173 & 0.069252 \\
$\mathrm{j}$ & 4 & 26 & 69 & 297 & 0.118890 \\
\hline
\end{tabular}

Tabelle 61 .

Volumen der Muskelindividuen in Halshaut.

\begin{tabular}{|c|c|c|c|c|c|}
\hline $\begin{array}{c}\text { Muskel- } \\
\text { nummer }\end{array}$ & $\begin{array}{c}\text { Haarzahl } \\
\text { in einer } \\
\text { Gruppe }\end{array}$ & Schnittzahl & $\begin{array}{c}\text { Zahl der } \\
\text { Muskel- } \\
\text { stïicke }\end{array}$ & $\begin{array}{c}\text { Gewicht der } \\
\text { ausgeschn. } \\
\text { Papierstücke }\end{array}$ & $\begin{array}{c}\text { Volumen des } \\
\text { Muskelindiv. }\end{array}$ \\
\hline a & 4 & 16 & 46 & $204.7 \mathrm{mg}$ & $0.081942 \mathrm{cmm}$ \\
b & 4 & 13 & 51 & 140 & 0.056042 \\
c & 4 & 17 & 47 & 105.2 & 0.042112 \\
d & 3 & 17 & 51 & 174.2 & 0.069733 \\
e & 3 & 14 & 40 & 183.9 & 0.073616 \\
f & 3 & 12 & 43 & 183.1 & 0.062047 \\
g & 3 & 11 & 24 & 102.3 & 0.073295 \\
h & 3 & 15 & 43 & 8040951 \\
i & 3 & 17 & 39 & 0.064929 \\
j & 2 & 15 & 45 & 0.032024 \\
\hline
\end{tabular}

Tabelle 62 .

Volumen der Muskelindividuen in Brusthaut.

\begin{tabular}{|c|c|c|c|c|c|}
\hline $\begin{array}{c}\text { Muskel- } \\
\text { nummer }\end{array}$ & $\begin{array}{c}\text { Haarzahl } \\
\text { in einer } \\
\text { Gruppe }\end{array}$ & Schnittzahl & $\begin{array}{c}\text { Zahl der } \\
\text { Muskel- } \\
\text { stücke }\end{array}$ & $\begin{array}{c}\text { Gewicht der } \\
\text { ausgeschn. } \\
\text { Papierstücke }\end{array}$ & $\begin{array}{c}\text { Volumen des } \\
\text { Muskelindiv. }\end{array}$ \\
\hline a & 3 & 18 & 50 & $202 \mathrm{mg}$ & $0.080861 \mathrm{cmm}$ \\
b & 3 & 17 & 49 & 297.6 & 0.119130 \\
c & 3 & 17 & 39 & 252 & 0.100876 \\
d & 3 & 13 & 43 & 159 & 0.086866 \\
e & 3 & 18 & 47 & 218 & 0.063648 \\
f & 3 & 14 & 33 & 243 & 0.062447 \\
g & 3 & 12 & 35 & 170.4 & 0.097273 \\
h & 3 & 14 & 48 & 189.2 & $0.06821]$ \\
i & 2 & 16 & 48 & 0.075737 \\
\hline
\end{tabular}

1) Nur am Scheitel bemerkte ich einige solche Arrektoren, die in der Nähe der Hautoberfläche mit denen der anderen Haargruppe miteinander verwachsen sind; bei der Volumenbestimmung des Muskelindividuums habe ich einen solchen Arrektor an der Verwachsungsstelle in die beiden Hälften eingeteilt und je eine Hälfte jeder Haargruppe hinzugefügt. 
Tabelle 63.

Volumen der Muskelindividuen in Bauchhaut.

\begin{tabular}{|c|c|c|c|c|c|}
\hline $\begin{array}{c}\text { Muskel- } \\
\text { nummer }\end{array}$ & $\begin{array}{c}\text { Haarzahl } \\
\text { in einer } \\
\text { Gruppe }\end{array}$ & Schnittzahl & $\begin{array}{c}\text { Zahl der } \\
\text { Muskel- } \\
\text { stücke }\end{array}$ & $\begin{array}{c}\text { Gewicht der } \\
\text { ausgeschn. } \\
\text { Papierstücke }\end{array}$ & $\begin{array}{c}\text { Volumen des } \\
\text { Muskelindiv. }\end{array}$ \\
\cline { 1 - 5 } $\mathrm{a}$ & 3 & 17 & 59 & $327 \mathrm{rng}$ & $0.130899 \mathrm{cmm}$ \\
$\mathrm{b}$ & 3 & 19 & 61 & 247 & 0.098875 \\
$\mathrm{c}$ & 3 & 24 & 78 & 391 & 0.156518 \\
$\mathrm{~d}$ & 2 & 14 & 42 & 115 & 0.046035 \\
$\mathrm{e}$ & 2 & 17 & 34 & 90 & 0.036027 \\
$\mathrm{f}$ & 2 & 24 & 63 & 201 & 0.080461 \\
$\mathrm{~g}$ & 2 & 22 & 76 & 341.8 & 0.136823 \\
$\mathrm{~h}$ & 2 & 17 & 59 & 159.7 & 0.063928 \\
$\mathrm{i}$ & 2 & 22 & 118 & 210 & 0.084063 \\
$\mathrm{j}$ & 1 & 14 & 23 & 24.4 & 0.009767 \\
\hline
\end{tabular}

Tabelle 64.

Volumen der Muskelindividuen in Rückenhaut.

\begin{tabular}{|c|c|c|c|c|c|}
\hline $\begin{array}{c}\text { Muskel- } \\
\text { nummer }\end{array}$ & $\begin{array}{c}\text { Haarzahl } \\
\text { in einer } \\
\text { Gruppe }\end{array}$ & Schnittzahl & $\begin{array}{c}\text { Zahl der } \\
\text { Muskel- } \\
\text { stücke }\end{array}$ & $\begin{array}{c}\text { Gewicht der } \\
\text { ausgeschn. } \\
\text { Papierstücke }\end{array}$ & $\begin{array}{c}\text { Volumen des } \\
\text { Muskelindiv. }\end{array}$ \\
\cline { 1 - 5 } $\mathrm{a}$ & 4 & 23 & 75 & 239 ing & $0.095672 \mathrm{cmm}$ \\
$\mathrm{b}$ & 3 & 25 & 76 & 177.8 & 0.071174 \\
$\mathrm{c}$ & 3 & 22 & 65 & 161 & 0.064449 \\
$\mathrm{~d}$ & 3 & 25 & 64 & 175 & 0.070053 \\
$\mathrm{e}$ & 2 & 22 & 53 & 107.1 & 0.042872 \\
$\mathrm{f}$ & 2 & 22 & 78 & 150 & 0.060045 \\
$\mathrm{~g}$ & 2 & 21 & 42 & 75 & 0.030023 \\
$\mathrm{~h}$ & 2 & 21 & 42 & 92.2 & 0.036908 \\
$\mathrm{i}$ & 2 & 17 & 46 & 85 & 0.034026 \\
$\mathrm{j}$ & 2 & 19 & 40 & 50.5 & 0.020215 \\
\hline
\end{tabular}

Tabelle 65 .

Volumen der Muskelindividuen in Gesässhaut.

\begin{tabular}{|c|c|c|c|c|c|}
\hline $\begin{array}{c}\text { Muskel- } \\
\text { nummer }\end{array}$ & $\begin{array}{c}\text { Haarzahl } \\
\text { in einer } \\
\text { Gruppe }\end{array}$ & Schnittzahl & $\begin{array}{c}\text { Zahl der } \\
\text { Muskel- } \\
\text { stïcke }\end{array}$ & $\begin{array}{c}\text { Gewicht der } \\
\text { ausgeschn. } \\
\text { Papierstücke }\end{array}$ & $\begin{array}{c}\text { Volumen des } \\
\text { Muskelindiv. }\end{array}$ \\
\cline { 1 - 3 } a & 5 & 25 & 117 & $604.3 \mathrm{mg}$ & $0.241903 \mathrm{cmm}$ \\
$\mathrm{b}$ & 5 & 27 & 188 & 782.6 & 0.313277 \\
$\mathrm{c}$ & 5 & 21 & 102 & 564 & 0.225770 \\
$\mathrm{~d}$ & 5 & 21 & 80 & 540.8 & 0.216483 \\
$\mathrm{e}$ & 4 & 22 & 90 & 473.1 & 0.189383 \\
$\mathrm{f}$ & 3 & 28 & 86 & 448.2 & 0.179415 \\
$\mathrm{~g}$ & 3 & 20 & 70 & 272 & 0.108882 \\
$\mathrm{~h}$ & 3 & 21 & 65 & 317.1 & 0.126936 \\
$\mathrm{i}$ & 2 & 26 & 69 & 258.5 & 0.103478 \\
$\mathrm{j}$ & 2 & 22 & 63 & 223.3 & 0.089387 \\
\hline
\end{tabular}


Quantitative Untersuchung der Anhangsorgane der Haut bei einem erwachsenen Ainu. 479

\section{Tabelle 66.}

Volumen der Muskelindividuen im Oberarm.(Beugeseite).

\begin{tabular}{|c|c|c|c|c|c|}
\hline $\begin{array}{c}\text { Muskel- } \\
\text { numiner }\end{array}$ & $\begin{array}{c}\text { Haarzahl } \\
\text { in einer } \\
\text { Gruppe }\end{array}$ & Schnittzahl & $\begin{array}{c}\text { Zahl der } \\
\text { Muskel- } \\
\text { stücke }\end{array}$ & $\begin{array}{c}\text { Gewicht der } \\
\text { ausgeschn. } \\
\text { Papierstücke }\end{array}$ & $\begin{array}{c}\text { Volumen des } \\
\text { Muskelindiv. }\end{array}$ \\
\cline { 2 - 3 } \cline { 5 - 6 } a & 3 & 22 & 63 & $249 \mathrm{mg}$ & $0.099675 \mathrm{cmm}$ \\
$\mathrm{b}$ & 3 & 11 & 30 & 212.3 & 0.084984 \\
$\mathrm{c}$ & 3 & 12 & 29 & 248.8 & 0.099595 \\
$\mathrm{~d}$ & 3 & 15 & 48 & 198.4 & 0.079420 \\
$\mathrm{e}$ & 2 & 12 & 49 & 116.7 & 0.046715 \\
$\mathrm{f}$ & 2 & 9 & 34 & 145.1 & 0.058084 \\
$\mathrm{~g}$ & 2 & 17 & 39 & 98 & 0.039230 \\
$\mathrm{~h}$ & 2 & 14 & 46 & 154 & 0.061647 \\
$\mathrm{i}$ & 2 & 12 & 36 & 160 & 0.064048 \\
$\mathrm{j}$ & 1 & 13 & 21 & 62.5 & 0.025019 \\
\hline
\end{tabular}

Tabelle 67.

Volumen der Muskelindividuen in Oberarm (Streckseite).

\begin{tabular}{|c|c|c|c|c|c|}
\hline $\begin{array}{c}\text { Muskel- } \\
\text { nummer }\end{array}$ & $\begin{array}{c}\text { Haarzahl } \\
\text { in einer } \\
\text { Gruppe }\end{array}$ & schnittzahl & $\begin{array}{c}\text { Zahl der } \\
\text { Muskel- } \\
\text { stücke }\end{array}$ & $\begin{array}{c}\text { Gewicht der } \\
\text { ausgeschn. } \\
\text { Papierstücke }\end{array}$ & $\begin{array}{c}\text { Volumen des } \\
\text { Muskelindiv. }\end{array}$ \\
\cline { 1 - 2 } a & 3 & 16 & 70 & $376.5 \mathrm{mg}$ & $0.150714 \mathrm{cmm}$ \\
b & 3 & 19 & 77 & 423 & 0.169328 \\
c & 3 & 19 & 68 & 223 & 0.089267 \\
d & 3 & 16 & 85 & 373 & 0.149313 \\
e & 3 & 22 & 69 & 249.2 & 0.099755 \\
f & 3 & 21 & 74 & 265 & 0.106081 \\
g & 3 & 20 & 86 & 292 & 0.116888 \\
h & 2 & 20 & 69 & 220.6 & 0.088307 \\
i & 2 & 19 & 54 & 222 & 0.088867 \\
j & 2 & 18 & 56 & 170.5 & 0.068252 \\
\hline
\end{tabular}

Tabelle 68.

Volumen der Muskelindividuen im Vorderarm (Beugeseite).

\begin{tabular}{|c|c|c|c|c|c|}
\hline $\begin{array}{c}\text { Muskel- } \\
\text { nummer }\end{array}$ & $\begin{array}{c}\text { Haarzahl } \\
\text { in einer } \\
\text { Gruppe }\end{array}$ & Schnittzahl & $\begin{array}{c}\text { Yahl der } \\
\text { Muskel- } \\
\text { stücke }\end{array}$ & $\begin{array}{c}\text { Gewicht der } \\
\text { ausgeschn. } \\
\text { Papierstücke }\end{array}$ & $\begin{array}{c}\text { Volumen des } \\
\text { Muskelindiv. }\end{array}$ \\
\hline a & 3 & 17 & 61 & $214 \mathrm{mg}$ & $0.085665 \mathrm{cmm}$ \\
$\mathrm{b}$ & 3 & 17 & 81 & 225 & 0.090068 \\
$\mathrm{c}$ & 3 & 13 & 37 & 223 & 0.089267 \\
$\mathrm{~d}$ & 2 & 22 & 52 & 97 & 0.038829 \\
$\mathrm{e}$ & 2 & 21 & 44 & 131 & 0.052440 \\
$\mathrm{f}$ & 2 & 20 & 65 & 152.5 & 0.061046 \\
$\mathrm{~g}$ & 2 & 23 & 66 & 116 & 0.046435 \\
$\mathrm{~h}$ & 2 & 23 & 55 & 83.8 & 0.033545 \\
$\mathrm{i}$ & 2 & 13 & 32 & 111.4 & 0.044594 \\
$\mathrm{j}$ & 1 & 22 & 46 & 63.5 & 0.025419 \\
\hline
\end{tabular}


Tabelle 69.

Volumen der Muskelindividuen im Vorderarm (Streckseite).

\begin{tabular}{|c|c|c|c|c|c|}
\hline $\begin{array}{c}\text { Muskel- } \\
\text { nummer }\end{array}$ & $\begin{array}{c}\text { Haarzahl } \\
\text { in einer } \\
\text { Gruppe }\end{array}$ & Schnittzahl & $\begin{array}{c}\text { Zahl der } \\
\text { Muskel- } \\
\text { stücke }\end{array}$ & $\begin{array}{c}\text { Gewicht der } \\
\text { ausgesehn. } \\
\text { Papierstücke }\end{array}$ & $\begin{array}{c}\text { Volumen des } \\
\text { Muskelindiv. }\end{array}$ \\
\cline { 1 - 2 } a & 3 & 11 & 36 & $364 \mathrm{mg}$ & $0.145710 \mathrm{cn}$ m \\
b & 3 & 13 & 46 & 364 & 0.145710 \\
$\mathrm{c}$ & 3 & 14 & 39 & 284 & 0.113686 \\
$\mathrm{~d}$ & 3 & 12 & 46 & 248 & 0.099275 \\
$\mathrm{e}$ & 3 & 12 & 40 & 355.9 & 0.142468 \\
$\mathrm{f}$ & 3 & 12 & 52 & 561 & 0.224570 \\
$\mathrm{~g}$ & 3 & 10 & 43 & 311 & 0.124494 \\
$\mathrm{~h}$ & 2 & 10 & 32 & 171.9 & 0.068812 \\
$\mathrm{i}$ & 2 & 8 & 32 & 184.9 & 0.074016 \\
$\mathrm{j}$ & 1 & 9 & 25 & 93.8 & 0.037549 \\
\hline
\end{tabular}

Tabelle 70 .

Volumen der Muskelindividuen im Oberschenkel (nnedial).

\begin{tabular}{|c|c|c|c|c|c|}
\hline $\begin{array}{c}\text { Muskel- } \\
\text { nummer }\end{array}$ & $\begin{array}{c}\text { Haarzahl } \\
\text { in einer } \\
\text { Gruppe }\end{array}$ & Schnittzahl & $\begin{array}{c}\text { Zahl der } \\
\text { Muskel- } \\
\text { stücke }\end{array}$ & $\begin{array}{c}\text { Gewicht der } \\
\text { ausgeschn. } \\
\text { Papierstücke }\end{array}$ & $\begin{array}{c}\text { Volumen des } \\
\text { Muskelindiv. }\end{array}$ \\
\hline a & 3 & 12 & 25 & $115 \mathrm{mg}$ & $0.046035 \mathrm{cmm}$ \\
b & 3 & 14 & 44 & 140 & 0.056042 \\
c & 3 & 14 & 23 & 75 & 0.030023 \\
d & 3 & 11 & 58 & 237.1 & 0.094912 \\
e & 3 & 14 & 39 & 157 & 0.062847 \\
f & 3 & 14 & 65 & 218.1 & 0.087306 \\
g & 3 & 14 & 64 & 56.9 & 0.022777 \\
h & 2 & 11 & 20 & 46.6 & 0.018654 \\
j & 2 & 10 & 12 & 100.5 & 0.040230 \\
\hline
\end{tabular}

Tabelle 71 .

Volumen der Muskelindividuen im Oberschenkel (lateral).

\begin{tabular}{|c|c|c|c|c|c|}
\hline $\begin{array}{c}\text { Nuskel- } \\
\text { nummer }\end{array}$ & $\begin{array}{c}\text { Maarzahl } \\
\text { in einer } \\
\text { Gruppe }\end{array}$ & Schnittzahl & $\begin{array}{c}\text { Zahl der } \\
\text { Muskel- } \\
\text { stïcke }\end{array}$ & $\begin{array}{c}\text { Gewicht der } \\
\text { ausgeschn. } \\
\text { Papierstücke }\end{array}$ & $\begin{array}{c}\text { Volumen des } \\
\text { Iuskelindiv. }\end{array}$ \\
\cline { 1 - 2 } $\mathrm{a}$ & 3 & 23 & 84 & $370 \mathrm{mg}$ & $0.148112 \mathrm{cmm}$ \\
$\mathrm{b}$ & 3 & 22 & 94 & 561.6 & 0.224810 \\
$\mathrm{c}$ & 3 & 23 & 63 & 169 & 0.067651 \\
$\mathrm{~d}$ & 3 & 26 & 85 & 451 & 0.180536 \\
$\mathrm{e}$ & 3 & 17 & 43 & 562 & 0.144909 \\
$\mathrm{f}$ & 3 & 13 & 24 & 162.8 & 0.065169 \\
$\mathrm{~g}$ & 3 & 28 & 84 & 355 & 0.142107 \\
$\mathrm{~h}$ & 3 & 26 & 65 & 199.4 & 0.079820 \\
$\mathrm{i}$ & 2 & 21 & 72 & 354 & 0.141707 \\
$\mathrm{j}$ & 2 & 22 & 61 & 152.4 & 0.061006 \\
\hline
\end{tabular}


Quantitative Untersuchung der Anhangsorgane der Haut bei einem erwachsenen Ainu. 481

Tabelle 72 .

Volumen der Muskelindividuen im Unterschenkel (Streckseite).

\begin{tabular}{|c|c|c|c|c|c|}
\hline $\begin{array}{c}\text { Muskel- } \\
\text { nummer }\end{array}$ & $\begin{array}{c}\text { Haarzahl } \\
\text { in einer } \\
\text { Gruppe }\end{array}$ & Schnittzahl & $\begin{array}{c}\text { Zahl der } \\
\text { Muskel- } \\
\text { stücke }\end{array}$ & $\begin{array}{c}\text { Gewicht der } \\
\text { ausgeschn. } \\
\text { Papierstücke }\end{array}$ & $\begin{array}{c}\text { Volumen des } \\
\text { Muskelindiv. }\end{array}$ \\
\cline { 1 - 4 } $\mathbf{a}$ & 3 & 15 & 50 & $656.5 \mathrm{mg}$ & $0.262798 \mathrm{cmm}$ \\
$\mathrm{b}$ & 3 & 15 & 49 & 433 & 0.173331 \\
$\mathrm{c}$ & 3 & 15 & 47 & 788 & 0.315438 \\
$\mathrm{~d}$ & 3 & 18 & 62 & 791.5 & 0.316839 \\
$\mathrm{e}$ & 3 & 16 & 56 & 487 & 0.194947 \\
$\mathrm{f}$ & 3 & 12 & 58 & 581.3 & 0.232696 \\
$\mathrm{~g}$ & 3 & 15 & 70 & 721 & 0.288618 \\
$\mathrm{~h}$ & 3 & 17 & 35 & 409 & 0.163724 \\
$\mathrm{i}$ & 3 & 16 & 46 & 861.3 & 0.344780 \\
$\mathrm{j}$ & 3 & 14 & 39 & 477.1 & 0.190984 \\
\hline
\end{tabular}

Tabelle 73.

Volumen der Muskelindividuen im Unterschenkel (Beugeseite).

\begin{tabular}{|c|c|c|c|c|c|}
\hline $\begin{array}{l}\text { Muskel- } \\
\text { nummer }\end{array}$ & $\begin{array}{l}\text { Haarzahl } \\
\text { in einer } \\
\text { Gruppe }\end{array}$ & Schnittzahl & $\begin{array}{l}\text { Zahl der } \\
\text { Muskel- } \\
\text { stücke }\end{array}$ & $\begin{array}{l}\text { Gewicht der } \\
\text { ausgeschn. } \\
\text { Papierstücke }\end{array}$ & $\begin{array}{l}\text { Volumen des } \\
\text { Muskelindiv. }\end{array}$ \\
\hline $\begin{array}{l}\mathrm{a} \\
\mathrm{b} \\
\mathrm{c} \\
\mathrm{d} \\
\mathrm{e} \\
\mathrm{f} \\
\mathrm{g} \\
\mathrm{h} \\
\mathrm{i} \\
\mathrm{j}\end{array}$ & $\begin{array}{l}3 \\
3 \\
3 \\
3 \\
3 \\
3 \\
1 \\
1 \\
-\end{array}$ & $\begin{array}{r}7 \\
16 \\
17 \\
9 \\
10 \\
12 \\
11 \\
8 \\
- \\
-\end{array}$ & $\begin{array}{l}14 \\
54 \\
37 \\
23 \\
19 \\
61 \\
16 \\
15 \\
-\end{array}$ & $\begin{array}{l}316 \quad \mathrm{mg} \\
225 \\
394.1 \\
244.5 \\
270 \\
546.5 \\
71 \\
95 \\
= \\
-\end{array}$ & $\begin{array}{l}0.126496 \mathrm{cmm} \\
0.090068 \\
0.157759 \\
0.097874 \\
0.108082 \\
0.218765 \\
0.028421 \\
0.038029 \\
- \\
-\end{array}$ \\
\hline
\end{tabular}




\section{Tabellarische Zusammenstellung.}

In folgenden ınöchte ich die obigen Befunde noch einmal tabellarisch zusammenstellen.

1. Schweissdrüse.

a. Menge und Ausmündungszahl der Drüse in den einzelnen Körperteilen.

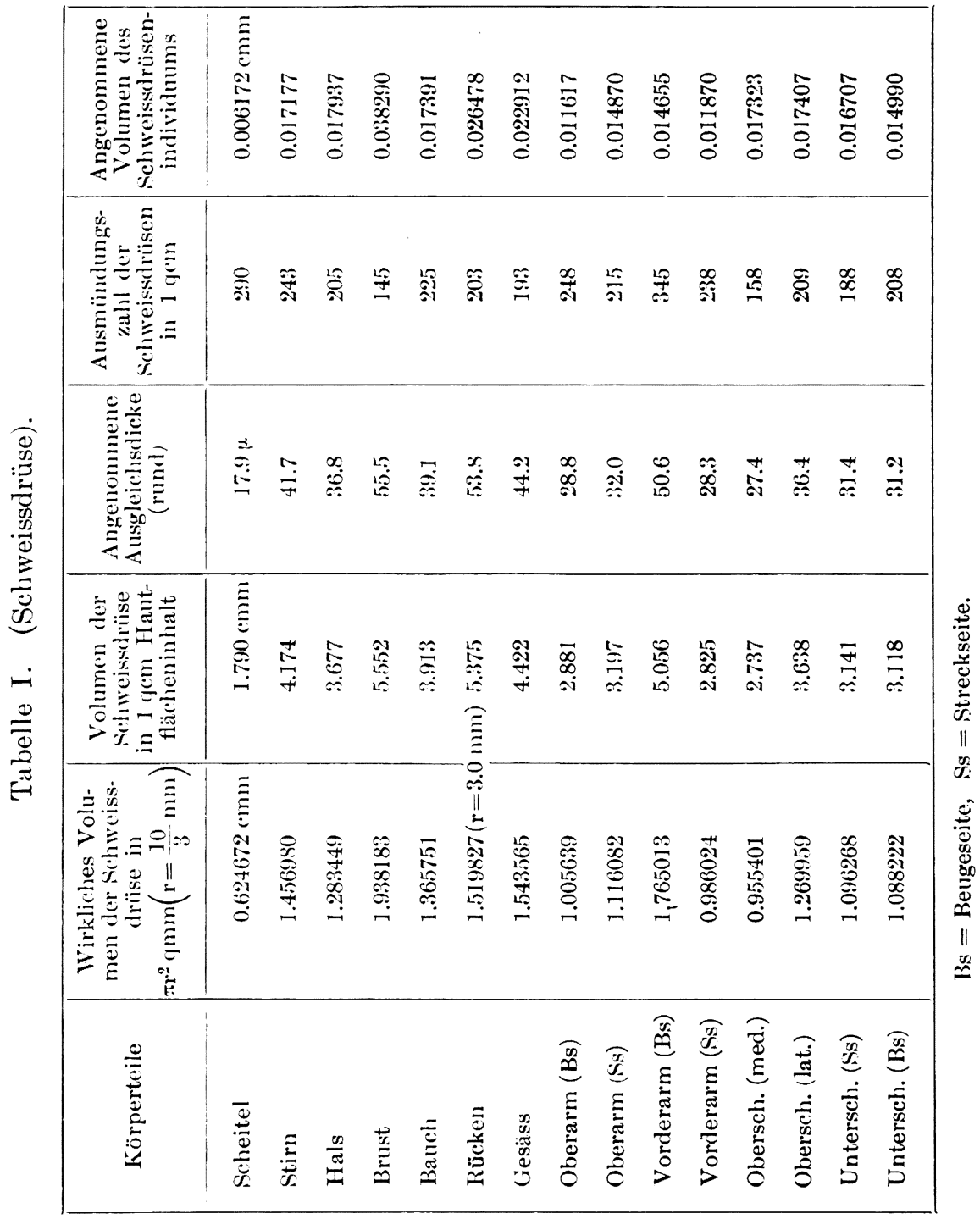


Quantitative Untersuchung der Anhangsorgane der Haut bei einem erwachsenen Ainu. 483

b. Reihenfolge der Mengengrösse und Ausmündungszahl der Drüse in einzelnen Körperteilen.

\begin{tabular}{|c|c|c|c|c|c|c|c|c|c|c|c|c|c|c|c|c|}
\hline 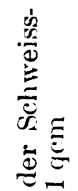 & Z & 蛋 & ๕̊̊̆ & $\underset{\sim}{\infty}$ & $\stackrel{9}{A}$ & $\stackrel{\infty}{\approx} \approx$ & ผัฐิ & $\frac{12}{\sim}$ & ళ్రి & $\stackrel{\text { ڤ̊ }}{\circ}$ & ㅇำ & ஸิ̊ & 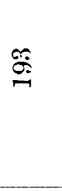 & $\stackrel{\infty}{\sim}$ & $\stackrel{\infty}{\stackrel{\infty}{\sim}}$ & 㝵 \\
\hline 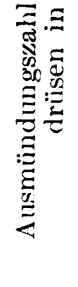 & 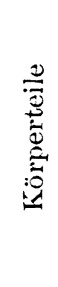 & 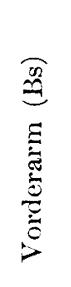 & 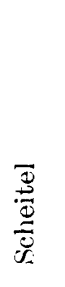 & 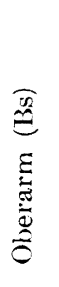 & : & 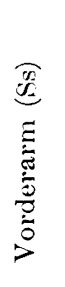 & 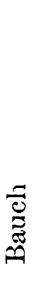 & 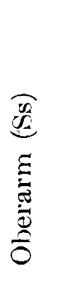 & 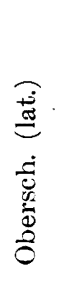 & 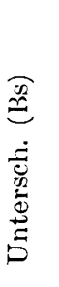 & $\stackrel{\frac{\sigma x}{\sigma}}{\stackrel{\Xi}{\leftrightarrows}}$ & 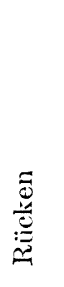 & 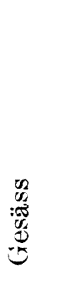 & 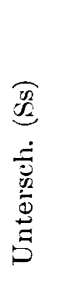 & 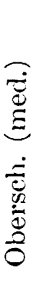 & 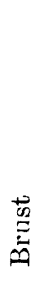 \\
\hline 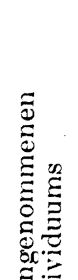 & 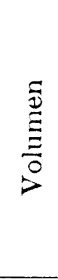 & 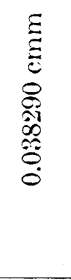 & 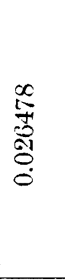 & 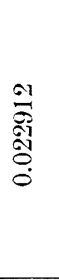 & 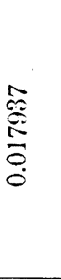 & 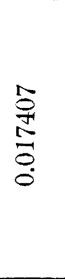 & 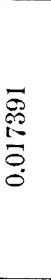 & 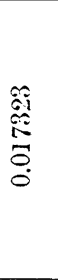 & 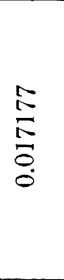 & 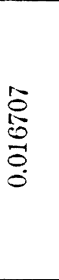 & $\begin{array}{l}\stackrel{8}{\stackrel{8}{+}} \\
\stackrel{+}{\circ} \\
\stackrel{0}{\circ}\end{array}$ & $\begin{array}{l}\stackrel{0}{0} \\
\stackrel{0}{\$} \\
\stackrel{0}{0} \\
\stackrel{0}{0}\end{array}$ & 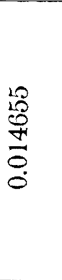 & 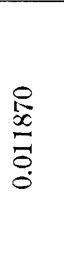 & $\begin{array}{l}\tilde{\sigma} \\
\stackrel{0}{0} \\
0 \\
0\end{array}$ & $\begin{array}{l}\hat{N} \\
\overline{8} \\
8 \\
\stackrel{0}{0}\end{array}$ \\
\hline 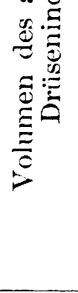 & 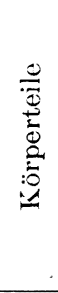 & $\stackrel{\vec{v}}{\overrightarrow{\tilde{\omega}}}$ & 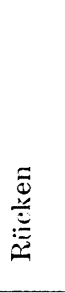 & 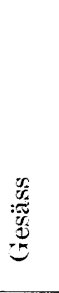 & $\frac{0}{E}$ & 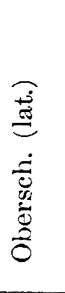 & 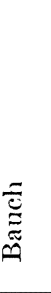 & 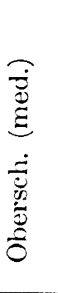 & $\Xi$ & 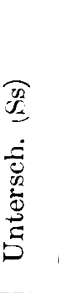 & 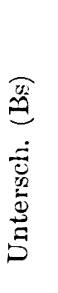 & 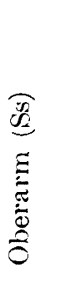 & 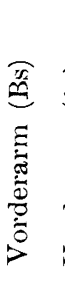 & 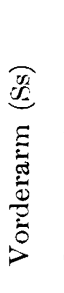 & 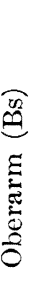 & $\frac{\bar{\Xi}}{\stackrel{Ð}{\circlearrowright}}$ \\
\hline 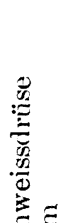 & 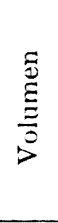 & 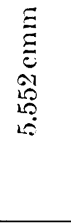 & 里 & 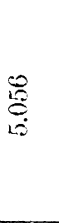 & 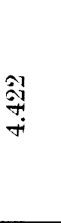 & 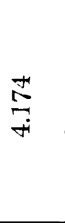 & مै & 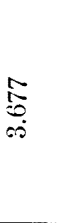 & $\begin{array}{l}\infty \\
\stackrel{\infty}{0} \\
\stackrel{0}{0}\end{array}$ & $\frac{\widehat{S}}{\stackrel{5}{\sigma}}$ & $\underset{\sim}{\vec{H}}$ & $\begin{array}{l}\underset{\sim}{\leftrightarrows} \\
\stackrel{\infty}{*}\end{array}$ & $\begin{array}{l}\vec{\infty} \\
\infty \\
\stackrel{\infty}{0}\end{array}$ & $\begin{array}{l}19 \\
\text { of } \\
\text { of } \\
\text { id }\end{array}$ & 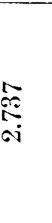 & $\stackrel{8}{\stackrel{D}{\leftrightarrow}}$ \\
\hline 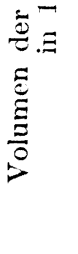 & 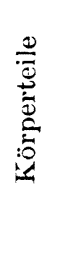 & 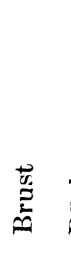 & 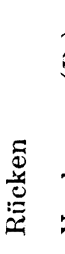 & 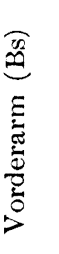 & 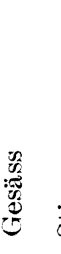 & 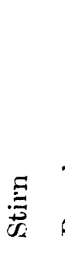 & 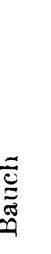 & $\stackrel{\frac{\pi}{\pi}}{\pi}$ & 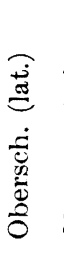 & 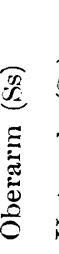 & 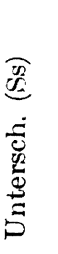 & 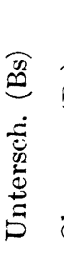 & 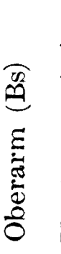 & 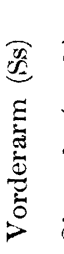 & 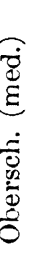 & 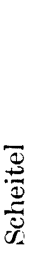 \\
\hline
\end{tabular}




\section{c. Menge und Ausmündungszahl der Drüse in den Hauptkörperabschnitten.}

Tabelle III. (Schweissdrüse).

\begin{tabular}{|c|c|c|c|c|c|c|}
\hline & \multicolumn{2}{|c|}{$\begin{array}{l}\text { Volumen der Schweiss- } \\
\text { drüse in } 1 \mathrm{gcm}\end{array}$} & \multicolumn{2}{|c|}{$\begin{array}{l}\text { Volumen der angenomme- } \\
\text { nen Drüsenindividuen }\end{array}$} & \multicolumn{2}{|c|}{$\begin{array}{l}\text { Ausmündungszahl } \\
\text { der Schweissdrüsen } \\
\text { in } 1 \mathrm{qcm}\end{array}$} \\
\hline & Körperteile & Volumen & Körperteile & Volumen & Körperteile & Zahl \\
\hline $\begin{array}{l}\text { ganzer } \\
\text { Körper }\end{array}$ & $\begin{array}{l}\text { Rumpf } \\
\text { Hals } \\
\text { Extremität } \\
\text { Kopf }\end{array}$ & $\begin{array}{l}4.816 \mathrm{cmm} \\
3.677 \\
3.324 \\
2.982\end{array}$ & $\begin{array}{l}\text { Rumpf } \\
\text { Hals } \\
\text { Extremität } \\
\text { Kopf }\end{array}$ & $\begin{array}{l}0.026268 \mathrm{cmm} \\
0.017937 \\
0.014930 \\
0.011675\end{array}$ & $\begin{array}{l}\text { Kopf } \\
\text { Extremität } \\
\text { Hals } \\
\text { Rumpf }\end{array}$ & $\begin{array}{l}267 \\
226 \\
205 \\
192\end{array}$ \\
\hline Kopf & $\begin{array}{l}\text { Stirn } \\
\text { Scheitel }\end{array}$ & $\begin{array}{l}4.174 \\
1.790\end{array}$ & $\begin{array}{l}\text { Stirn } \\
\text { Scheitel }\end{array}$ & $\begin{array}{l}0.017177 \\
0.006172\end{array}$ & $\begin{array}{l}\text { Scheitel } \\
\text { Stirn }\end{array}$ & $\begin{array}{l}290 \\
243\end{array}$ \\
\hline Rumpf (a) & $\begin{array}{l}\text { Brust } \\
\text { Rücken } \\
\text { Gesäss } \\
\text { Bauch }\end{array}$ & $\begin{array}{l}5.552 \\
5.375 \\
4.422 \\
3.913\end{array}$ & $\begin{array}{l}\text { Brust } \\
\text { Rücken } \\
\text { Gesäss } \\
\text { Bauch }\end{array}$ & $\begin{array}{l}0.038290 \\
0.026478 \\
0.022912 \\
0.017391\end{array}$ & $\begin{array}{l}\text { Bauch } \\
\text { Rücken } \\
\text { Gesäss } \\
\text { Brust }\end{array}$ & $\begin{array}{l}225 \\
203 \\
193 \\
145\end{array}$ \\
\hline Rumpf (b) & $\begin{array}{l}\text { Dorsalseite } \\
\text { Ventralseite }\end{array}$ & $\begin{array}{l}4.899 \\
4.733\end{array}$ & $\begin{array}{l}\text { Ventralseite } \\
\text { Dorsalseite }\end{array}$ & $\begin{array}{l}0.027841 \\
0.024695\end{array}$ & $\begin{array}{l}\text { Dorsalseite } \\
\text { Ventralseite }\end{array}$ & $\begin{array}{l}198 \\
185\end{array}$ \\
\hline $\begin{array}{l}\text { Extremität } \\
\qquad(\mathbf{a})\end{array}$ & $\begin{array}{l}\text { obere Extr. } \\
\text { untere Extr. }\end{array}$ & $\begin{array}{l}3.490 \\
3.159\end{array}$ & $\begin{array}{l}\text { untere Extr. } \\
\text { obere Fxtr. }\end{array}$ & $\begin{array}{l}0.016607 \\
0.013253\end{array}$ & $\begin{array}{l}\text { obere Fxtr. } \\
\text { untere Extr. }\end{array}$ & $\begin{array}{l}262 \\
191\end{array}$ \\
\hline $\begin{array}{l}\text { Extremität } \\
\text { (b) }\end{array}$ & $\begin{array}{l}\text { Distalis } \\
\text { Proximalis }\end{array}$ & $\begin{array}{l}3.535 \\
3.113\end{array}$ & $\begin{array}{l}\text { Proximalis } \\
\text { Distalis }\end{array}$ & $\begin{array}{l}0.015304 \\
0.014556\end{array}$ & $\begin{array}{l}\text { Distalis } \\
\text { Proximalis }\end{array}$ & $\begin{array}{l}245 \\
208\end{array}$ \\
\hline $\begin{array}{l}\text { obere Fxtr. } \\
\text { (a) }\end{array}$ & $\begin{array}{l}\text { Vorderarm } \\
\text { Oberarm }\end{array}$ & $\begin{array}{l}3.941 \\
3.039\end{array}$ & $\begin{array}{l}\text { Vorderarm } \\
\text { Oberarm }\end{array}$ & $\begin{array}{l}0.013263 \\
0.013244\end{array}$ & $\begin{array}{l}\text { Vorderarm } \\
\text { Oberarm }\end{array}$ & $\begin{array}{l}292 \\
232\end{array}$ \\
\hline $\begin{array}{l}\text { obere Fxtr. } \\
\text { (b) }\end{array}$ & $\begin{array}{l}\text { Bengeseite } \\
\text { Streckseite }\end{array}$ & $\begin{array}{l}3.969 \\
3.011\end{array}$ & $\begin{array}{l}\text { Streckseite } \\
\text { Beugeseite }\end{array}$ & $\begin{array}{l}0.013370 \\
0.013136\end{array}$ & $\begin{array}{l}\text { Beugeseite } \\
\text { Streckseite }\end{array}$ & $\begin{array}{l}297 \\
227\end{array}$ \\
\hline Oberarm & $\begin{array}{l}\text { Streckseite } \\
\text { Beugeseite }\end{array}$ & $\begin{array}{l}3.197 \\
2.881\end{array}$ & $\begin{array}{l}\text { Streckseite } \\
\text { Beugeseite }\end{array}$ & $\begin{array}{l}0.014870 \\
0.011617\end{array}$ & $\begin{array}{l}\text { Beugeseite } \\
\text { Streckseite }\end{array}$ & $\begin{array}{l}248 \\
215\end{array}$ \\
\hline Vorderarm & $\begin{array}{l}\text { Beugeseite } \\
\text { Streckseite }\end{array}$ & $\begin{array}{l}5.056 \\
2.825\end{array}$ & $\begin{array}{l}\text { Beugeseite } \\
\text { Streckseite }\end{array}$ & $\begin{array}{l}0.014655 \\
0.011820\end{array}$ & $\begin{array}{l}\text { Beugeseite } \\
\text { Streckseite }\end{array}$ & $\begin{array}{l}345 \\
238\end{array}$ \\
\hline untere Extr. & $\begin{array}{l}\text { Obersch. } \\
\text { Untersch. }\end{array}$ & $\begin{array}{l}3.188 \\
3.130\end{array}$ & $\begin{array}{l}\text { Obersch. } \\
\text { Untersch. }\end{array}$ & $\begin{array}{l}0.017365 \\
0.015849\end{array}$ & $\begin{array}{l}\text { Untersch. } \\
\text { Obersch. }\end{array}$ & $\begin{array}{l}198 \\
184\end{array}$ \\
\hline Obersch. & $\begin{array}{l}\text { lateral } \\
\text { medial }\end{array}$ & $\begin{array}{l}3.638 \\
2.737\end{array}$ & $\begin{array}{l}\text { lateral } \\
\text { medial }\end{array}$ & $\begin{array}{l}0.017407 \\
0.017323\end{array}$ & $\begin{array}{l}\text { lateral } \\
\text { medial }\end{array}$ & $\begin{array}{l}209 \\
158\end{array}$ \\
\hline Untersch. & $\begin{array}{l}\text { Streckseite } \\
\text { Bengeseite }\end{array}$ & $\begin{array}{l}3.141 \\
3.118\end{array}$ & $\begin{array}{l}\text { Streckseite } \\
\text { Beugeseite }\end{array}$ & $\begin{array}{l}0.016707 \\
0.014990\end{array}$ & $\begin{array}{l}\text { Bengeseite } \\
\text { Streckseite }\end{array}$ & $\begin{array}{l}208 \\
188\end{array}$ \\
\hline
\end{tabular}


Quantitative Untersuchung der Anhangsorgane der Haut bei einem erwachsenen Ainu. 485

2. Talgdrüse.

a. Menge der Drüse in den einzelnen Körperteilen.

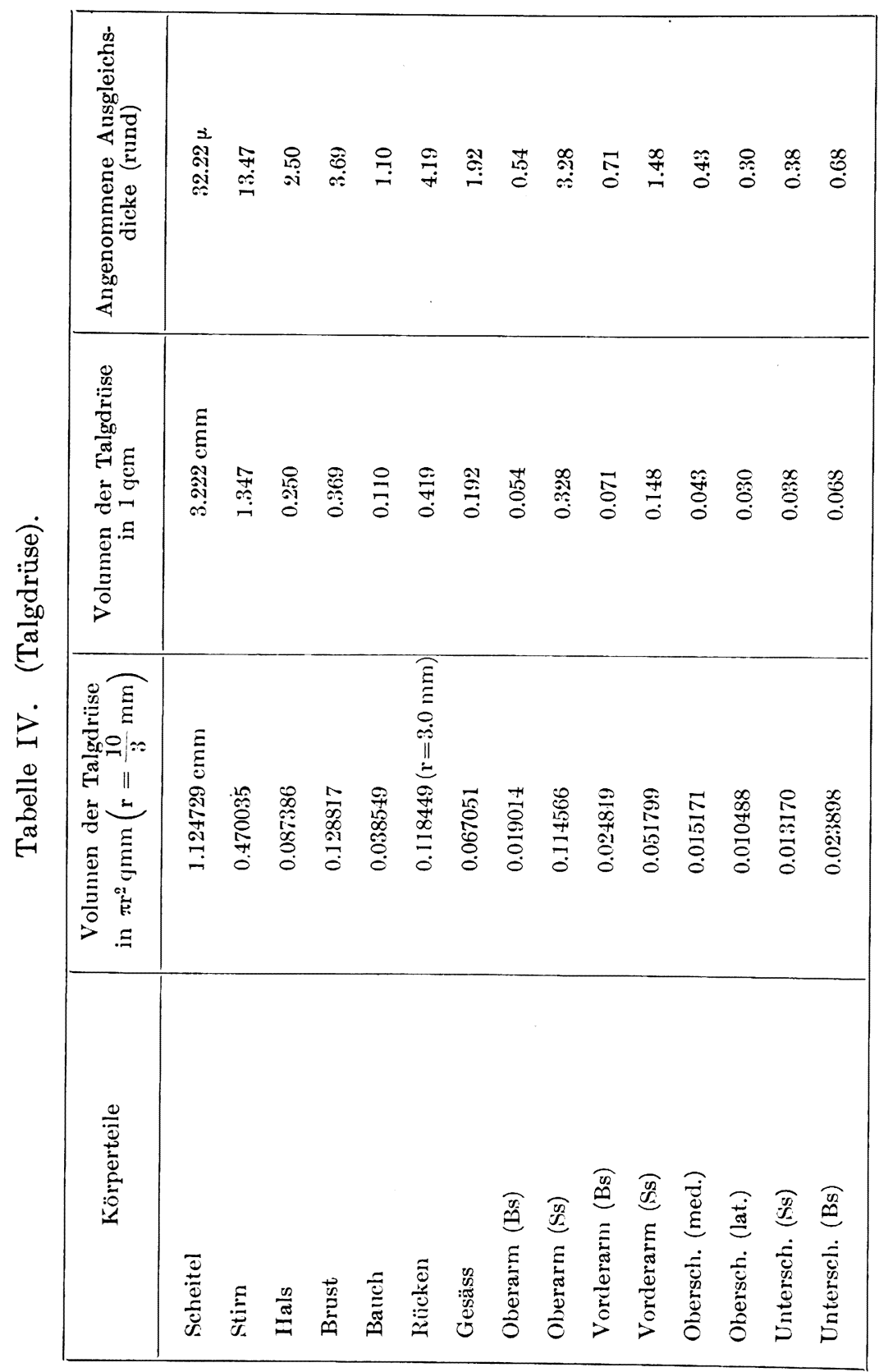


Tabelle V. (Talgdrüse).

\begin{tabular}{|c|c|c|c|}
\hline \multirow[b]{2}{*}{ Körperteile } & \multicolumn{3}{|c|}{ Gruppe aus 1 Haar } \\
\hline & $\begin{array}{c}\text { Zahl der } \\
\text { Haargruppe }\end{array}$ & $\begin{array}{l}\text { Gewicht der } \\
\text { ausgeschn. } \\
\text { Papierstücke }\end{array}$ & $\begin{array}{l}\text { Volumen des } \\
\text { Drüsenindiv. in } \\
\text { einer Haargruppe }\end{array}$ \\
\hline Scheitel & - & - & - \\
\hline Hals & - & - & - \\
\hline Brust & - & - & - \\
\hline Bauch & 1 & $4.3 \mathrm{mg}$ & $0.001721 \mathrm{cmm}$ \\
\hline Rücken & -. & & - \\
\hline Gesäss & - & - & - \\
\hline Oberarm ( $\mathrm{Bs}$ ) & ] & 2.8 & 0.001121 \\
\hline Oberarm (Ss) & $\ldots$ & - & - \\
\hline Vorderarm (Bs) & 1 & 1.5 & 0.000600 \\
\hline Vorderarm (ss) & 1 & 7.9 & 0.003162 \\
\hline Obersch. (med.) & - & - & - \\
\hline Obersch. (lat.) & - & - & - \\
\hline Untersch. (Ss) & - & - & - \\
\hline Untersch. (Bs) & 2 & 5.9 & 0.002362 \\
\hline
\end{tabular}

\begin{tabular}{|c|c|c|c|c|c|}
\hline \multicolumn{3}{|c|}{ Gruppe aus 2 Haaren } & \multicolumn{3}{|c|}{ Gruppe aus 3 Haaren } \\
\hline $\begin{array}{l}\text { Zahl der } \\
\text { Haar- } \\
\text { gruppe }\end{array}$ & $\begin{array}{l}\text { Gewicht der } \\
\text { ausgeschn. } \\
\text { Papierstücke }\end{array}$ & $\begin{array}{c}\text { Volumen des } \\
\text { Drüsenindiv. in } \\
\text { einer Haargruppe }\end{array}$ & $\begin{array}{c}\text { Zahl der } \\
\text { Haar- } \\
\text { gruppe }\end{array}$ & $\begin{array}{l}\text { Gewicht der } \\
\text { ausgeschn. } \\
\text { Papierstïcke }\end{array}$ & $\begin{array}{l}\text { Volumen des } \\
\text { Drüsenindiv. in } \\
\text { einer Haargruppe }\end{array}$ \\
\hline - & - & - & - & - & - \\
\hline 1 & 20 $\mathrm{mg}$ & $0.008006 \mathrm{cmm}$ & 6 & $32.8 \mathrm{mg}$ & $0.013143 \mathrm{cmm}$ \\
\hline 2 & 37 & 0.014792 & 8 & 57.6 & 0.023042 \\
\hline 6 & 20.5 & 0.008193 & 3 & 18.3 & 0.007326 \\
\hline 6 & 15.7 & 0.006291 & 3 & 32.4 & 0.012983 \\
\hline 2 & 7 & 0.002802 & 3 & 9.4 & 0.003776 \\
\hline 5 & 5.8 & 0.002314 & 4 & 9.4 & 0.003776 \\
\hline 3 & 13.3 & 0.005311 & 7 & 31.1 & 0.012467 \\
\hline 6 & 5 & 0.001982 & 3 & 16.1 & 0.006431 \\
\hline 2 & 9 & 0.003583 & 7 & 22.2 & 0.008904 \\
\hline 3 & 2.2 & 0.000881 & 7 & 7.2 & 0.002877 \\
\hline 2 & 3.7 & 0.001481 & 8 & 6.9 & 0.002762 \\
\hline 一 & 一 & - & 10 & 10 & 0.003991 \\
\hline 一 & - & - & 6 & 12 & 0.004784 \\
\hline
\end{tabular}

\begin{tabular}{|c|c|c|c|c|c|}
\hline \multicolumn{3}{|c|}{ Gruppe aus 4 Haaren } & \multicolumn{3}{|c|}{ Gruppe aus 5 Haaren } \\
\hline $\begin{array}{l}\text { Zahl der } \\
\text { Haar- } \\
\text { gruppe }\end{array}$ & $\begin{array}{l}\text { Gewicht der } \\
\text { ausgeschn. } \\
\text { Papierstücke }\end{array}$ & $\begin{array}{c}\text { Volumen des } \\
\text { Drüsenindiv. in } \\
\text { einer Haargruppe }\end{array}$ & $\begin{array}{l}\text { 7ahl der } \\
\text { Haar- } \\
\text { gruppe }\end{array}$ & $\begin{array}{l}\text { Gewicht der } \\
\text { ausgeschn. } \\
\text { Papierstücke }\end{array}$ & $\begin{array}{c}\text { Volumen des } \\
\text { Drïsenindiv. in } \\
\text { einer Haargiuppe }\end{array}$ \\
\hline 3 & $74.2 \mathrm{mg}$ & $0.029689 \mathrm{cmm}$ & 5 & $104.3 \mathrm{mg}$ & $0.041768 \mathrm{cmm}$ \\
\hline 3 & 43.2 & 0.017293 & - & 一 & 一 \\
\hline- & - & - & - & - & - \\
\hline 一 & - & - & - & - & 一 \\
\hline 1 & 62.4 & 0.024979 & - & - & - \\
\hline 1 & 17.2 & 0.006885 & 4 & 19.4 . & 0007746 \\
\hline- & - & - & - & - & - \\
\hline- & - & - & 一 & - & 一 \\
\hline - & 一 & - & - & - & - \\
\hline
\end{tabular}

\begin{tabular}{|c|c|c|}
\hline \multicolumn{3}{|c|}{ Gruppe aus 6 Haaren } \\
\hline $\begin{array}{c}\text { Zahl der } \\
\text { Haar- } \\
\text { gruppe }\end{array}$ & $\begin{array}{c}\text { Gewicht der } \\
\text { ausgeschn. } \\
\text { Papierstücke }\end{array}$ & $\begin{array}{c}\text { Volumen des } \\
\text { Drüsenindiv. in } \\
\text { einer Haargruppe }\end{array}$ \\
\hline 2 & $118.7 \mathrm{mg}$ & $0.047516 \mathrm{cmm}$ \\
- & - & - \\
- & - & - \\
- & - & -
\end{tabular}


Quantitative Untersuchung der Anhangsorgane der Haut bei einem erwachsenen Ainu. 487

b. Menge der Drüse in den Hauptkörperabschnitten.

Tabelle VI. (Talgdrüse).

\begin{tabular}{|c|c|c|}
\hline & \multicolumn{2}{|c|}{ Volumen der Talgdrüse in $1 \mathrm{gcm}$} \\
\hline & Körperteile & Volumen \\
\hline \multirow{4}{*}{ ganzer Körper } & Kopf & $2.285 \mathrm{cmm}$ \\
\hline & Rumpf & 0.273 \\
\hline & Hals & 0.250 \\
\hline & Extremität & 0.098 \\
\hline \multirow{2}{*}{ Kopf } & Scheitel & 3.222 \\
\hline & Stirn & 1.347 \\
\hline \multirow{4}{*}{ Rumpf (a) } & Rücken & 0.419 \\
\hline & Brust & 0.369 \\
\hline & Gesäss & 0.192 \\
\hline & Bauch & 0.110 \\
\hline \multirow{2}{*}{ Rumpf (b) } & Dorsalseite & 0.306 \\
\hline & Ventralseite & 0.240 \\
\hline \multirow{2}{*}{ Extremität (a) } & ohere Extr. & 0.150 \\
\hline & untere Fxtr. & 0.045 \\
\hline \multirow{2}{*}{ Extremität (b) } & Proximalis & 0.114 \\
\hline & Distalis & 0.081 \\
\hline \multirow{2}{*}{ obere Extr. (a) } & Oberarm & 0.191 \\
\hline & Vorderarm & 0.110 \\
\hline \multirow{2}{*}{ obere Extr. (b) } & Streckseite & 0.238 \\
\hline & Beugeseite & 0.063 \\
\hline \multirow{2}{*}{ Oberarm } & Streckseite & 0.328 \\
\hline & Beugeseite & 0.054 \\
\hline \multirow{2}{*}{ Vorderarm } & Streckseite & 0.148 \\
\hline & Beugeseite & 0.071 \\
\hline \multirow{2}{*}{ untere Extr. } & Untersch. & $0.05: 3$ \\
\hline & Obersch. & 0.037 \\
\hline \multirow{2}{*}{ Obersch. } & medial & 0.043 \\
\hline & lateral & 0.030 \\
\hline \multirow{2}{*}{ Untersch. } & Beugeseite & 0.068 \\
\hline & Streckseite & 0.038 \\
\hline
\end{tabular}


c. Reihenfolge der Mengengrösse der Drüse in einzelnen Körperteilen.

Tabelle VII. (Talgdrüse, Reihenfolge).

\begin{tabular}{|l|c|l|l}
\hline \multicolumn{2}{c|}{$\begin{array}{c}\text { Volumen der Talgdrüse } \\
\text { in 1 qcm }\end{array}$} & \multicolumn{2}{c}{$\begin{array}{c}\text { Volumen der Talgdrüsenindiv. } \\
\text { von 1 Haar }\end{array}$} \\
\hline \multicolumn{1}{c|}{ Körperteile } & Volumen & \multicolumn{1}{c}{ Körperteile } & Volumen \\
\hline Scheitel & $3.222 \mathrm{cmm}$ & Vorderarm (Ss) & $0.003162 \mathrm{cmm}$ \\
Stirn & 1.347 & Untersch. (Bs) & 0.002362 \\
Rücken & 0.419 & Bauch & 0.001721 \\
Brust & 0.369 & Oberarm (Bs) & 0.001121 \\
Oberarm (Ss) & 0.328 & Vorderarm (Bs) & \\
Hals & 0.250 & & \\
Gesäss & 0.192 & & \\
Vorderarm (Ss) & 0.148 & & \\
Bauch & 0.110 & & \\
Vorderarm (Bs) & 0.071 & & \\
Untersch. (Bs) & 0.068 & & \\
Oberarm (Bs) & 0.054 & & \\
Obersch. (med.) & 0.043 & & \\
Untersch. (Ss) & 0.038 & & \\
Obersch. (lat.) & 0.030 & & \\
\hline
\end{tabular}

\begin{tabular}{|c|c|c|c|}
\hline \multicolumn{2}{|c|}{$\begin{array}{c}\text { Volumen der Talgdrüsenindiv. } \\
\text { von } 2 \text { Haaren }\end{array}$} & \multicolumn{2}{|c|}{$\begin{array}{c}\text { Volumen der Talgdrüsenindiv. } \\
\text { von } 3 \text { Haaren }\end{array}$} \\
\hline Körperteile & Volumen & Körperteile & Volumen \\
\hline $\begin{array}{l}\text { Brust } \\
\text { Bauch } \\
\text { Hals } \\
\text { Rücken } \\
\text { Oberarm (Ss) } \\
\text { Vorderarm (Ss) } \\
\text { Gesäss } \\
\text { Oberarm (Bs) } \\
\text { Vorderarm (Bs) } \\
\text { Obersch. (lat.) } \\
\text { Obersch. (med.) }\end{array}$ & $\begin{array}{l}0.014792 \mathrm{cmm} \\
0.008193 \\
0.008006 \\
0.006291 \\
0.005311 \\
0.003583 \\
0.002802 \\
0.002314 \\
0.001982 \\
0.001481 \\
0.000881\end{array}$ & $\begin{array}{l}\text { Brust } \\
\text { Hals } \\
\text { Rücken } \\
\text { Oberarm (Ss) } \\
\text { Vorderarm (Ss) } \\
\text { Bauch } \\
\text { Vorderarm (Bs) } \\
\text { Untersch. (Bs) } \\
\text { Untersch. (Ss) } \\
\text { Gesäss } \\
\text { Oberarm (Bs) } \\
\text { Obersch. (med.) } \\
\text { Obersch. (lat.) }\end{array}$ & $\begin{array}{l}0.023042 \mathrm{cmm} \\
0.013143 \\
0.012983 \\
0.012467 \\
0.008904 \\
0.007326 \\
0.006431 \\
0.004784 \\
0003991 \\
0.003776 \\
0.003776 \\
0.002877 \\
0.002762 \\
\end{array}$ \\
\hline
\end{tabular}

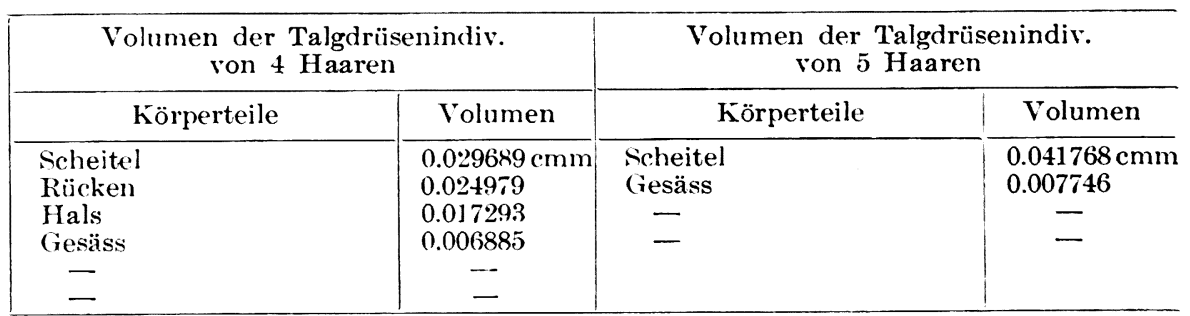

\begin{tabular}{|c|c|}
\hline \multicolumn{2}{|c|}{$\begin{array}{c}\text { Volumen der Talgdrüsenindiv. } \\
\text { von 6 Haaren }\end{array}$} \\
\hline Körperteile & Volumen \\
\hline $\begin{array}{c}\text { Scheitel } \\
\text { - }\end{array}$ & $0.0475] 6 \mathrm{cmm}$ \\
\hline
\end{tabular}


Quantitative Untersuchung der Anhangsorgane der Haut bei einem erwachsenen Ainu. 489

3. Haarbalgmuskel.

a. Menge des Muskels in den einzelnen Körperteilen.

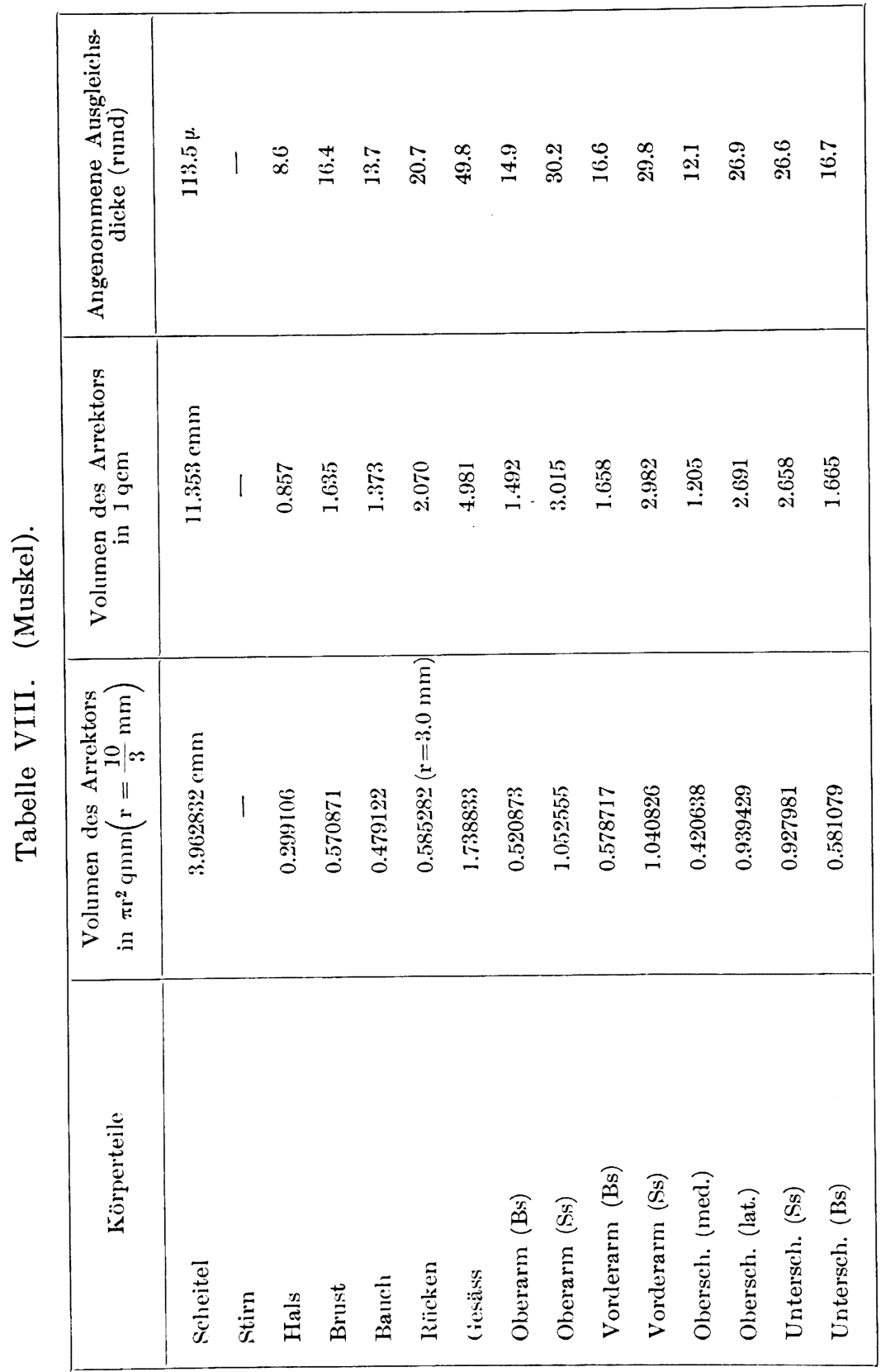


Tabelle IX. (Muskel).

\begin{tabular}{|c|c|c|c|}
\hline \multirow[b]{2}{*}{ Körperteile } & \multicolumn{3}{|c|}{ Gruppe aus 1 Haar } \\
\hline & $\begin{array}{c}\text { Zahl der } \\
\text { Haargruppe }\end{array}$ & $\begin{array}{l}\text { Gewicht der } \\
\text { ausgeschn. } \\
\text { Papierstücke }\end{array}$ & $\begin{array}{l}\text { Volumen des } \\
\text { Muskelindiv. in } \\
\text { einer Haargruppe }\end{array}$ \\
\hline Scheitel & - & - & - \\
\hline Hals & - & - & - \\
\hline Brust & - & - & - \\
\hline Bauch & 1 & $24.4 \mathrm{mg}$ & $0.009767 \mathrm{cmm}$ \\
\hline Rücken & - & - & - \\
\hline Gesäss & - & - & - \\
\hline Oberarm (Bs) & 1 & 62.5 & 0.025019 \\
\hline Oberarm ( $\mathrm{Ss}$ ) & - & - & - \\
\hline Vorderarm (Bs) & 1 & 63.5 & 0.025419 \\
\hline Vorderarm (Ss) & ] & 93.8 & 0.037548 \\
\hline Obersch. (med.) & - & - & - \\
\hline Obersch. (lat.) & - & - & - \\
\hline Untersch. (Ss) & - & - & - \\
\hline Intersch. (Bs) & 2 & 83 & 0.033225 \\
\hline
\end{tabular}

\begin{tabular}{|c|c|c|c|c|c|}
\hline \multicolumn{3}{|c|}{ Gruppe aus 2 Haaren } & \multicolumn{3}{|c|}{ Gruppe aus 3 Haaren } \\
\hline $\begin{array}{l}\text { Zahl der } \\
\text { Haar- } \\
\text { gruppe }\end{array}$ & $\begin{array}{l}\text { (iewicht der } \\
\text { ausgeschn. } \\
\text { Papierstücke }\end{array}$ & $\begin{array}{c}\text { Volumen des } \\
\text { Muskelindiv. in } \\
\text { einer Haargruppe }\end{array}$ & $\begin{array}{c}\text { Zahl der } \\
\text { Haar- } \\
\text { gruppe }\end{array}$ & $\begin{array}{l}\text { Gewicht der } \\
\text { ausgeschn. } \\
\text { Papierstïcke }\end{array}$ & $\begin{array}{c}\text { Volumen des } \\
\text { Muskelindiv. in } \\
\text { einer Haargruppe }\end{array}$ \\
\hline- & - & - & - & - & -1 \\
\hline 1 & $80 \mathrm{mg}$ & $0.032024 \mathrm{cmm}$ & 6 & $160.1 \mathrm{mg}$ & $0.064095 \mathrm{cmm}$ \\
\hline 2 & 179.8 & 0.071974 & 8 & 218.1 & 0.087296 \\
\hline 6 & 186.3 & 0.074556 & 3 & 321.7 & 0.128764 \\
\hline 6 & 93.3 & 0.037348 & 3 & 171.3 & 0.068559 \\
\hline 2 & $\mathbf{2 4 0 . 9}$ & 0.096433 & 3 & 345.8 & 0.138411 \\
\hline 5 & 134.8 & 0.053945 & 4 & 227.1 & 0.090919 \\
\hline 3 & 204.4 & 0.081809 & 7 & 314.5 & 0.125907 \\
\hline 6 & 115.3 & 0.046148 & 3 & 220.7 & 0.088333 \\
\hline 2 & 178.4 & 0.071414 & 7 & 355.4 & 0.142273 \\
\hline 3 & 68 & 0.027220 & 7 & 167.4 & 0.067028 \\
\hline 2 & 253.2 & 0.101357 & 8 & 328.9 & 0.131639 \\
\hline - & - & - & 10 & 620.6 & 0.248416 \\
\hline - & - & - & 6 & 332.7 & 0.133174 \\
\hline \multicolumn{3}{|c|}{ (iruppe aus + Haaren } & \multicolumn{3}{|c|}{ Gruppe aus 5 Haaren } \\
\hline $\begin{array}{c}\text { Zahl der } \\
\text { Haar- } \\
\text { gruppe }\end{array}$ & $\begin{array}{l}\text { (iewicht der } \\
\text { ausgeschn. } \\
\text { Palierstücke }\end{array}$ & $\begin{array}{c}\text { Volumen des } \\
\text { Muskelindiv. in } \\
\text { einer Haargruppe }\end{array}$ & $\begin{array}{c}\text { Zahl der } \\
\text { Haar- } \\
\text { gruppe }\end{array}$ & $\begin{array}{l}\text { Gewicht der } \\
\text { ausgeschn. } \\
\text { Papierstücke }\end{array}$ & $\begin{array}{c}\text { Volumen des } \\
\text { Iuskelindiv. in } \\
\text { einer Haargruppe }\end{array}$ \\
\hline 3 & $206.3 \mathrm{mg}$ & $0.082596 \mathrm{cmm}$ & 5 & $381.2 \mathrm{mg}$ & $0.152595 \mathrm{cmm}$ \\
\hline 3 & 150 & 0.060032 & - & - & - \\
\hline - & - & - & - & - & 一 \\
\hline 一 & - & - & - & - & - \\
\hline 1 & 289 & 0.095672 & 一 & - & - \\
\hline 1 & 473.1 & $0.18938: 3$ & 4 & 622.9 & 0.249358 \\
\hline - & - & - & - & - & - \\
\hline - & - & - & - & -- & - \\
\hline
\end{tabular}

\begin{tabular}{|c|c|c|}
\hline \multicolumn{3}{|c|}{ Gruppe aus 6 Haaren } \\
\hline $\begin{array}{c}\text { Zahl der } \\
\text { Haar- } \\
\text { grupne }\end{array}$ & $\begin{array}{c}\text { Gewicht der } \\
\text { ausgeschn. } \\
\text { Papierstücke }\end{array}$ & $\begin{array}{c}\text { Volumen des } \\
\text { Muskelindiv. in } \\
\text { einer Haargruppe }\end{array}$ \\
\hline 2 & $408.5 \mathrm{mg}$ & $0.163524 \mathrm{cmm}$ \\
- & - & - \\
- & - & - \\
- & - & -
\end{tabular}


Quantitative Untersuchung der Anhangsorgane der Haut bei einem erwachsenen Ainu. 491

b. Menge des Muskels in den Hauptkörperabschnitten.

Tabelle X. (Muskel).

\begin{tabular}{|c|c|c|}
\hline & \multicolumn{2}{|c|}{ Volumen des Arrektors in $1 \mathrm{gcm}$} \\
\hline & Körperteile & Volumen \\
\hline ganzer Körper & $\begin{array}{l}\text { Kopf } \\
\text { Rumpf } \\
\text { Extremitä.t } \\
\text { Hals }\end{array}$ & $\begin{array}{l}11.353 \mathrm{cmm} \\
2.515 \\
2.171 \\
0.857\end{array}$ \\
\hline Kopf & $\begin{array}{l}\text { Scheitel } \\
\text { Stirn }\end{array}$ & $\begin{array}{c}11.353 \\
-\end{array}$ \\
\hline Rumpf (a) & $\begin{array}{l}\text { Giesäss } \\
\text { Riicken } \\
\text { Brust } \\
\text { Bauch }\end{array}$ & $\begin{array}{l}4.981 \\
2.070 \\
1.635 \\
1.373\end{array}$ \\
\hline Rumpf (b) & $\begin{array}{l}\text { Dorsalseite } \\
\text { Ventralseite }\end{array}$ & $\begin{array}{l}3.526 \\
1.504\end{array}$ \\
\hline Extremität (a) & $\begin{array}{l}\text { obere Extr. } \\
\text { intere Fxtr. }\end{array}$ & $\begin{array}{l}2.287 \\
2.055\end{array}$ \\
\hline Extremität (b) & $\begin{array}{l}\text { Distalis } \\
\text { Proximalis }\end{array}$ & $\begin{array}{l}2.241 \\
2.101\end{array}$ \\
\hline obere Fxtr. (a) & $\begin{array}{l}\text { Vorderarm } \\
\text { Oberarm }\end{array}$ & $\begin{array}{l}2.320 \\
2.254\end{array}$ \\
\hline obere Extr. (b) & $\begin{array}{l}\text { Streckseite } \\
\text { Bengeseite }\end{array}$ & $\begin{array}{l}2.999 \\
1.575\end{array}$ \\
\hline Oherarm & $\begin{array}{l}\text { Streckseite } \\
\text { Beugeseite }\end{array}$ & $\begin{array}{l}3.015 \\
1.492\end{array}$ \\
\hline Vorderarm & $\begin{array}{l}\text { Streckseite } \\
\text { Beugeseite }\end{array}$ & $\begin{array}{l}2.982 \\
1.658\end{array}$ \\
\hline untere $\mathbf{E x} \mathbf{r}$. & $\begin{array}{l}\text { Untersch. } \\
\text { Obersch. }\end{array}$ & $\begin{array}{l}2.162 \\
1.948\end{array}$ \\
\hline Obersch. & $\begin{array}{l}\text { lateral } \\
\text { medial }\end{array}$ & $\begin{array}{l}2.691 \\
1.205\end{array}$ \\
\hline Untersch. & $\begin{array}{l}\text { Streckseite } \\
\text { Beugeseite }\end{array}$ & $\begin{array}{l}2.658 \\
1.665\end{array}$ \\
\hline
\end{tabular}


c. Reihenfolge der Mengengrösse des Muskels in einzelnen Körperteilen.

Tabelle XI. (Muskel, Reihenfolge).

\begin{tabular}{|l|c|l|l}
\hline \multicolumn{2}{c|}{$\begin{array}{c}\text { Volumen des Arrektors } \\
\text { in 1 qcm }\end{array}$} & \multicolumn{2}{c}{$\begin{array}{c}\text { Volumen des } \\
\text { von 1 Huskelindiv. }\end{array}$} \\
\hline \multicolumn{1}{c|}{ Körperteile } & Volumen & \multicolumn{1}{c}{ Körperteile } & Volumen \\
\hline Scheitel & $11.353 \mathrm{cmm}$ & Vorderarm (Ss) & $0.037548 \mathrm{cmm}$ \\
Gesäss & 4.981 & Untersch. (Bs) & 0.033225 \\
Oberarm (Ss) & 3.015 & Vorderarm (Bs) & 0.025419 \\
Vorderarm (Ss) & 2.982 & Oberarm (Bs) & 0.025019 \\
Obersch. (lat.) & 2.691 & Bauch & \\
Untersch. (Ss) & 2.658 & & \\
Rücken & 2.070 & & \\
Untersch. (Bs) & 1.665 & & \\
Vorderarm (Bs) & 1.658 & & \\
Brust & 1.635 & & \\
Oberarm (Bs) & 1.492 & & \\
Bauch & 1.373 & & \\
Obersch. (med.) & 1.205 & & \\
Hals & 0.857 & & \\
\hline
\end{tabular}

\begin{tabular}{|c|c|c|c|}
\hline \multicolumn{2}{|c|}{$\begin{array}{c}\text { Volumen des Muskelindiv. } \\
\text { von } 2 \text { Haaren }\end{array}$} & \multicolumn{2}{|c|}{$\begin{array}{c}\text { Volumen des Muskelindiv. } \\
\text { von } 3 \text { Haaren }\end{array}$} \\
\hline Körperteile & Volumen & Körperteile & Volumen \\
\hline $\begin{array}{l}\text { Obersch. (lat.) } \\
\text { Gesäss } \\
\text { Oberarm (Ss) } \\
\text { Bauch } \\
\text { Brust } \\
\text { Vorderarm (Ss) } \\
\text { Oberarm (Bs) } \\
\text { Vorderarm (Bs) } \\
\text { Rücken } \\
\text { Hals } \\
\text { Obersch. (med.) }\end{array}$ & $\begin{array}{l}0.101357 \mathrm{cmm} \\
0.096433 \\
0.081809 \\
0.074556 \\
0.071974 \\
0.071414 \\
0.053945 \\
0.046148 \\
0.037348 \\
0.032024 \\
0.027220\end{array}$ & $\begin{array}{l}\text { Untersch. (Ss) } \\
\text { Vorderarm (Ss) } \\
\text { Gesäss } \\
\text { Untersch. (Bs) } \\
\text { Obersch. (lat.) } \\
\text { Bauch } \\
\text { Oberarm (Ss) } \\
\text { Oberarm (Bs) } \\
\text { Vorderarm (Bs) } \\
\text { Brust } \\
\text { Rücken } \\
\text { Obersch. (med.) } \\
\text { Hals }\end{array}$ & $\begin{array}{l}0.248416 \mathrm{cmm} \\
0.142273 \\
0.138411 \\
0.133174 \\
0.131639 \\
0.128764 \\
0.125907 \\
0.090919 \\
0.088333 \\
0.087296 \\
0.068559 \\
0.067028 \\
0.064095\end{array}$ \\
\hline
\end{tabular}

\begin{tabular}{|c|c|c|c|}
\hline \multicolumn{2}{|c|}{$\begin{array}{c}\text { Volumen des Muskelindiv. } \\
\text { von } 4 \text { Haaren }\end{array}$} & \multicolumn{2}{|c|}{$\begin{array}{l}\text { Volumen des Muskelindiv. } \\
\text { von } 5 \text { Haaren }\end{array}$} \\
\hline Körperteile & Volumen & Körperteile & Volumen \\
\hline $\begin{array}{l}\text { Gesäss } \\
\text { Rücken } \\
\text { Scheitel } \\
\text { Hals } \\
- \\
-\end{array}$ & $\begin{array}{l}0.189383 \mathrm{~cm} m \\
0.095672 \\
0.082596 \\
0.060032 \\
- \\
-\end{array}$ & $\begin{array}{l}\text { Gesäss } \\
\text { Scheitel } \\
- \\
-\end{array}$ & $\begin{array}{c}0.249358 \mathrm{cmm} \\
0.152595 \\
-\end{array}$ \\
\hline
\end{tabular}

\begin{tabular}{|c|c|}
\hline \multicolumn{2}{|c|}{$\begin{array}{c}\text { Volumen des Muskelindiv. } \\
\text { von 6 Haaren }\end{array}$} \\
\hline Körperteile & Volumen \\
\hline Scheitel \\
-
\end{tabular}


Quantitative Untersuchung der Anhangsorgane der Haut bei einem erwachsenen Ainu. 493

\section{Zusammenfassung.}

In den obigen Schlusstabellen (Tab. I-XI) sind die genaueren Mengenverhältnisse der Anhangsorgane der Haut bei einem erwachsenen Ainu angegeben. Im folgenden werde ich die wichtigeren Befunde zusammenfassend erwähnen.

1. Das Volumen der in $1 \mathrm{qcm}$ Hautflächeninhalt befindlichen Schweissdrüsen variiert nach den Körperteilen in hohem Masse, wie in Tabelle I und II gezeigt. Die Drüsenmenge ist an der Brust (5.552 cmm) am grössten in den 15 untersuchten Körperteilen, daun folgen der Rücken $(5.375 \mathrm{cmm})$, die Beugeseite des Vorderarms $(5.056 \mathrm{cmm})$, das Gesäss $(4.422 \mathrm{cmm})$, die Stirn $(4.174 \mathrm{cmm})$, der Bauch $(3.913 \mathrm{cmm})$, der Hals $(3.677 \mathrm{cmm})$, die Lateralseite des Oberschenkels $(3.638 \mathrm{cmm})$, die Streckseite des Oberarms $(3.197 \mathrm{cmm})$, die Streckseite des Unterschenkels $(3.141 \mathrm{cmm})$, die Beugeseite des Unterschenkels $(3.118 \mathrm{cmm})$, die Beugeseite des Oberarms $(2.881 \mathrm{cmm})$, die Streckseite des Vorderarms $(2.825 \mathrm{cmm})$ und die Medialseite des Oberschenkels $(2.737 \mathrm{cmm})$; sie ist am geringsten am Scheitel $(1.790 \mathrm{cmm})$. Also beläuft die relative Schwankungsbreite der Schweissdrüsenmenge sich auf ca. $3: 1$.

Die Ausmündungszahl der Schweissdrüsen in den verschiedenen. Körperteilen schwankt auch erheblich, so in $1 \mathrm{qcm}$ zwischen 345 auf der Beugeseite des Vorderarms und 145 an der Brust. Zwischen diesen beiden kommen der Scheitel (290), die Beugeseite des Oberarms (248), die Stirn (243), die Streckseite des Vorderarms (238), der Bauch (225), die Streckseite des Oberarms (215), die Lateralseite des Oberschenkels (209), die Beugeseite des Unterschenkels (208), der Hals (205), der Rücken (203), das Gesäss (193), die Streckseite des Unterschenkels (188) und die Medialseite des Oberschenkels (158). Also beträgt die relative Schwankungsbreite der Ausmündungszahl der Schweissdrüse ca. 2:1 (Tab. I und II).

Wie von Taniguchi zuerst vorläufig angenommen wurde, wenn eine Schweissdrüse nur eine Ausmündung besitzt, so wird das Volumen der einzelnen Schweissdrüse leicht berechnet, nämlich :

$$
\left(\frac{\text { Menge der Schweissdrüse in } 1 \mathrm{qcm}}{\text { Zahl der Ausmündung in } 1 \mathrm{qcm}}\right) \text {. }
$$

Diese angenommene einzelne Schweissdrüsenmenge schwankt auch nach den Körperteilen erheblich, so ist sie an der Brust am reichlichsten $(0.038290 \mathrm{cmm}$ in $1 \mathrm{qcm})$, dann folgen der Rücken $(0.026478 \mathrm{cmm})$, das Gesäss $(0.022912 \mathrm{cmm})$, der Hals $(0.017937 \mathrm{cmm})$, die Lateralseite des 
Oberschenkels $(0.017407 \mathrm{~cm}$ ) $)$ der Bauch $(0.017391 \mathrm{cmm})$, die Medialseite des Oberschenkels $(0.017323 \mathrm{cmm})$, die Stirn $(0.017177 \mathrm{cmm})$, die Streckseite des Unterschenkels $(0.016707 \mathrm{cmm})$, die Beugeseite des Unterschenkels $(0.014990 \mathrm{cmm})$, die Streckseite des Oberarms $(0.011870 \mathrm{cmm})$, die Beugeseite des Vorderarms $(0.014655 \mathrm{cmm})$, die Streckseite des Vorderarms $(0.011870 \mathrm{cmm})$, die Beugeseite des Oberarms $(0.011617 \mathrm{cmm})$ und aın Scheitel $(0.006172 \mathrm{cmm})$ ist sie am kleinsten; also beträgt die relative Schwankungsbreite ca. 6:1 (Tab. I und II).

Die noch genaueren gegenseitigen Verhältnisse der Menge des Drüsenindividuums, die der gesamten Schweissdrüsenmenge und der Zahl der Drüsenausıündung in einem bestimmten Hautflächeninhalt sind auch in Tabelle II angegeben. Daraus kann man leicht verstehen, wie es schon von Mitarbeitern aus unserem Institut konstatiert ist, dass das Volumen der Schweissdrüse in $1 \mathrm{qcm}$ und das Volumen des angenommenen Drüsenindividuums in einem bestimmten Hautflächeninhalt, im grossen und ganzen miteinander parallel stehen, doch nach den Körperteilen eine kleine Schwankung aufweisend. Doch in der Brust und im Scheitel herrschen die umgekehrten Mengenverhältnisse zwischen der Menge und Zahl, wie die Tabelle II zeigt, d.h. an der Brust ist die Drüsenmenge in $1 \mathrm{qcm}$ Hautstück am grössten $(5.552 \mathrm{cmm})$, wie schon angegeben, doch ist die Zahl der Ausmündungen in demselben Hautstück befindlichen Schweissdrüsen am geringsten (145). Auch am Scheitel kann man gleichfalls fast so entgegengesetzte Mengenverhältuisse bemerken.

Die relative Schwankungsbreite der Drüsenmenge in einem bestimmten Hautflächeninhalt, die der angenommenen Drüsenindividuen und die der Ausmündungszahl sind: ca. 3:1, 6:1, 3:1. Aus obigen Tatsachen kann man leicht ersehen, dass die relative Schwankungsbreite der Drüsenmenge und der Ausmündungszahl fast gleich gross ist.

Aus der Tabelle III erkennt man noch klarer, dass das Volumen der Schweissdrüse unter den vier eingeteilten Hauptkörperstellen-Kopf, Hals, Rumpf und Extremitäten-im Rumpf am grössten ist $(4.816 \mathrm{cmm}$ in $1 \mathrm{qcm})$, dam folgen der Hals $(3.677 \mathrm{cmm})$, -die Extremitäten (3.324 $\mathrm{cmm})$ und am geringsten ist es im Kopf $(2.982 \mathrm{cmm})$, besonders im Scheitel $(1.790 \mathrm{cmm})$; so ist der relative Grenzwert ca. 1.2:1. Die Ausmündungszahl der Schweissdrüse ist aber im Kopf am reichlichsten (267 in $1 \mathrm{qcm}$ ), damn folgen die Extremitäten (226), der Hals (205) und am geringsten ist sie im Rumpf (192); so ist der Grenzwert auch ca. $1.2: 1$. So kann man leicht erkennen, dass die relative Schwankungsbreite der Drüsenmenge und diè der Ausmündungszahl fast gleich gross 
sind. Im Kopf ist die Drüsenmenge an der Stirn (4.174 cmm in $1 \mathrm{qcm})$ ca. $2.5 \mathrm{mal}$ grösser als am Scheitel $(1.790 \mathrm{cmm})$, aber die Zahl der Ausmündung ist am Scheitel (290 in $1 \mathrm{qcm}$ ) etwas zahlreicher als an der Stirn (243). So ist das Volumen des Drüsenindividuums an der Stirn $(0.017177 \mathrm{cmm})$ ca. $3 \mathrm{mal}$ grösser als am Scheitel $(0.006172 \mathrm{cmm})$. Im Rumpf ist die Drüsenmenge in $1 \mathrm{qcm}$ Hautstück an der Brust am grössten $(5.552 \mathrm{cmm})$, dann folgen der Rücken (5.375 crmm), das Gesäss (4.422 cmm), und an Bauch $(3.913 \mathrm{cmm})$ ist sie am geringsten. Daraus kann man sagen, dass die Drüsenmenge etwas grösser an der oberen Hälfte $(5.464 \mathrm{cmm})$ des Rumpfes als an der unteren $(4.168 \mathrm{cmm}$ ) ist (in der Tabelle nicht angegeben). Aber die Ausmündungszahl der Schweissdrüse in 1 qcm Hautstück ist am Bauch am grössten (225), dann folgen der Rücken (203), das Gesäss (193), und an der Brust (145) ist sie am geringsten. Die Drüsenmenge ist auf der Dorsalfläche des Körpers $(4.899 \mathrm{cmm})$ etwas reichlicher als auf der ventralen $(4.733 \mathrm{cmm})$ (Tab. III). Die Ausmündungszahl der Schweissdrüse in $1 \mathrm{gcm}$ Hautstück ist auf der Ventralseite (185) etwas weniger als auf der Dorsalseite (198). In den Extremitäten ist die Drüsenmenge an der oberen $(3.490 \mathrm{cmm}$ in $1 \mathrm{qcm})$ etwas grösser als an der unteren $(3.159 \mathrm{cmm})$, und die obere Extremität besitzt am Vorderarm $(3.941 \mathrm{cmm})$ eine viel grössere Drüsenmenge als am Oberarm $(3.039 \mathrm{cmm})$, aber die untere Extremität besitzt die fast gleiche Drüsenmenge auf dem Ober-(3.188 cmm) und Unterschenkel $(3.130 \mathrm{cmm})$. Also kann man wohl sagen, dass in den Extremitäten die Menge der Schweissdrüsen im grossen und ganzen an den distalen Regionen $(3.535 \mathrm{cmm})$ etwas grösser als an den proximalen $(3.113 \mathrm{cmm})$ ist. Auch die Zahl der Ausmündungen in den Extremitäten ist an der oberen (262) viel reichlicher als an der unteren (191), und die obere Extremität besitzt am Vorderarm (292) etwas mehr als am Oberarm (232), sowie die untere Extremität am Unterschenkel (198) mehr als am Oberschenkel (184). Also kann man wohl sagen, dass in den Extremitäten die Zahl der Drüsenausmündungen auch an den distalen Regionen (245) etwas grösser als an den proximalen (208) ist. In der cberen Extremität ist die Drüsenmenge an der Beugeseite des Vorderarms am grössten $(5.056 \mathrm{cmm}$ in $1 \mathrm{qcm})$ und zwischen den anderen 3 untersuchten Teilen der oberen Extremität ist nicht so deutlicher Unterschied der Drüsenmenge unter sich zu finden, wenugleich sie auf der Beugeseite etwas $(3.969 \mathrm{cmm})$ grösser als auf der Streckseite $(3.011 \mathrm{cmm})$ ist.

Auch kann man die gleichen Zahlenverhältnisse bei der Ausmündung wie bei der Drüsenmenge bemerken ; so ist deren Zahl auf der Beugeseite des Vorderarms am grössten (345), und in den anderen 3 untersuchten 
Teilen bemerkte ich keinen so deutlichen Unterschied. Im Oberschenkel ist die Menge und Ausmündungszahl der Schweissdrüse auf der lateralen Seite viel grösser als auf der medialen. Im Unterschenkel ist die Menge der Drüse fast gleich gross auf der Beuge- und Streckseite. Aber die Ausmündungszahl ist auf der Beugeseite (208) etwas grösser als auf der Streckseite (188). In den Extremitäten sind die Ausmündungszahl sowie die Drüsenmenge in grossen und ganzen auf der Beugeseite grösser als auf der Streckseite.

2. Das Volumen der Talgdrüsen auf $1 \mathrm{qcm}$ Hautflächeninhalt (Tab. IV und VII) ist am Scheitel am grössten $(3.222 \mathrm{cmm})$, dann folgen die Stirn $(1.347 \mathrm{cmm})$, der Rücken $(0.419 \mathrm{cmm})$, die Brust $(0.369 \mathrm{cmm})$, die Streckseite des Oberarms $(0.328 \mathrm{cmm})$, der Hals $(0.250 \mathrm{cmm})$, das Gesäss $(0.192 \mathrm{cmm})$, die Streckseite des Vorderarms $(0.148 \mathrm{cmm})$, der Bauch $(0.110 \mathrm{cmm})$, die Beugeseite des Vorderarms $(0.071 \mathrm{cmm})$, die Beugeseite des Unterschenkels $(0.068 \mathrm{cmm})$, die Beugeseite des Oberarms $(0.054 \mathrm{cmm})$, die Medialseite des Oberschenkels $(0.043 \mathrm{cmm})$ und die Streckseite des Unterschenkels $(0.038 \mathrm{cmm})$; es ist am geringsten auf der Lateralseite des Oberschenkels $(0.030 \mathrm{cmm})$, so dass die relative Schwankungsbreite auffallend gross, ca. 100:1 ist.

Die aus einem Haar bestehende Haargruppe konnte ich in 5 Körperstellen unter den 14 untersuchten Körperteilen (die Stirn nicht untersucht) vorfinden, so in Streckseite des Vorderarms, Beugeseite des Unterschenkels, Beugeseite des Oberarms, Beugeseite des Vorderarms und Bauch; die Häufigkeit des Vorkommens der aus einem Haar bestehenden Haargruppe ist in einem bestinmten Hautflächeninhalt nach den Körperteilen beträchtlich verschieden (Tab. 32-45). Das Volumen der einzelnen Talgdrüse, die mit solcher Haargruppe im Zusaınmenhaing steht, ist auf der Streckseite des Vorderarms am grössten $(0.003162 \mathrm{cmm})$, dann folgen die Beugeseite des Unterschenkels $(0.002362 \mathrm{cmm})$, der Bauch $(0.001721 \mathrm{cmm})$, die Beugeseite des Oberarms $(0.001121 \mathrm{cmm})$, und auf der Beugeseite des Vorderarms ist es am geringsten $(0.000600 \mathrm{cmm})$. Also beträgt die relative Schwankungsbreite der Talgdrüsenmenge, die mit einer solchen Haargruppe im Zusanmenhang steht, ca. $5: 1$.

Die aus zwei Haaren bestehende Haargruppe fand ich in 11 Körperteilen, aber nicht im Scheitel und Unterschenkel; die Häufigkeit ist nach den Körperteilen auch sehr verschieden (Tab. 32-45). Die einzelne Talgdrüse, die mit einer zweihaarigen Haargruppe im Zusammenhang steht, hat an der Brust die grösste Menge $(0.014792 \mathrm{cmm})$, danach kommen der Bauch $(0.008193 \mathrm{cmm})$, der Hals $(0.008006 \mathrm{cmm})$, der Rücken $(0.006291 \mathrm{cmm})$, die Streckseite des Oberarıns $(0.005311 \mathrm{cmm})$, 
die Streckseite des Vorderarms $(0.003583 \mathrm{cmm})$, das Gesäss (0.002802 $\mathrm{cmm})$, die Beugeseite des Oberarms $(0.002314 \mathrm{cmm})$, die Beugeseite des Vorderaims $(0.001982 \mathrm{cmm})$ und die Lateralseite des Oberschenkels $(0.001481 \mathrm{cmm})$. Sie ist am geringsten auf der Medialseite des Oberschenkels $(0.000881 \mathrm{cmm})$; so beträgt die relative Schwankungsbreite der Talgdrüsenmenge, die zu der \%weihaarigen Haargruppe im Zusammenhang steht, ca. $16: 1$.

Die aus drei Haaren bestehende Haargruppe bemerkte ich in allen untersuchten Körperteilen mit Ausnabme des Scheitels (Tab. 32-45). Das Volumen der einzelnen Talgdrüse, die bei solcher Haargruppe vorkommt, ist an der Brust am grössten $(0.023042 \mathrm{cmm})$, dann folgen der Hals $(0.013143 \mathrm{cmm})$, der Rücken $(0.012983 \mathrm{cmm})$, die Streckseite des Oberarms $(0.012467 \mathrm{cmm})$, die Streckseite des Vorderarms $(0.008904 \mathrm{cmm})$, der Bauch $(0.007326 \mathrm{cmm})$, die Beugeseite des Vorderarms $(0.006431 \mathrm{cmm})$, die Beugeseite des Unterschenkels $(0.004784 \mathrm{cmm})$, die Streckseite des Unterschenkels $(0.003991 \mathrm{cmm})$, das Gesäss (0.003776 $\mathrm{cmm})$, die Beugeseite des Oberarms $(0.003776 \mathrm{cmm})$ und die Medialseite des Oberschenkels $(0.002877 \mathrm{cmm})$. Am wenigsten ist sie auf der Lateralseite des Oberschenkels $(0.002762 \mathrm{cmm})$; so ist der relative Grenzwert ca. $8: 1$.

Die aus vier Haaren bestehende Haargruppe bemerkte ich in den vier folgenden Körperteilen d.h. in Scheitel, Rücken, Hals und Gesäss. Die einzelne Talgdrüse, die mit der vierhaarigen Haargruppe im Zusammenhang steht, hat am Scheitel die grösste Menge $(.0 .029689 \mathrm{cmm})$, dann folgen der Rücken $(0.024979 \mathrm{cmm})$, der Hals $(0.017293 \mathrm{cmm})$, und sie ist am Gesäss $(0.006885 \mathrm{cmm})$ ain wenigsten ; so ist der Grenzwert ca. $5: 1$.

Die aus fünf Haaren bestehende Haargruppe fand ich nur in zwei Körperteilen, Scheitel und Gesäss. Das Volumen der dazu gehörigen einzelnen Talgdrüse, wie in Tabelle VII gezeigt, ist am Scheitel 0.041768 $\mathrm{cmm}$ und am Gesäss $0.007746 \mathrm{cmm}$. Also beträgt die relative Schwankungsbreite der Menge ca. $6: 1$.

Die aus sechs Haaren bestehende Haargruppe fand ich nur an Scheitel; das Volumen der dazu gehörigen einzelnen Talgdrüse, ist $0.047516 \mathrm{cmm}$.

In den vier eingeteilten Hauptabteilungen des Körpers fand ich, dass die Menge der Talgdrüse in 1 qcm Hautflächeninhalt im Kopf am grössten ist $(2.285 \mathrm{cmm})$, dann folgen der Rumpf $(0.273 \mathrm{cmm})$, der Hals $(0.250 \mathrm{cmm})$, und am geringsten ist sie in den Extremitäten $(0.098 \mathrm{cmm})$, indem die relative Schwankungsbreite sich auf ca. 23:1 beläuft (Tab. 
VI). Im Kopf ist die Menge am Scheitel etwa 3 mal grösser als an der Stirn, wie in Tabelle VI gezeigt. Im Rumpf ist sie am Rücken (0.419 cmm in $1 \mathrm{gcm})$ und an der Brust $(0.369 \mathrm{cmm})$ grösser als ain Gesäss $(0.192 \mathrm{cmm})$ und Bauch $(0.110 \mathrm{cmm})$; also auf der Dorsalseite $(0.306 \mathrm{cmm})$ ist die Menge der Talgdrüse etwas grösser als auf der Ventralseite $(0.240 \mathrm{cmm})$. Also kann man wohl sagen, dass die Talgdrüsenmenge ca. 2 mal grösser an der oberen Hälfte $(0.394 \mathrm{cmm})$ des Rumpfes als auf der unteren $(0.151 \mathrm{cmm})$ ist (in der Tabelle nicht angegeben). In den Extremitäten ist sie an der oberen $(0.150 \mathrm{cmm})$ etwa 3 mal grösser als an der unteren $(0.045 \mathrm{cmm})$ und an den proximalen Regionen (0.114 $\mathrm{cmm})$ grösser als an den distalen $(0.081 \mathrm{cmm})$. In den oberen Extremitäten ist sie auf dem Oberarm $(0.191 \mathrm{cmm})$ etwas grösser als auf dem Vorderarm $(0.110 \mathrm{cmm})$. Auch in den oberen Extremitäten ist auf der Streckseite $(0.238 \mathrm{cmm})$ die Menge der Talgdrüse viel reichlicher als auf der Beugeseite $(0.063 \mathrm{cmm})$. In den unteren Extremitäten ist sie am Unterschenkel $(0.053 \mathrm{cmm})$ grösser als am Oberschenkel $(0.037 \mathrm{cmm})$. Am Oberschenkel ist sie auf der medialen Fläche $(0.043 \mathrm{cmm})$ grösser als auf der lateralen $(0.030 \mathrm{cmm})$ und am Unterschenkel ist sie auf der Bengeseite $(0.068 \mathrm{cmm})$ viel grösser als auf der Streckseite $(0.038 \mathrm{cmm})$. Aus oben erwähnten Befunden kamn man leicht ersehen, dass in der oberen Extremität die Menge der Talgdrüse an den proximalen Regionen grösser als an den distalen und in der unteren Extremität ganz umgekehrt gross ist (Tabelle VI).

3. Die Menge der Haarbalgmuskeln in $1 \mathrm{qcm}$ Hautflächeninhalt (Tab. VIII und XI) ist am Scheitel $(11.353 \mathrm{cmm})$ am grössten, dann folgen das Gesäss $(4.981 \mathrm{cmm})$, die Streckseite des Oberarms $(3.015 \mathrm{cmm})$, die Streckseite des Vorderarms $(2.982 \mathrm{cmm})$, die Lateralseite des Oberschenkels $(2.691 \mathrm{cmm})$, die Streckseite des Unterschenkels $(2.658 \mathrm{cmm})$, der Rücken $(2.070 \mathrm{cmm})$, die Beugeseite des Unterschenkels $(1.665 \mathrm{cmm})$, die Beugeseite des Torderarms $(1.658 \mathrm{cmm})$, die Brust $(1.635 \mathrm{cmm})$, die Beugeseite des Oberarms $(1.492 \mathrm{cmm})$, der Bauch $(1.373 \mathrm{cmm})$ und die Medialseite des Oberschenkels $(1.205 \mathrm{cmm})$. Und sie ist am Hals am geringsten $(0.857 \mathrm{cmm})$, so dass die relative Schwankungsbreite ca. 13:1 beträgt.

Die Häufigkeit des Auftretens der einhaarigen Haargruppe (s. oben) ist in einem bestimmten Hautflächeninhalt nach den Körperteilen beträchtlich verschieden (Tab. 60-73). Das Volumen des einzelnen Haarbalgmuskels, der mit einer solchen Haargruppe im Zusammenhang steht, ist auf der Streckseite des Vorderarms $(0.037548 \mathrm{cmm})$ an grössten, dann, folgen die Beugeseite des Unterschenkels $(0.033225 \mathrm{cmm})$, die 
Quantitative Untersuchung der Anhangsorgane der Haut bei einem erwachsenen Ainu. 499

Beugeseite des Vorderarms $(0.025419 \mathrm{cmm})$, die Beugeseite des Oberarms $(0.025019 \mathrm{cmm})$ und am Bauch $(0.009767 \mathrm{cmm})$ ist es am geringsten. Also beträgt die relative Schwankungsbreite der Muskelmenge, die mit einer solchen Haargruppe im Zusammenhang steht, ca. 4:1.

Der einzelne Haarbalgmuskel, der mit der zweihaarigen Haargruppe (s. oben) im Zusammenhang steht, hat auf der Lateralfläche des Oberschenkels die grösste Menge $(0.101357 \mathrm{cmm})$, damn kommen das Gesäss $(0.096433 \mathrm{cmm})$, die Streckseite des Oberarms $(0.081809 \mathrm{cmm})$, der Bauch $(0.074556 \mathrm{cmm})$, die Brust $(0.071974 \mathrm{cmm})$, die Streckseite des Vorderarms $(0.071414 \mathrm{cmm})$, die Beugeseite des Oberarms $(0.053945 \mathrm{cmm})$, die Beugeseite des Vorderarms $(0.046148 \mathrm{cmm})$, der Rücken $(0.037348 \mathrm{cmm})$ und der Hals $(0.032024 \mathrm{cmm})$; sie ist am geringsten auf der Medialseite des Oberschenkels (0.027220 cmm) ; so beträgt die relative Schwankungsbreite der Muskelmenge, ca. $4: 1$.

Das Volumen des einzelnen Haarbalgmuskels, der bei der dreihaarigen Haargruppe (s. oben) vorkommt, ist auf der Streckseite des Unterschenkels am grössten $(0.248416 \mathrm{cmm})$; auf diesem Körperteile fand ich ausschliesslich die dreihaarigen Haargruppen, wie die Tabelle 72 zeigt. Dann kommen die Streckseite des Vorderarms $(0.142273 \mathrm{cmm})$, das Gesäss $(0.138411 \mathrm{cmm})$, die Beugeseite des Unterschenkels $(0.133174 \mathrm{cmm})$, die Lateralseite des Oberschenkels $(0.131639 \mathrm{cmm})$, der Bauch $(0.128764 \mathrm{cmm})$, die Streckseite des Oberarms $(0.125907 \mathrm{cmm})$, die Beugeseite des Oberarms $(0.090919 \mathrm{cmm})$, die Beugeseite des Vorderarms $(0.088333 \mathrm{cmm})$, die Brust $(0.087296 \mathrm{cmm})$, der Rücken $(0.068559 \mathrm{cmm})$ und die Medialseite des Oberschenkels $(0.067028 \mathrm{cmm})$. Es ist am kleinsten am Hals $(0.064095$ $\mathrm{cmm}$ ). So ist der relative Grenzwert ca. $4: 1$.

In den Körperteilen mit vierhaarigen Haargruppen (s. oben) ist die einzelne Menge des Haarbalgmuskels, am Gesäss am grössten (0.189383 $\mathrm{cmm})$, dann folgen der Rücken $(0.095672 \mathrm{cmm})$, der Scheitel $(0.082596$ cmm), und an geringsten ist sie am Hals $(0.060032 \mathrm{cmm})$; so ist der relative Grenzwert ca. $3: 1$.

Das Volumen des dazu gehörigen einzelnen Haarbalgmuskels in der fünfhaarigen Haargruppe (s. oben), wie in Tabelle XI gezeigt, ist am Gesäss $0.249358 \mathrm{cmm}$ und am Scheitel $0.152595 \mathrm{cmm}$. Also beträgt die relative Schwankungsbreite der Menge ca. 1.6:1.

Das Volumen des einzelnen Haarbalgmuskels ist im Scheitel mit der sechshaarigen Haargruppe (s. oben) ist $0.163524 \mathrm{cmm}$. Auch kann man leicht verstehen, dass, wie schon oben angegeben, je grösser die Zahl der Haare in einer Haargruppe ist, desto grösser die Menge des einzelnen Haarbalgmuskels ist, und dass die im bestimmten Hautflächeninhalt 
vorkommende Muskelmenge im allgemeinen mit der Menge des eimzelnen Muskels Hand in Hand geht.

Die Mengenverhältnisse in den vier eingeteilten Hauptkörperteilen sind in Tabelle $\mathrm{X}$ angegeben ; so. ist die Menge des Haarbalgmuskels im Kopf $(11.353 \mathrm{cmm}$ in $1 \mathrm{qcm})$ am grössten, dann folgen der Rumpf $(2.515 \mathrm{cmm})$, die Extremitäten $(2.171 \mathrm{cmm})$, und im Hals $(0.857 \mathrm{cmm})$ ist sie am wenigsten, indem die relative Schwankungsbreite sich auf ca. 13:1 beläuft. Am Kopf ist die Muskelmenge am Scheitel $(\mathbf{1 1 . 3 5 3} \mathrm{cmm})$ besonders auffallend gross. Wie schon angegeben, komnte ich nicht die Stirn untersuchen, da hier die Haarbalgmuskeln sehr klein waren. Bei der Stirn sind in der Nähe der Hautoberfläche die Muskeln netzartig durchkreuzt und schwer voneinander zu unterscheiden, da die Muskeln gleichmässig zerstreut sich finden. Aber auf der flüchtigen mikroskopischen Betrachtung scheint ihre Menge dem Scheitel nächst zu folgen. Im Rumpf ist die Muskelmenge am Gesäss $(4.981 \mathrm{cmm})$ am grössten, dann folgen der Rücken $(2.070 \mathrm{cmm})$, die Brust $(1.635 \mathrm{cmm})$, und am geringsten ist sie am Bauch $(1.373 \mathrm{cmm})$. Daraus kann man erkennen, dass der Haarbalgmuskel reichlicher auf der dorsalen Körperfläche $(3.526 \mathrm{cmm})$ als auf der ventralen $(1.504 \mathrm{cmm})$ vorkommt. Noch kann man wohl sagen, dass der Haarbalgmuskel etwa 2 mal reichlicher an der unteren Hälfte $(3.177 \mathrm{cmm})$ des Rumpfes als der oberen $(1.853 \mathrm{cmm})$ ist (in der Tabelle nicht angegeben). In den Extremitäten ist er an der oberen $(2.287 \mathrm{cmm})$ reichlicher als an der unteren $(2.055 \mathrm{cmm})$ und bei beiden distal $(2.241 \mathrm{cmm})$ reichlicher als proximal $(2.101 \mathrm{cmm})$. In der oberen Extremität ist sie am Vorderarm $(2.320 \mathrm{cmm})$ ein wenig reichlicher als am Oberarm $(2.254 \mathrm{cmm})$ und auf der Streckseite $(2.999 \mathrm{cmm})$ mehr als auf der Beugeseite $(1.575 \mathrm{cmm})$. In der unteren Extremität ist sie am Unterschenkel $(2.162 \mathrm{cmm})$ grösser als am Oberschenkel $(1.948 \mathrm{cmm})$, beim Oberschenkel auf der Lateralfläche $(2.691 \mathrm{cmm})$ viel grösser als auf der medialen $(1.205 \mathrm{cmm})$. Am Unterschenkel ist sie auf der Streckseite $(2.658 \mathrm{cmm})$ grösser als auf der Beugeseite $(1.665 \mathrm{cmm})$. Deshalb kann man mit Sicherheit sagen, dass in den Extremitäten die Menge des Haarbalgmuskels auf der Streckseite viel reichlicher als auf der Beugeseite ist, wie die Tabelle $\mathrm{X}$ zeigt.

Zum Schluss erfülle ich eine mir angenehme Pflicht, indem ich Herrn Professor K. Okajima für seine stete freundliche Unterstützung meinen herzlichsten Dank ausspreche.

November 1932. 